\title{
XVI
}

Aus dem Anscharkrankenhause (Prof. Göbell) und der Psychiatrischen und Nervenklinik zu Kiel (Geh.-Rat Siemerling).

\section{Eine familiäre Trophoneurose der unteren Extremitäten.}

\author{
Von \\ Prof. Dr. med. Rudolf Göbell, und Prof. Dr. med. Werner Runge, \\ Direktor des Anscharkiankenhauses u. der \\ Chirurgischen Universitätspoliklinik, Kiel. \\ Oberarzt der Kgl. Psychiatrischen und \\ Nervenklinik, Kiel.
}

(Hierzu Tafeln I-III und 4 Schemata im Text.)

Wir hatten Gelegenheit, folgende sechs Mitglieder einer Familie, die mit einer äusserst seltenen Familienkrankheit behaftet waren, zu untersuchen. Ueber ein weiteres Mitglied dieser Familie, das im Auslande lebt, erhielten wir schriftlichen Bericht.

Fall 1. Hinrich W., 54 Jahre alt, Arbeiter.

Anamnese: Fräher gesund. Während der dreijährigen Militärdienstzeit bei der Infanterie nach Anstrengungen zuerst Auftreten von Schmerzen, ,Sengeln und Kribbeln" in den Unterschenkeln bis zu den Knien hinauf, was dann weiterhin auch nach der Militärzeit zuweilen auftrat. Patient beobachlete eine Besserung der Schmerzen, wenn er die Füsse durch Ausziehen der Strümpfe abkühlte. Seit der Militärzeit zuweilen Schwarzfärbung und Abfallen der Grosszehennägel unter geringen Schmerzen nach vorheriger Rötung der Zehen. Ein anfallsweises Absterben, Blau- oder Weisswerden der Füsse oder Zehen wurde nie beobachtet. Im Alter von 41 Jahren traten Schmerzon im linken Grosszehenballen auf, wo sich danach eine "Spalte" bildete, die juckte. Im Verlauf von etwa 8 Tagen Anschwellung des ganzen linken Fusses, Arzt sprach von "Blutvergiftung". Deswegen 11 Tage im Krankenhaus za B. behandelt. Nachdem 1 Jahr lang bei der Arbeit Schmerzen im ganzen linken Fuss und Unterschenkel bestanden hatten, ernente Geschwürsbildung an derselben Stelle, Anschwellung, Schmerzhaftigkeit und Rötung der rechten grossen Zehe, was spontan ohne Geschwürsbildung wieder schwand. Weiterhin mehrfache Wiederholung der Geschwürsbildung am linken Grosszehenballen ohne ersichtliche Ursache, mit Schmerzen in der Geschwürsgegend und Schwellang der Leistendrüsen. Im Alter von 47 Jabren erneute Krankenhausbehandlung in B. wegen 
eines grossen Geschwürs an der linken Fusssohle, das sich yom Grosszehenbis zum Kleinzehenballen erstreckte und mit lebhaften Schmerzen verbunden war. Während Auftreten des Geschwürs angeblich Rötung des Fusses. Weiterhin immer wieder erneutes Auftreten von Schmerzen und Geschwüren an derselben Stelle. Will nur einmal $3 / 4$ Jahre lang ganz frei von Beschwerden und Wrunden, in der letzten Zeit aber alle Augenblicke krank gewesen sein. Der Geschwürsbildung ging immer ein "taubes Gefübl" an der betreffenden Stelle voraus. Im April und Mai 19135 wöchiger Aufentbalt im Anscharkrankenhaus zu Kiel. Es hatte sich nach Auftreten eines Taubheitsgefühls sowie Rötung und Anschwellung der ganzen linken grossen Zehe ein Geschwür auf der Dorsalseite derselben gebildet. Im April 1913 musste die Exartikulation der grossen Zehe vorgenommen werden (Prof. Göbell).

Im Angust 1913 erneutes Geschwür an der Kleinzehenseite der linken Fusssoble. Im Oktober 1913 fand sioh bei einer Untersuchung im Anscharhaus am linken Kleinzehenballen ein nässender, $1 \mathrm{~cm}$ in die Tiefe gehender Defekt, der auf entsprechende Behandlung heilte. Am 29. 10. bestand an der Aussenseite des linken Kleinzehengelenks eine schwärzlich verfärbte Stelle, an der sich bald ein Geschwür entwickelte, dessen Sekret Streptokokken enthielt (Figg. 1 u. 2, Taf. I).

Befund im November 1913: Hände frei von Geschwären, Wunden und synkopeähnlichen Erscheinungen. Kniephänomene lebbaft, gleich. Achillessehnenreflex fehlt rechts, links spurweise vorhanden. Normaler Zehenreflex, kein Babinski. Sensibilitätsprüfung: An sämtlichen Zehen werden Pinselberührungen nicht lokalisiert, wird spitz und stumpf verwechselt, werden Nadelstiche nicht als sohmerzhaft empfunden. An beiden Füssen wird bis in die Gegend des Fussgelenks beiss nur als warm angegeben.

Umfang der Mitte der Oberschenkel rechts $1 \mathrm{~cm}$ geringer als links, der Mitte der Unterschenkel $1 / 2 \mathrm{~cm}$ geringer. Das ganze rechte Bein in toto etwas atrophischer als das linke, besonders die Gegend der Peronei. Elektrische Erregbarkeit für faradischen und galvanischen Strom in einzelnen Maskelgruppen rechts etwas herabgesetzt. Keine Entartungsreaktion. Grobe Kraft der unteren Extremitäten leidlich gut und beiderseits gleich. Fusspulse beiderseits gut und gleich zu fühlen.

Die Lumbalpunktion ergab keine Druckerhöhung, die Liquoruntersuchung keine pathologische Zellvermehrung, keine deutliche Trübung mit Ammoniumsulfat (Phase I) und nur eine Spur Trübung mit Magnesiumsulfat. Die Wassermann'sche Reaktion im Blut war negativ, ebenso nach einer erneuten Untersuchung am 8. 5. 1914 in der Kgl. psychiatrischen und Nervenklinik. Der übrige neurologische Befund war völlig negativ. Im Urin keine abnormen Bestandteile.

Der Befund am 8. 5. 1914 war im Grossen und Ganzen derselbe wie im November 1913. Eine Röntgenuntersuchung der Lendenwirbelsäule und des Kreuzbeins ergab normale Verhältnisse, keine Spaltbildung.

Befund am 20.7. 1914: 2. Zehe am linken Fuss stark geseliwollen. Unterseite von einem fast dreimarkstückgrossen Ulkus eingenommen. Links 
nach aussen hängt die Zehenspitze ohne Nagel. 3. Zehe etwas gerötet, der ganze Fuss geschwollen. Die Achillessehnenreflexe waren beiderseits nioht auszulösen. Füsse in normaler Weise gewölbt. W. gab noch an, dass seine Geschlechtsfunktionen in letzter Zeit etwas nachgelassen hätten. Vor einem Jahr hätten Bescbwerden beim Urinlassen bestanden. Der Urin sei öfters schwer abgelaufen, er habe öfter in kleinen Mengen urinieren müssen. Das habe etwa 1 Monat gedauert. Sensibilitätsprüfung siehe umstehendes Schema.

Befund am 4. 3. 1915: Markstückgrosses Geschwür an der Planta. pedis links, das seit 8 Tagen bestehen soll. W. gibt an, dass er einige Zeit vor der Entstehung des Geschwürs ein Brennen an der Vorderseite des Unterschenkels bis zur grossen Zehe gespürt habe. Wenn er arbeite, schwelle der Fuss an. Am Geschwür spüre er Schmerzen.

Befund am 12.7. 1916: W. ist vom 2. September 1915 bis zum 4. Juli 1916 arbeitsunfähig gewesen. Es bat sich wieder an seinem linken Fuss das alte Leiden eingestellt. Es bildete sich ein Geschwür an der Fusssohle, diesmal über dem Köpfchen des 2. Mittelfussknochens, und ausserdem ein Aufbruch $2 \mathrm{~cm}$ davon nach aussen. Im Januar 1916 stiess sich aus der unteren Wunde ein Knochen ab, und zwar ein fast $2 \mathrm{~cm}$ langes Stück des peripheren 3. Metatarsus. Ausserdem stiess sich Ende Juni aus der weiter aussen gelegenen Aufbruchstelle an der Fusssohle ein kleineres Stück Knochen ab, das hauptsächlich aus sponyiösem Knochengewebe besteht.

Der Zustand des linken Fusses ist jetzt folgender (Abb. 3 u. 4, Taf. I):

Es fehlt der Hallux, das Capitulum metatarsi $I$ ist von normaler Haut bedeckt. Von den Zehen liegen der 4 . und 5. im Grundgelenk stark hyperextendiert und im 2. Zwischengelenk flektiert auf dem Polster des Kleinzehenballens. Die 3. Zehe ist stark deformiert, Endphalanx mit Zehenkuppe liegen vor der 4. Zehe. Die 3. Zehe ist also im ersten Interphalangealgelenk nach aussen hin geknickt, von der 2. Zehe ist Grundglied, 2. Glied und Endglied erhalten, die Zehe steht in Flexionskontraktur. Mit der Sonde kann man nur $2 \mathrm{~mm}$ weit unter das Zehenende fahren. Das Zehenende trägt einen Clavus.

Das Geschwür an der Fusssohle ist von dicker verhornter Epidermis umgeben. Wenn man dieselbe abschneidet, so präsentiert sich das Geschwür mit einem flachen ausgezackten Rand und rotem Granulationsgewebe als Geschwürsgrund. Die Sonde gelangt jetzt nicht auf rauhen Knochen.

Der linke Mittelfuss ist gegenüber dem rechten geschwollen.

Der rechte Fuss ist bis auf die 4 Zehen normal. Die 4 Zehen stehen im Grundglied in Hyperextensionsstellung und im ersten Zwischengelenk in Flexionskontraktur. An der 2. Zehe fehlt der Nagel bis auf einen minimalen Rest völlig.

\section{Umfangsmasse:}

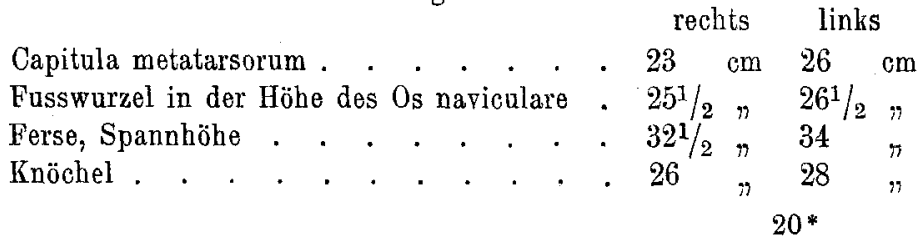


20. 7. 1914 .

Eall 1: Hinr. W.

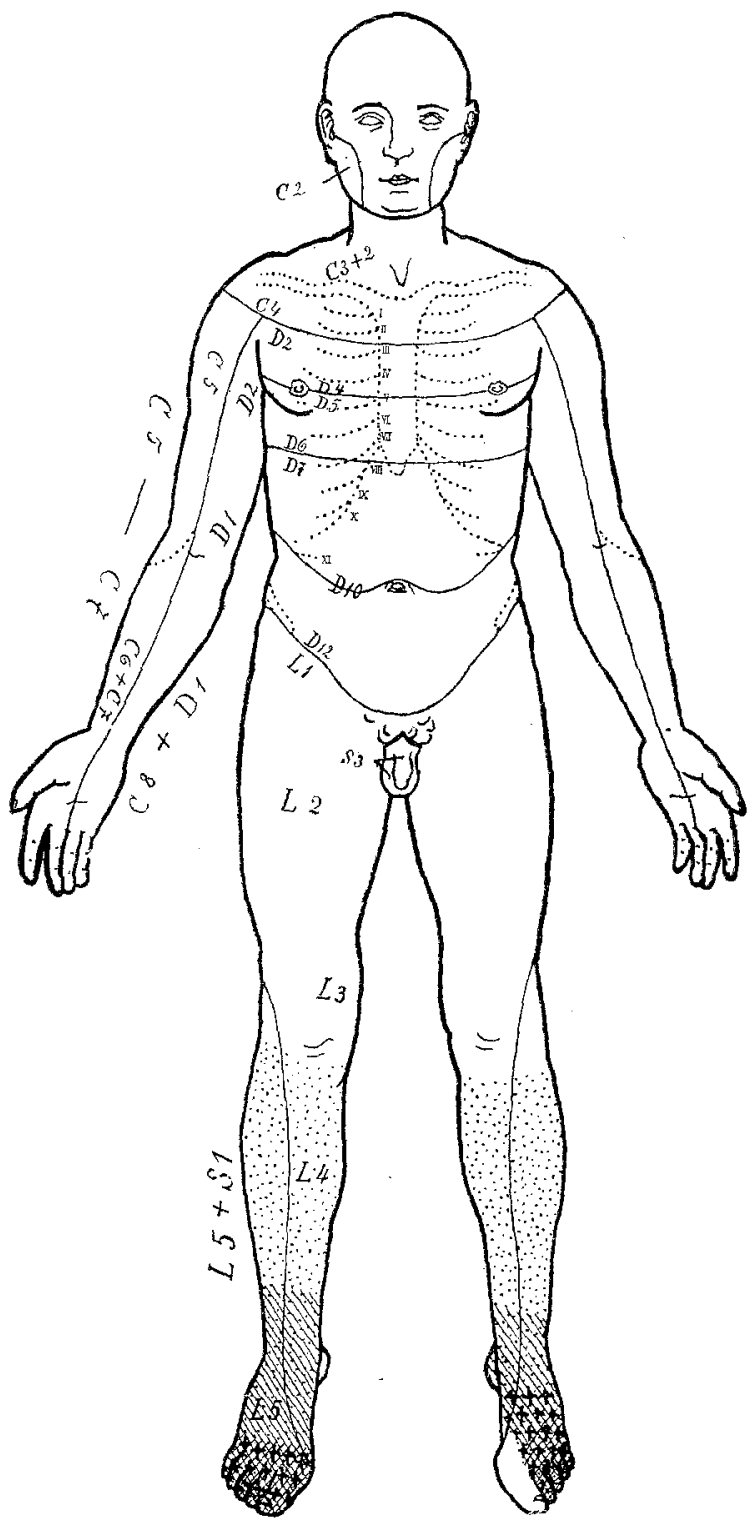

$\therefore \because \vdots=$ Berührung. $\quad / / I / /=$ Unterscheidungsvermögen $\mathrm{zwischen}$ 
20. 7. 1914 .

Fall 1: Hinr. W.

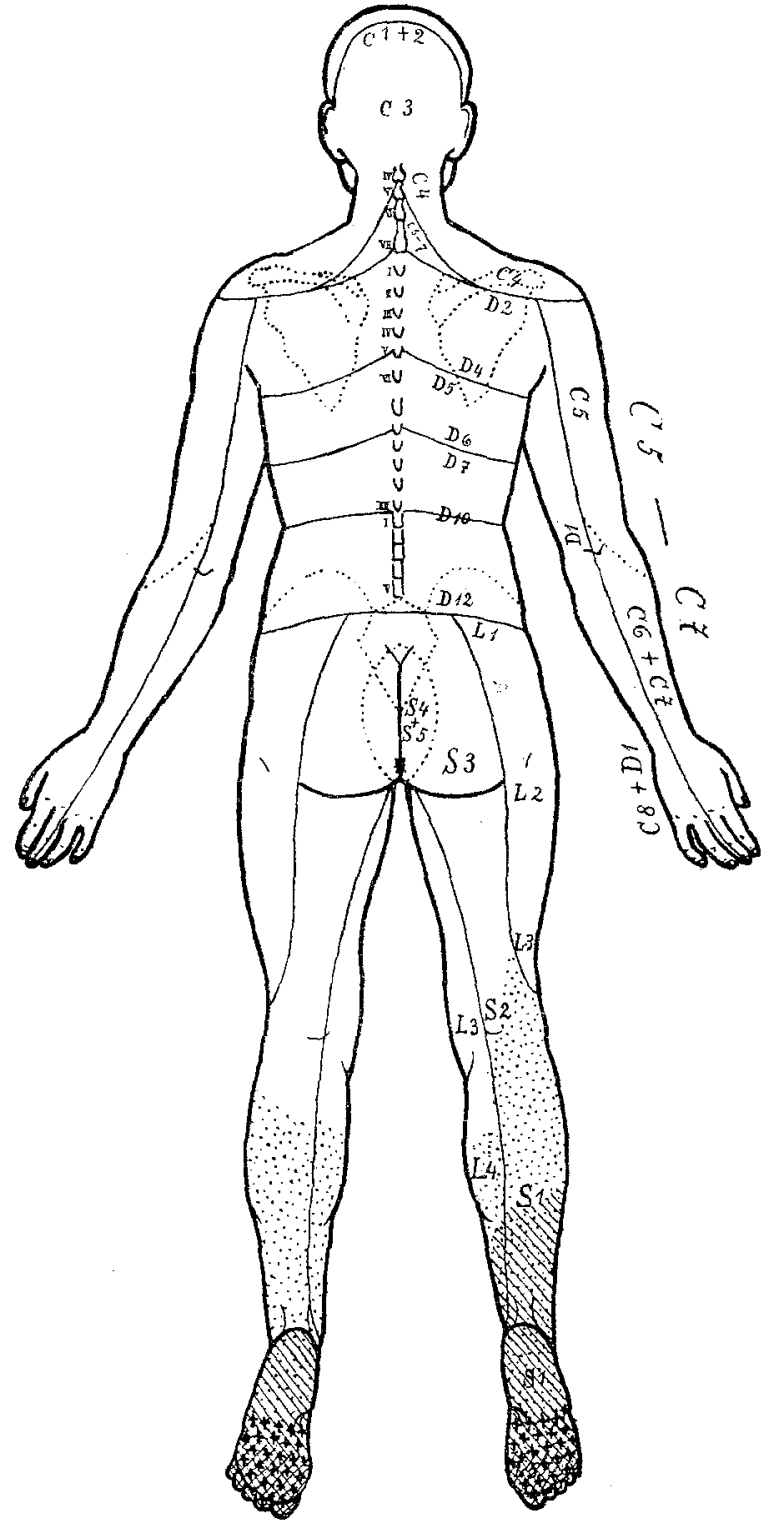

spitz und stumpf. $\quad \| 41=$ Sehmerz. $\quad+++=$ Temperatur. 
Am linken Untersobenkel sind die Venen deutlich erweitert, nur wenig geschlängelt. Die Haut des linken Fusses und des untersten Unterschenkelviertels ist stärker pigmentiert als die entsprechenden Partien rechts. Am linken Unterschenkel finden sich über dem inneren Knöchel unmittelbar darüber und handbreit über dem Knöchel zwischen Achillessehne und Tibiakante, ebenso weiter aufwärts in der Höhe des unteren Randes der Wade innen zwischen Schienbein und der hinteren Mittellinie verschieden grosse rötlich verfärbte, deutlich erhabene Hautpartien. Die grösste ist zehnpfennigstückgross. Alle sind druckempfindlich. Wie der Patient angibt, werden sie bei stärkerer Entzündung im Fuss grösser und fliessen schliesslich zusammen. Dann sind der ganze Fuss und die unteren zwei Drittel des Unterschenkels stark geschwollen und gerötet. Bei Druck auf die roten Stellen mit dem Objektträger verschwindet die Rötung völlig und es bleibt keine umschriebene Pigmentierung zurück wie bei Lupus der Haut. Die Herde in der Haut hängen nicht mit den Venen zusammen; man kann sie mit der Haut über die Venen wegschieben.

In der linken Schenkelbeuge sind zwei Lymphdrüsen deutlich geschwollen und vergrössert.

Von besonderer Wichtigkeit ist das Ausseben der abgestossenen Metatarsusepiphyse. Die obere Knochenfläche sieht durchaus wie eine Frakturfläche aus, an einer Eoke findet sich eine schräge Kante, keine Zeichen lakunärer Resorption wie an den osteomyelitischen Sequestern.

\section{Röntgenbefund:}

Linker Fuss ('Taf. II, R.-B. 1): Am 6. 3. 1913 zeigt ausgesprochenen Hallux valgus. Der Hallux bildet mit dem Metatarsus I einen nach aussen offenen Winkel von $135^{0}$, seine Basalfläche überragt aussen das Capitulum metatarsi I um $2 \mathrm{~mm}$. Innen springt die Gelenkfläche des Capitulum um $2 \mathrm{~mm}$ nach innen vor. An sie schliesst sich innen eine linsengrosse, eine stecknadelkopfgrosse Aufhellung umschliessende Knochenprominenz an. Plantarwärts liegen die stark vergrösserten Sesambeine; das meảiale halbmondförmige ist $2,2 \mathrm{~cm}$ lang, $1 \mathrm{~cm}$ breit. Das laterale Sesambein ist unregelmässig begrenzt und $1,5 \mathrm{~cm}$ lang, $0.8 \mathrm{~cm}$ breit.

Der Hallux selbst bietet ein sehr charakteristisches Bild. Die Gelenkspalte des Interphalangealgelenks fehlt, beide Gelenkenden zeigen deutlichen Schwund. Sie decken einander. Die Basis der Endphalanx sitzt dem Capitulum der Grundphalanx wie ein Helm auf. In der medialen Hälfte des Capitulum der Grundphalanx findet sich eine länglichrunde, kaum linsengrosse, von dichter strukturloser Knochensubstanz umgebene Aufhellung. Im Köpfchen des Endgliedes sieht man eine birsekorngrosse, von normalem Knochen begrenzte runde Aussparung (Vakuole).

Das Capitulum der Endphalanx der 2. Zehe ist verbreitert. Die Capitula metatarsorum II, III, IV haben normale Kontur und Zeichnung. Von der 5. Zehe ist nur noch die Basis einer Phalanx erhalten. Sie hat verwaschene Zeichnung. Ausserdem findet sich am lateralen Rande des Capitulum metatarsi 
$\checkmark$ ein tranbenkerngrosses Sesambein, und lateral ein gut linsengrosser, zum Teil von Capitulum gedeckter Knochenschatten mit klarer Zeichnung.

Nach der Exartikulation am 15. 3. 1915 und nach weiteren zwei sog. Anfällen am 13. 4. 1914 und am 11. 6. ist der Röntgenbefund folgender:

Taf.II, R.-B.2. Am linken Fuss fehlt der Hallux, das Capitulum metatarsi I zeigt zwei verschieden grosse, länglichrunde dunklere Schatten; am Rande subkortikal deutliche Aufhellung. An der 2. Zehe fehlt das Endglied fast völlig, das Capitulum der 2 . Phalanx ist abgeschrägt. Man sieht keino Arterienverkalkung.

Ta1. Il, R.B. 3. Am 13. 7. 1916 ist der Röntgenbefund des linken Fusses folgender:

Der Metatarsus I ist unverändert. Der Metatarsus II zeigt in ganzer Ausdehnung intensiven Knochenschatten. Ob das Capitulum mit der Basalphalanx eine Synostose eingegangen, lässt sich nicht sicher feststellen. Die Capitula metatarsalia III, IV, V fehlen. Der Metatarsus III endigt gaffelförmig. Die zugehörige Basalphalanx fehlt zur Hälfte, die restierende Diaphyse zeigt dichteren Knochenschatten, sie ist quer abgetrennt, wie abgehauen. Der Metatarsus IV bört in gleicher Höhe wie der III., wie quer abgeschnitten, auf, der Metatarsus $V$ schräg.

Die 3., 4. und 5. Zehe sind luxiert, die 3. liegt schräg vor dem Ende des 4. Metatarsus, die 4. Zehe leicht flektiert schräg über dem 5. Metatarsus, die 5. Zehe aussen rom 5. Metatarsus. Die Metartasi III, IV, V sind verdickt und mit periostitischen Auflagerungen verseben.

Vergleicht man R.-B. 1 vom 6. 3.1913 und R.-B. 3 vom 13. 7. 1916, so ist man überrascht durch die schweren Veränderungen, welche sich an dem linken Fuss abgespielt haben. Es fehlen die drei Capitula metatarsalia III, IV, V, die halbe Basis der Grundphalanx der 3 . Zehe, und 3 Zeken liegen in grotesker Luxationsstellung, wio im Fall 21 ron Levy und Ludloff. Die befallenen Knochen zeigen keine Atrophie, sondern vermehrte Knochenbildung (Hyperostose).

'Taf. II, R.-B. 4 des rechten Fusses: Die Kontur und Zeichnung an dem Mittelfussknochen ist durchaus normal. Am Grosszehen besteht geringe HalluxValgus-Bildung. Die Diaphyse des Grosszehen-Grundgliedes zeigt auch nach richtiger Projektion geringe Taillenbildung. Die Sesambeine sind normal. An der 2. Zehe fehlt das Endglied bis auf einen schmalen unregelmässigen Knochenschatten röllig. Die Begrenzung des Capitulum der 2. Phalanx ist unregelmässig. Die Grundpbalanx zeigt in der Mitte der Diaphyse etwas verwaschene Zeichnung und ganz geringe periostitische Auflagerungen. Ebenso ist die Zeichnung des Grundgliedes der 2. und 3. Zehe in der Diaphyse etwas verwaschen, die Begrenzung aber durchaus scharf. Die Endglieder sind an der 3. und 4. Zehe als normal zu bezeichnen, an der kleinen Zehe fehlt das 2. Glied, und die Gelenklinien des Interphalangealgelenks sind unregelmässig.

Bei dem bis dahin gesunden Mann, bei dem vielleicht schon von Jugend auf eine Atrophie des ganzen rechten Beines bestanden hatte, 
traten zuerst während der Militärzeit nach Anstrengungen sehmerzhafte Sensationen in den Unterschenkeln auf, die sich später öfter wiederbolten. Auch fielen seitdem zuweilen unter Schwarzwerden die Grosszehennagel nach vorhergehender Rötung der Zehen ab, wuchsen aber wieder. Im Alter von 41 Jabren begannen die von da ab fast dauernd vorhandenen Geschwüre zuerst am linken Grosszehenballen ohne ersichtliche Ursache aufzutreten. Es kam damals augenscheinlich zu einer Infektion der Wunde. Das Geschwür heilte zwar ab, jedoch wiederholte sich die Geschwürsbildung in den folgenden Jahren fortwährend. Ein besonders grosses Geschwür soll im 47. Lebensjahre bestanden haben, das fast die ganze Breite der Planta pedis in der Höhe der Zebenballen einnahm. Der Geschwürsbildung ging stets ein Gefühl von Taubheit an der betreffenden Stelle voraus, sie selbst war von Schmerzen begleitet. Wegen eines Geschwürs an der Dorsalseite der linken grossen Zehe musste diese im April 1913 exartikuliert werden. Die röntgenologische Untersuchung ergab schwere Knochenveränderungen. Bei der neurologischen Untersuchung im Herbst 1913 fanden wir ausser Atrophie des ganzen rechten Beines und Fehlen des rechten Achillesreflexes ausgesprochene Sensibilitätsstörungen an beiden Füssen und sämtlichen Zehen insofern, als die Tastempfindung, die Lokalisationsfähigkeit für Berührungen, die Schmerz- und Temperaturempfindung in diesen Gebieten herabgesetzt war. Eine spätere genauere Untersuchnng ergab sogar eine Herabsetzung der Lokalisationsfähigkeit im Bereich beider Unterschenkel und Füsse, während die Herabsetzung der übrigen Gefühlsqualitäten auf die Füsse, die stärkere Herabsetzung sogar auf die Zehen und die vordere Hälfte der Planta pedis beschränkt war. Die Grenzen der hypästhetischen Zonen schienen ungenau und verschwommen. Die Sensibilitätsstörungen beschränkten sich aber auf das Gebiet des 3., 4. und o. Lumbal- und des 1. und 2. Sakral-Segmentes. Dissoziierte Empfindungslähmung liess sich nicht nachweisen. Die Liquor- und Blutuntersuchung hatte ein negatives Resultat, nur die Untersuchung mit Magnesiumsulfat fiel andeutungsweise positiv ans. Wir haben es also mit trophischen Störungen ausschliesslich an den unteren Extremitäten zu tun, denen Sensibiliuätsstörungen ohne erheblichere vasomotorische Erscheinungen vorausgingen, ferner mit einer Atropbie des ganzen rechten Beines. Ob die vorïbergehende Blasenstörung von wesentlicher Bedeutung gewesen ist, lässt sich nicht sicher sagen. Thre Geringfügigkeit und restloses Verschwinden spricht eigentlich dagegen. Das Nachlassen der Potenz hängt möglicherweise nur mit dem Alter zusammen. Auf die Pathogenese des Falles wird später ausführlicher eingegangen. Im Sommer und Herbst1915 
sowie Winter 1915/16 stellten sich eruent schwere Erscheiunngen am linken Fuss ein. Die Destruktion desFusss keletts machte nnter starker Schwellung des Fusses und lymphangitischen Erscheinungen weitere Fortschritte.

Fall 2. Wilhelm W., 49 Jahre alt, Arbeiter, jetzt Invalide, Bruder des Vorigen.

Anamnese: Früher gesund. Nichts Auffälliges. Auf Schule gut gelernt, kam gut mit. Wegen jetziger Krankheit nicht gedient, 1884 zur Musterung. Heirat mit 20 Jahren, 6 Kinder, 3 Mädchen, 3 Jungen (Untersuchung der Söhne s. später). Vom 10. Lebensjahre ab viel Schmerzen, Reissen in den Zehen, besonders unter dem grossen Nagel. Nach Rötung der grossen Zehen stiess sich öfter der Nagel ab. Mit 19 Jahren Blasenbildung am Grosszehenballen erst rechts, dann links, Anschwellung des ganzen Fusses, ohne vorhergehende subjektive Sensationen, Zyanose oder synkopeartige Erscheinungen. Blasenbildungen wiederholten sich immer häufiger. Wenn die Blasen sich öffneten, entleerte sich wässerige Flüssigkeit und Eiter. Mit 34 Jahren besonders starkes Auftreten der Blasen- und Geschwürsbildung links unter heftigen Schmerzen nach anstrengenden Arbeiten an der Bahn. "Knochen kamen stückweise heraus". Seitdem soll auch der rechte Fuss bäufig kalt gewesen sein. Pat. hat damals viel in Kälte arbeiten müssen, wurde gänzlich Invalide.

1902 war Pat. in der chirurgischen Universitätsklinik in Kiel. Damals wurde von einer Amputation abgesehen, aus Sorge, es könnten sich Ernährungsstörungen am Strumpf einstellen.

In Winter 1912/13 hatte Pat. unsägliche Schmerzen in seinem linken Fuss. Er liess sich deshalb am 21. 5. 1913 in das Anscharkrankenhaus aufnehmen.

Befund im Mai 1913 (Anscharhaus) (Taf. I, Abb. 5 und 6): Linker Unterschenkel stark geschwollen, Haut derb, ödematös. Fusswurzel und Mittelfuss fehlen vollständig. An der Fusssohle 5 markstückgrosses Geschwür, dessen Grund von dem abgeschliffenen Ende der Tibia gebildet wird. Spitz and stumpf wird an einzelnen Stellen am Fuss verwechselt. Amputatio femoris osteoplastica nach Gritti, zu derPat. sichnur wegen der Schmerzen entschloss, die Heilung verlief völlig ungestört. Rechts Verkrüppelung der Zehen. Wenn rechter Fuss kalt werde, träte Reissen und Jucken in der Hacke auf. Keine Parästhesien an den Fingern. Immer viel Durst. Sex. Infektion negiert.

Wassermann am 10.5. 1913 zweifelhaft, am 18. 5. 1913 negativ. Im Urin: Kein Zucker, eine Spur Albumen.

Befund am 18. 11. 1913. Guter Ernährungszustand. Pupillen gleich, mittel weit, rund. Licht- und Konvergenzreaktion prompt und ausgiebig, Augenbewegungen frei. Andeutung von nystagmusähnlichen Zuckungen. Sprache ohne Besonderheiten. Gesicht rechts Spur mehr wie links innerviert. Beide kleinen Finger in den Interphalangealgelenken leicht gekrümmt (das sei allmählich durch schwere Arbeit gekommen). Achillesreflexe rechts vorhanden. Rechts normaler Zehenreflex. 
Linkes Bein über dem Knie amputiert. Reizlose Amputationsnarbe. Pinselberührungen werden überall, mit Ausnahme der Plantarseite der Zeben rechts, lokalisiert. Spitz und stumpf wird mit Ausnahme der Gegend des Metatarsale I. am Dorsum und der Planta pedis rechts gut unterschieden. Warm und kalt wird gut unterschieden, nur an denselben Stellen am Metatarsale I und Fusssohle verwechselt. An denselben Stellen starke Herabsetzung der Schmerzempfindung. Fusspulse gut za fühlen.

Puls 80, regelmässig. Blutdruck $140 \mathrm{~mm}$ (Riva-Rocci), Spur Albumen im Urin, keine Zylinder. Wassermann'sche Realtion im Blut zweifelhaft. Gibt noch an, leicht erregbar zu sein, früher, während seiner schweren Krankheit, mehrfach an Selbstmord gedacht zu haben.

Am 10. 5. 1914 war die Wassermann'sche Reaktion im Blut negativ. Im Urin kein Albumen mehr.

Röntgenbefund.

Taf. Il, R.-B. 5, linker Fuss: Starke Verbreiterung des unteren Tibiaschattens. Ausserordentliche Verdichtung des Knochensehattens der Tibia (Hyperostose der Tibia). Starke unregelmässige Verbreiterung des Fibulaschattens (periostitische Auflagerungen), ausserdem die Reste der atrophischen Zehenknochen.

Taf. II, R.-B. 6, rechter Fuss: Starke Verbreiterung des I. Mittelfussknochens, mässige des II. - Periostitische Auflagerungen an der Metatarsus VDiaphyse. Von der 2. Zehe steht noch die capitulumlose Grundphalanx. Der dünne Schaft und die etwas ausgeschweifte Basis haben Krückenform.

Die Basis der Grundphalanx des Hallux bildet eine grosse $\mathrm{Haube}$ über dem verbreiterten Capitulum metatarsi I. In letzterem finden sich am Rande kleine Lücken und innen eine linsengrosse Partie ron dichteren Knochen.

Am Grosszeh lässt sich Grund- und Endglied nicht mehr unterscheiden. Im peripheren Teil sieht man drei runde verschieden grosse Knochenlücken (Vakuolen).

Die starke Verbreiterung des ersten Mittelfussknochens und die mässige des zweiten hängt nicht etwa damit zusammen, dass der Röbrenabstand ein geringerer gewesen ist. Vergleichende Messungen ergeben für die Metatarsen folgende Masse:

bei Hinrich W. bei Wilhelm W.

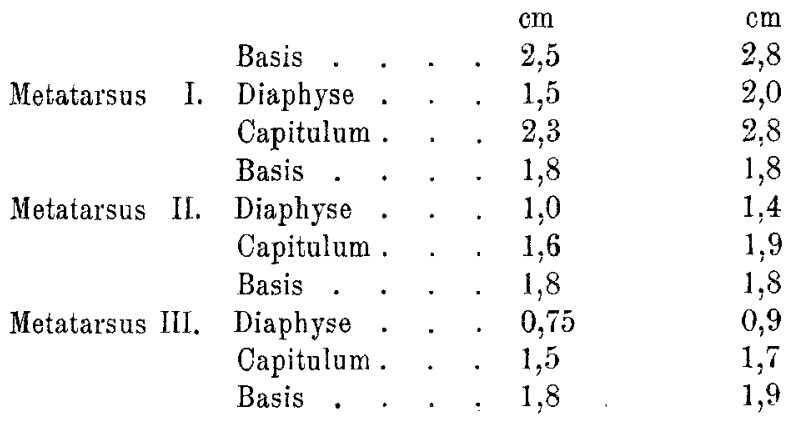




\section{bei Hinrich W. bei Wilhelm W.}

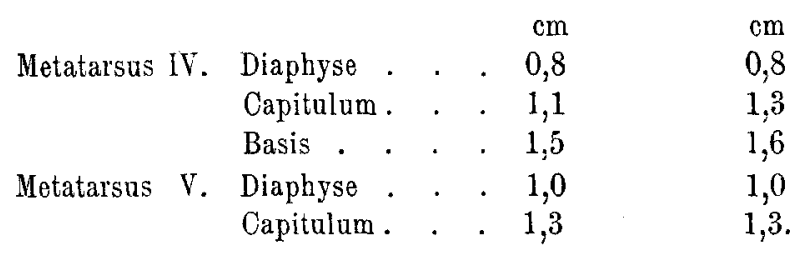

Es besteht also kein Zweifel, dass bei Wilhelm W. eine recht erbebliche Verbreiterung des Metatarsus I und II vorlag, auch geben beide dichteren Knochenschatten.

An der 3. Zehe sieht die Grundphalanx wie ein Kragenknopf aus, die Basis ist breit, die Diaphyse relativ schmal, auf dem Capitulum der Phalanx sitzt nur eine Phalange.

An der 4. Zehe ist die sonst normal gebildete, nur mit unebener Gelenkfläche versehene Endphalanx dicht an das Capitulum metatarsi IV herangerückt. Dazwischen liegen zwei Knochenschatten in Subluxationsstellung, wie sie durch Projektion zweier normaler Phalangen niemals zustande kommen können. An der 5. Zehe ist das Endglied merkwürdig gross, das 2. Glied fehlt offenbar, die verzeichnete Grundphalanx befindet sich in Subluxationsstellung, ihre Basis ist deformiert.

Am Metatarsus $V$ sieht man $1 \mathrm{~cm}$ oberhalb des Capitulum medial gelegen eine deutliche $1 \frac{1}{2} \mathrm{~cm}$ lange Verdickung. Am Ende dieser Verdickung zeigt der Metatarsus $V$ eine ganz geringe Knickung. Man sieht eine feine quere Linie in den medialen Zweidritteln der Diaphyse.

Sehr wahrscheinlich haben wir hier die Residuen einer queren Fissur vor uns.

Das Präparat des amputierten linken Fusses zeigt folgendes:

Unteres Tibiaende sklerosiert, Spongiosa $1^{1} / 2$ bis $2 \mathrm{~cm}$ tief in festere Substan\% verwandelt, eburnëisiert, beim Durchsägen in der Längsrichtnng erweist sich das untere Tibiaende weniger hart als die Tibiadiaphyse, deren Compacta sehr fest und hart, fast $1 \mathrm{~cm}$ dick ist.

Die Fibula ist ebenfalls stark verdiokt, sie zeigt starke unregelmässige periostitische Auflagerungen, die bei der Tibia am Schaft feblen, am unteren Tibiaende aber nach hinten hin eine Verbreiterung des Durchmessers um $1 \mathrm{~cm}$ bewirkt haben.

Die Haut am Unterschenkel ist nicht elephantiastisch verdickt.

Von Muskulatur ist nur sehr wenig zu sehen, sie ist zum grössten Teil verfettet.

Die Gehfläche der Tibia ist von einem einfachen niedrigen Ulkussaum umgeben.

Die Zehenstummel enthalten zum Teil keinen, zum Teil ganz osteoporotischen Knochen. Man kann die Zehen glatt in der Längsrichtung mit einem Messer durchschneiden.

Die mikroskopische Untersuchung ergibt unten am Stumpf den 
Befund eines Ulcus simplex. Es findet sich keine Lepra, keine Lues, lieine End- oder Mesarteriitis, keine Arteriosklerose.

Im unteren Untersohenkeldrittel besteht die Epidermis aus einer relativ dünnen Epithelschicht, das Bindegewebe der Kutis ist stark hyperplastisch. Die Lymphräume sind erweitert. An mehreren Stellen liegen Rundzellenanhäufungen dicht unter der Epidermis, auch die Umgebung der erweiterten Venen ist kleinzellig infiltriert (Elephantiasis).

Nachträgliche Untersuchung.

Am 8.4. 1916 kam Pat. nochmals in die Königl. psychiatrische und Nervenklinik zur Aufnahme. Er gab an: Seit November 1915 befinde er sich wieder schlechter, habe Reissen in der kleinen Zehe und der Hacke des rechten Fusses verspürt. Konnte deshalb öfter nicht schlafen. Im ganzen waren die Schmerzen aber so erträglich, dass er bis Ende Januar 1916 im Garten arbeiten konnte und damals noch $3 / 4$ Stunden lang gehen konnte. Danach sei jedoch Anfang Februar der Fussrücken angeschwollen. Seit jener Zeit entstand auch eine Blase am Fussrücken, die aufging und sich in ein Geschwür verwandelte. Aus diesem entleerten sich andauernd kleine Knochensplitter. Bereits im September 1915 habe sich ein Blase am rechten Kleinzehenballen gebildet, die aufging, worauf sich ein Knochenstück zeigte, das allmählich abgestossen wurde (ca. 3-4 cm lang). Das Geschwür babe sich danach wieder geschlossen. -- Wunden habe er sonst vorher am rechten Fuss nicht gehabt, nur vor 25 Jahren am Grosszehenballen. Damals hätten sich keine Knochen abgestossen.

Befund: Reizlose Amputationsnarbe am linken Oberschenkel. Rechtes Bein in toto stark geschwollen, hühnereigrosse Schwellung in der rechten Leistengegend, die schmerzhaft ist. Rechter Fuss unförmig, besonders am Fussrücken stark geschwollen, Haut an Fusssoble und Fussrücken stark gescbwollen. In der Gegend des Metatarsale I am Fussrücken zwei Fistelöffnungen, die verklebt sind. Zehen stark verkürzt, stellen nur noch kurze Stummel dar. Zwischen 1, und 2. Zehe fluktuierende Schwellung. Unter der Hacke eine schwärzlich verfärbte5 Pfennigstückgrosse Stelle, Achillesreflex nicht auszulösen. Kniephänomen vorhanden. Zehenreflex feblt. Ausgesprochene Plattfussstellung des rechten Fusses. Plantar- und Dorsalflexion des Fusses mit leidlich guter Kraft möglich. Zehen vollkommen unbeweglich (siehe Taf. I, Abb. 7 und 8).

Pinselberührungen an derFusssoble im vorderen Teil, an den Zehen nicht angegeben, am Unterschenkel und Fuss ungenau lokalisiert, am übrigen Körper gut lokalisiert. Spitz und Stumpf an den verdickten Stellen des Fussrückens und vorderen Teil der Fusssohle sowie auch an der Aussenseite des rechten Unterschenkels verwechselt, an den Zehen nicht empfunden.

Schmerzempfindung an der Fusssohle, besonders im vorderen Teil, und Fussrücken herabgesetzt, an den Zehen aufgehoben.

An der Fusssohle und am Fussrücken und etwas oberbalb desselben öfter kalt statt warm angegeben, bei längerer Berührung meist richtig empfunden. 
Puls 100, regelmässig. Radialis etwas rigide. Innere Organe obne Besonderheiten, jedoch im Urin 10 pro Mille Eiweiss! Spuren von Saccharum. Mikroskopisch keine Zylinder, vereinzelte Leukozyten und Epithelien. Temperatur 38,0 .

Die Lumbalpunktion am 16. 4. ergab einen Druck von $120 \mathrm{~mm}$, im Liquor Spur Trübung mit Magnesiumsulfat, 1 Lymphozyt in $1 \mathrm{~mm}$. Die Wasserasannsche Reaktion war bei Auswertung von $1,8-0,25$, ebenso wie die Wassermannsche Reaktion im Blut negativ.

Die Blutuntersuchung am 28. 4. (Dr. Kankeleit) ergab: Hämoglobin 90 pCt. (Sahli). Rote Blutkörperchen 4950000 , weisse Blutkörperchen 7000 . Blutbild: Neutrophile polynukleäre Leukozyten $62 / 3 \mathrm{pCt}$., Eosinophile $12 / 3 \mathrm{pCt}$., Uebergangszellen $1 \mathrm{pCt}$, grosse mononukleäre Zellen $12 \mathrm{pCt}$., kleine Lymphozyten $16^{1} / 3$ pCt., grosse Lymphozyten $12 / 3$ pCt., Mastzellen $2 / 3$ pCt.

Der Eiweissgehalt sank bei fleischarmer Diät am nächsten Tage bereits auf 5 pH., der Zucker verschwand ganz, kehrte auch nicht wieder. Der Eiweissgehalt schwankte weiterhin zwischen 5 und und $21 / 2 \mathrm{pM}$. und betrug am 30. 4. vor der Entlassung 31/2 pM. Die Urinmenge war anfangs etwas niedrig, $700-1000 \mathrm{ccm}$, sie stieg dann auff 1500-1700 in 24 Stunden. Zylinder oder eine grössere Anzahl von Epithelien oder Leukozyten wurden bei mehrfachen Untersuchungen nicht gefunden. Im weiteren Verlauf der Beobachtung ging die Schwellung des Fusses auf Behandlung mit essigsaurer Tonerde und Bettruhe ebenso wie die Leistendrüsenanschwellung rechts stark zurück. Jedoch blieb die Form des Fusses eine sehr plumpe wie sic Taf. I, Abb. 7 u. 8 zeigen.

Schmerzen traten nicht mehr auf, selbst dann nicht, wenn Pat. auf dem Fuss ging. Am 1. 5. wurde Pat. zur weiteren chirurgisehen Behandlung und Durchleuchtung in das Anscharhaus verlegt, entzog sich aber der Behandlung, ohne dass der Arzt ihn geseben hatte.

Eine im hiesigen physiologischen Institut von Herrn Prof. Dr. Höber, dem wir an dieser Stelle unseren besten Dank aussprechen, vorgenommene genauere Urinuntersuchnng ergab keine Substanzen des tieferen Eiweissabbaus, wie am Filtrat des Ammonsulfats festgestellt wurde. Anhaltspunkte für das Vorbandensein freier Aminosäuren fehlten.

Bei dem 49jährigen Mann traten bereits vom 10. Lebensjahr ab scbmerzhafte Sensationen in den Zehen, besonders unter dem Nagel der grossen Zebe auf. Auch hier stiessen sich ohne ersichtlichen Grund die Gross-Zebennägel $a b$, ein Vorgang, der schon anf trophische Störungen hindeutet. Bereits im 19. Lebensjahr, also erheblich früher als bei dem Bruder, zeigte sich eine Neigung zu Blasenbildungen an den Gross-Zehen. ballen, die sich im 34. Jahr verstärkte und zu Geschwürsbildungen führte, wobei sich die ersten Knocbenstücke abstiessen. Es ist nicht ganz sicher, ob die trophischen Störungen zuerst an den Knochen oder der Haut aufgetreten sind. Da die Blasenbildung hier so lange Zeit vor den ersten bemerkbaren Symptomen an den Knochen auftrat, da ferner in beiden 
Fällen schon frühzeitig die Nägel abfieleu, ist es wahrscheinlicher, dass zunächst nur trophische Störungen in der Haut vorhanden waren. Irgendwelche vasomotorischen Erscheinungen, Synkope ${ }_{\alpha}$ oder Asphyxie, hatten sich nicht gezeigt. Erst seit dem 34. Lebensjahr, als der Patient häufig in grosser Kälte arbeiten musste, soll der rechte Fuss oft eiskalt gewesen sein. Die trophischen Störungen an den Knochen und die geschwürigen Veränderungen an den Füssen sind dann allmählich so stark geworden, dass der Patient gänzlich invalide wurde. Zeitweise traten wohl auch infektiöse Erscheinungen und phlegmonöse Entzündungen, bei denen der Fuss stark anschwoll, auf. Im 49. Lebensjahr waren die Knochen bereits soweit abgestossen, dass der Patient mit dem linken Bein sozusagen auf dem abgeschliffenen Ende der Tibia ging, die im Grunde eines grossen Geschwüres frei lag. Dass ein solches Gehen und Abschleifen überhaupt möglich war, deutet auf eine Herabsetzung der Tiefen-Sensibilität, besonders der Schmerzempfindung hin. Das ganze Fusskelett zeigte röntgenologisch schwere Veränderungen. Schliesslich wurde die Amputation über dem Knie notwendig. Irgendwelche Anhaltspunkte für Tuberkulose, Lepra oder Lues fanden sich am amputierten Bein nicht. Auch in diesem Falle liessen sich am rechten Fuss Sensibilitätsstörungen, eiue Herabsetzung aller Gefühlsqualitäten an der Planta und am Dorsum pedis in der Gegend des Metatarsale I, aber keine dissoziierte Empfindungs lähmung nachweisen. Bei einer emeuten genaueren Untersuchung fanden sich noch ausgedehntere Störungen, die aber nicht über das Gebiet des 1. Sakral- und 5. Lumbalsegmentes hinausgingen, diese jedoch auch nicht ganz ausfüllten. Die Grenzen dieser Störungen waren etwas verschwommen. - Die Tatsache, dass die Fusspulse gut zu fühlen waren, ist deshalb wichtig, weil bei dem Patienten ein leichter Grad von Arteriosklerose mit zeitweiliger Eiweissausscheidung und leicht erhöhtem Blutdruck vorhanden ist. Auf diese Arteriosklerose sind also die trophischen Störungen an den Füssen nicht zurückzuführen, zumal die mikroskopische Untersuchung einfaches Ulcus simplex und keine Gefässveränderungen ergab. Aus dem zweimaligen zweifelhaften Ausfall der Wassermannschen Reaktion kaun man keine Schlüsse auf eine Lues ziehen, zumal die Wassermann'sche Reaktion zwei weitere Male negativ war. Es handelt sich also, genau wie beim Bruder des Patienten, um weitgehende trophische Störungen an den unteren Extremitäten, die sich auf Haut, Knochen, hier besonders auf die Gelenkenden, erstrecken. Sebr interessant ist es nun, dass neuerdings, nachdem am rechten Fuss jahrelang nur Sensibilitätsstörungen nachzuweisen waren und der Patient, abgesehen von den oben beschriebenen nur röntgenologisch nachweisbaren Knochen- 
veränderungen, nur über allerhand Sensationen dort zu klagen gehabt hatte, auch hier im Verlauf des letzten halben Jahres erheblich schwerere trophische Störungen zur Entwicklung kamen, die jetzt in der Hauptsache die Knochen befielen, während sich die Fistelbildungen־an der Haut offenbar erst sekundär im Anschluss an die arthritischen Veränderungen ausgebildet hatten. Ueber 25 Jahre war es also in diesen Gegenden nicht $z a$ stärkeren trophischen Störungen gekommen und damals waren überhaupt nur "Blasen" am Grosszehenballen aufgetreten. Als Begleitbzw. Folgeerscheinungen der jetzt so ausgedehnten Zerstörungen am rechten Fuss ergab die Untersuchung eine sehr starke Leistendrüsenschwellung rechts, die auf Bettbehandlung etwas zurückging, anfangs leichtes Fieber, eine sebr starke Eiweissausscheidung im Urin bis zu $10 \mathrm{pM}$., obne dass sich daneben Nierenepithelien bzw. Zylinder im Urin gefunden hätten, eine relative Vermehrung der grossen mononukleären Zellen und den grossen Lymphozyten im Blutbild und dadurch eine Veränderung des Blutbildes, wie wir sie bei der sog. Pseudoleukämie zuweilen zu sehen bekommen. Dieser Blutbefund sei hier zunächst nur registriert. Eine genauere Erklärung der Ursache dieser Veränderung ist bis jetzt nicht möglich, zumal wir bisher bei unsern anderen Kranken keine genauere Blutuntersuchung vornehmen konnten. Nur soviel lässt sich mit ziemlicher Sicherheit sagen, dass die Blutveränderung nicht die Ursache für die trophischen Prozesse darstellt, da uns für eine solche Annahme jegliche Analogie bei den zahlreichen Formen sonstiger Blutkrankheiten feblt, dass sie vielmehr nur Begleit- oder Folgeerscheinung jener Prozesse sein kann und vielleicht irgendeine Beziehung zu der starken Affektion der Lymphdrüsen in der rechten Leistenbeuge hat. Die ausserordentlich starke Eiweissausscheidung steht möglicher Weise mit dem ausgedehnten Gewebszerfall am rechten Fuss und der Ausscheidung toxischer Produkte, auf deren Vorhandensein auch das leichte Fieber hinweist, in Zusammenhang. Es erseheint uns jedenfalls sebr fraglich, ob sie allein auf die früher schon nachweisbare chronische Nierenveränderung zurückzuführen ist. Dass letztere für die Krankheit im übrigen vicht typisch ist, zeigt das Fehlen einer Eiweissausscheidung in Fall 1. - Die Liquoruntersuchung ergab ebenso wie in Fall 1 eine ganz leicht positive Magnesiumsulfatreaktion. Auf die Bedeutung dieser sei später eingegangen.

Bei dem Zustandekommen der jetzigen schweren trophischen Veränderungen am rechten Fuss scheint sowohl hier, wie in Fall 1, der Grad der Inanspruchnahme der Füsse eine gewisse Rolle zu spielen: wenigstens gab Wilhelm W. an, dass sich im September 1915 die erste "Blase" am rechten Fuss gebildet habe, nachdem er einmal beim Holzsägen Jängere 
Zeit gestanden habe, was ihm wohl zuviel geworden sei. Ferner haben sich die trophischen Störungen weiterhin offenbar infolge körperlicher Arbeit im Garten und längerem Gehen sehr schnell verschlimmert und den hier festgestellten Grad erreicht.

Im Gegensatz zu dem relativ geringen neurologischen Befund gab also das Röntgenbild einen wichtigen Fingerzeig für den weiteren Verlauf. Im Jahre 1914 waren die röntgenologisch nachweisbaren Veränderungen relativ schwerer als die neurologischen, die nur in Sensibilitätsstörungen bestanden.

Fall 3. Christian W., 52 Jahre alt, Sehneider in Genf, Bruder der Vorigen. Eine Untersuchung konnte nicht stattfinden, jedoch sandte uns der Pat. am 30. 7. 1914 einen scbriftlichen Bericht, aus dem Folgendes hervorgeht:

Mit 22 Jahren zum Militär. Bald Auftreten einer Wunde an der kleinen Zehe des linken Fusses, aus der sich ein Knochenstück abstiess. Deshalb Aufnahme ins Lazarett. Heilung der Wunde nach einigen Wochen, Entlassung aus dem Lazarett. Jedoch traten bald mehrmals bintereinander starke Schwellungen der linken kleinen Zehe, so dass Patient noch dreimal ins Lazarett aufgenommen werden musste, auf. Er will dort mit Wasserglas und Gips behandelt sein. Nach der 4. Aufnabme ins Lazarett wurde Patient vom Militär entlassen. Die Füsse sollen dann bis zum 33. Lebensjahr gesund geblieben sein. Damals und seitdem will Patient öfter kleine Blasen oder Wunden an den Zehen gehabt haben, welche immer leicht zugeheilt seien. Im April 1914 trat eine etwa einmarkstückgrosse Wunde am Grosszehenballen links auf, „wie bei unserm Vater". Zugleich soll auch eine Wunde an der grossen Zehe bestanden baben, wobei der Nagel abfiel. Beide Wunden sezernierten reichlich und beilten im Verlauf eines Monats. Störungen beim Wasserlassen sind nie aufgetreten.

Der dritte Bruder in dieser Familie litt also genau an denselben trophischen Störungen an den Füssen, wie die beiden anderen. Sie machten sich auch hier zuerst, wie beim ältesten Bruder, während der Militärzeit, also zur Zeit der stärksten Inanspruchnahme der Füsse bemerkbar. Pat. wurde deshalb $4 \mathrm{mal}$ ins Lazarett aufgenommen und schliesslich vom Militär entlassen; ein Beweis, von wie grosser Wichtigkeit die Krankheit für die Frage der Militärtauglicbkeit werden kann. Es handelte sich auch hier um Geschwüre, aus denen sich frühzeitiger als bei den anderen Fällen Knochenstücke abstiessen. Infolge dieser Geschwüre kam es mehrfach zu einer stärkeren Wundinfektion. Im Gegensatz zu dem Verlauf der Krankheit bei den beiden anderen Brüdern, blieben die Füsse bis zum 33. Lebensjahre gesund, was vielleicht auf die sitzende Lebensweise des Mannes als Schneider zurückzuführen ist, bei der ja die Füsse wenig in Anspruch genommen werden. Vom 33. Lebensjahre ab jedoch zeigten sich wieder geringere trophische Störungen 
an den Zehen in Form von Blasen und Wunden, im 52. Lebensjahr grössere Geschwüre an der linken Grosszehe und am linken Grosszehenballen. Auch diese Wanden heilten dann langsam. Zu stärkeren Störungen an den Knochen scheint es also nur einmal im Beginu gekommen zu sein. Ausgezeichnet ist die Krankbeit in diesem Fall durch ihr ausserordentlicb langsames Fortschreiten bzw. Stationärbleiben.

Fall 4. Johann W., 50 Jahr alt, Landmann, Vetter der Vorigen (räterlicherseits). (Patient wurde auf seiner Landstelle im Dorfe B. bei E. von uns aufgesucht, war leider nicht zu bewegen, zu einer genaueren Röntgenuntersuchung nach Kiel zu kommen.)

Anamnese: Während der Militärzeit im Alter von 20 Jahren Auftreten von Blasen an der linken grossen Zehe, am Zwischengelenk. Die grosse Zehe wurde deshalb entfernt. Später immer wieder Auftreten von Geschwüren an den Zehen und in der harten Haut der Fusssohlen. Vorher habe sich immer eine stark verdickte Hant, eine Art Hähnerauge, gebildet. Wurde diese entfernt, so befand sich darunter das Geschwür. Dabei zuweilen Auftreten von Entzündungen mit Schwellungen der Leistendrüsen. Knochenstücke kamen aus den Geschwüren, teils zog Patient sie sich selbst mit der Zange heraus, teils wurden sie spontan abgestossen. Nie vasomotorische Störungen. Nie an Bettnässen gelitten. Ist, trotzdem die Affektion an beiden Füssen auftrat, arbeitsfähig geblieben. Besorgt selber das Vieh, fährt auf einem Damenrad, da er auf ein solches leichter herauf und herunter kommt als auf ein Herrenrad.

Befund: Beide Füsse viel kürzer als normale, stark verbreitert.

$A m$ rechten Fuss scheinbar sämtliche Zehen vorhanden, die aber bei näherer Betrachtung nur stark verkürzte Stummel mit Nägel darstellen. Die 2. Zehe ist nur ein loser Weichteilstummel, an der 1., 3. und 5. Zehe ist meist nur die 1. Phalange erhalten. Am rechten Grosszehenballen Narben, die von sebr lange offen gebliebenen Wunden herrühren sollen. Am kleinen Zehenballen sehr stark verdickte Haut. die ebenfalls zuweilen von Geschwüren eingenommen gewesen sein soll. Vom Metatarsus I ist etwa $2 / 3$ erhalten, vom 2., 3. und 4. Metatarsus fehlen die Capitula, der 5. Metatarsus ist scheinbar erhalten. Die Zehen liegen dorsalwärts, dicht aneinander geschmiegt über den Enden der Ossa metatarsalia. Bewegung im Talocruralgelenk nur wenig behindert. Pro- und Supination stark beschränkt.

Am linken Fuss fehlt die grosse Zehe, die anderen Zehen sind mit Nägeln versehene Stummel. Die 2. und 5. Zehe enthalten keine Knochen, die 3. und 4. Zehe enthält je eine Phalanx. An der sehr stark schwieligen Sohlenhautbefindet sich in der Mitte des Mittelfusses ein kleinfingernagelgrosses Ulkus mit scharfen, von starker sobwieliger Haut gebildeten Rändern und wenig belegtem graurötlichen Grund. Patient steckt für gewöhnlich Watte mit Provenceöl hinein. Am Grosszehenballen befindet sich inmitten stark verdickter Haut eine Narbe. Von den Mittelfussknochen ist der 1. Metatarsus nur zur Hälfte, der 2. nur zu $2 / 3$ erhalten, vom 3., 4. und 5. fehlt das Capitulum und wenig mehr. Dorsalflexion beiderseits bis $80^{\circ}$, Pantarflexion rechts bis 130 , links bis $120^{\circ}$ 
möglioh. Umfänge der Waden beiderseits gleich, die der Oberschenkel $18 \mathrm{~cm}$ oberbalb des oberen Randes der Patella beiderseits $48 \mathrm{~cm}$.

Neurologischer Befund: Kniephänomene sehr lebhaft, desgleichen Achillessehnenreflexe. Kein deutlicher Plantarreflex. Pinselberührungen werden im unteren Drittel beider Unterschenlel und an den Füssen und Zehen mangelhaft lokalisiert. An den Fusssohlen und Zehen wird spitz und stumpf nicht unterschieden. Schmerzempfindung ist überall normal. Temperaturempfindung an den Fusssoblen und Zehen berabgesetzt. Wirbelsäule ohne Besonderheiten. Wassermann'sche Reaktion im Blut negativ.

Auch in diesem Fall bildeten sich zuerst während der Anstrengungen der Vilitärzeit "Blasen“ an der linken grossen Zehe, die schliesslich in Geschwüre übergingen und zur Amputation der Zehe führten. Nach Verdickung der Haut traten immer wieder Geschwüre an den Fusssohlen und Zehen auf, Teile der Phalangen und der Mittelfussknochen stiessen sich ab, so dass schliesslich grosse Teile der Phalangen und des Mittelfusses fehlten, die Zehen kleinen Stummeln glicheu, die ganzen Füsse stark verkürzt und verbreitert waren und ein äusserst charakteristisches. Aussehen hatten, das an Elefantenfüsse erinnerte. Die Sensibilitätsstörungen erstreckten sich hier auf etwas grössere Flächen als in den anderen Fällen, nämlich auf den Bereich des 4. und o. Lumbal- und auf den des 1. und 2. Sakralsegmentes. Sie waren auch hier ziemlich unscharf begrenzt.

Fall 5 . WilhelmW., 25 Jabre alt, Arbeiter, Sohn des obigen WilbelmW.

Anamnese: Geburt leicht. Als Kind Masern. Nie Krämpfe, Obnmachten, Sobwindel. Mit 2 Jahren laufen und spreoben golernt. Mit 14 Jahron Kopfverletzung, rannte gegen eine Ofenplatte, nicht bewusstlos, kein Erbrechen. Auf der Schule etwas schwer gelernt, besonders Auswendiglernen und Rechnen fiel schwer. Aus der 2. Klasse konfirmiert, Ziel der Schule nicht erreicht. Nach der Schulzeit bei Banern in Stellung. Nie Bettnässen oder erschwertes. Ürinlassen.

Mit 20 Jahren Blase an der linken grossen Zehe, die nach 3 Wochen wieder heilte. Mit 23 Jahren „wunde Stellen" auf dem Fussrücken, an der Grosszehen- und Kleinzehenseite, die rot aussahen und eine wässerige Flüssigkeit sezernierten und schmerzten. Dieselben bestanden etwa $3 / 4 \mathrm{~J}$ ahre, heilten dann. Sollen nicht durch enge oder schlecht sitzende Stiefel verursacht sein. Vorher schon 14 tägige Sohwellung der linken Hacke, später auch der rechten Hacke. Alles dies wiederholte sich seitdem im Sommer und hielt den Sommer über an. Sowie Patient sich mit dem Gehen schonte, sei es besser geworden. Barfuss oder in Holzpantoffeln könne er nicht gehen, da ihn die Füsse dann schmorzten. Die Füsse seien "zu weich". Wenn er längere Zeit gehe, habe er Schmerzen in den Waden. Starke Schweissfüsse. Nie eingeschlafenes Gefühl in den Zehen, nie anfallsweise auftretende Weiss- oder Blaufärbung der 
Zehen. Stuhlgang in Ordnung. Soll zum Kriegsdienst eingezogen werden, wünschtAttest zwecks Befreiung vom Militärdienst oder Schonung bei demselben.

Befund am 25. 8. 1914: Ueber den Hinterkopf quer verlaufende, $18 \mathrm{~cm}$ lange, bogenförmige, nicht druckempfindlicbe Narbe. Schädel anf Druck und Beklopfen nicht empfindlich. Gesicht asymmetrisch. Ohren wenig differenziert. Im Oberkiefer nur 2 Schneidezähne, im Unterkiefer Zähne sehr klein. Hirnnerven frei. Reflexe der oberen Extremitäten, Kniephänomene und Achillessehnenreflexe in normaler Stärke und beiderseits gleich vorhanden, desgleichen Abdominal- und Cremasterreflexe, Motilität und grobe Kraft der oberen und unteren Extremitäten beiderseits gleich und gat. Mechanische Muskelerregbarkeit und vasomotorisches Nachröten nicht gesteigert. Plantarreflex: Zehen werden beim Bestreichen der Fusssohlen alle dorsal flektiert. Kein Rombergsches Phänomen. Hyperhidrosis man. und ped. Herz: erster Ton an allen Ostien unrein. Innere Organe ohne Besonderheiten. An der Sehne des Extensor halluc. longus links etwa fünfpfennigstäckgrosse, dunkelpigmentierte Stelle, desgleichen an der Aussenseite des linken Fusses in der Gegend der Fusswurzel. An der Sehne des rechten Extensor halluc. longus eine gleiche Stelle. Trägt Leinwandlappen um die Füsse, da sie sonst schmerzten. Sensibilitätsprüfung siehe Schema. Patient macht etwas imbezillen Eindruck. Eine Intelligenzprüfung ergab ziemlich geringe Kenntnisse, besonders im Rechnen.

Bei dem 25jährigen, mit einigen Degenerationszeichen behafteten, wenio begabten jungen Mann, sind die Krankheitserscheinungen viel weniger ausgeprägt als in den übrigen Fällen. Nit 20 und 23 Jahren traten seiner Angabe nach "wunde Stellen" an den Fussrücken, Schwellung an den Hacken auf, die nicht etwa durch seblechtes Schubzeng verursacht sein sollen, wogegen auch das lange, 3/4 Jahre dauernde Anhalten des Wundseins spricht, das sich von da ab jeden Sommer wiederbolte. Immerhin scheint das Auftreten des Wundseins bis zu einem gewissen Grade von der Inanspruchnahme der Füsse abhängig zu sein, wie wir das auch in den übrigen Fällen beobachteten, da es, wenn der Pat. mit Gehen sich schonte, besser wurde. Vasomotorische Störungen fehlten, dagegen zeigten sich sekretorische, in Form von Hyperhidrosis der Extremitäten. Als einziger wesentlicher objektiver Befund sind die narbigen Veränderungen an den Stellen des früheren Wundseins zu erwähnen. Ausserdem bestand auch hier eine quantitative Herabsetzung der Empfindlichkeit für sämtliche Gefühlsqualitäten an Füssen und Unterschenkeln, die sich ebenfalls wieder auf die Gebiete des 5. Lumbal- und 1. Sakralsegmentes beschränkte. Dissoziierte Empfindungslähmung, Blasenstörungen, Muskelatrophien fehlten. Es erhebt sich die Frage, ob hier bei dem geringfügigen Befund überhaupt pathologische Veräuderungen angenommen werden können, zumal ja Begehrungsvorstellungen bei den Angaben des Pat. mitgesprochen baben können. 
25. 8.1914.

Fall 2: Wilhelm W.

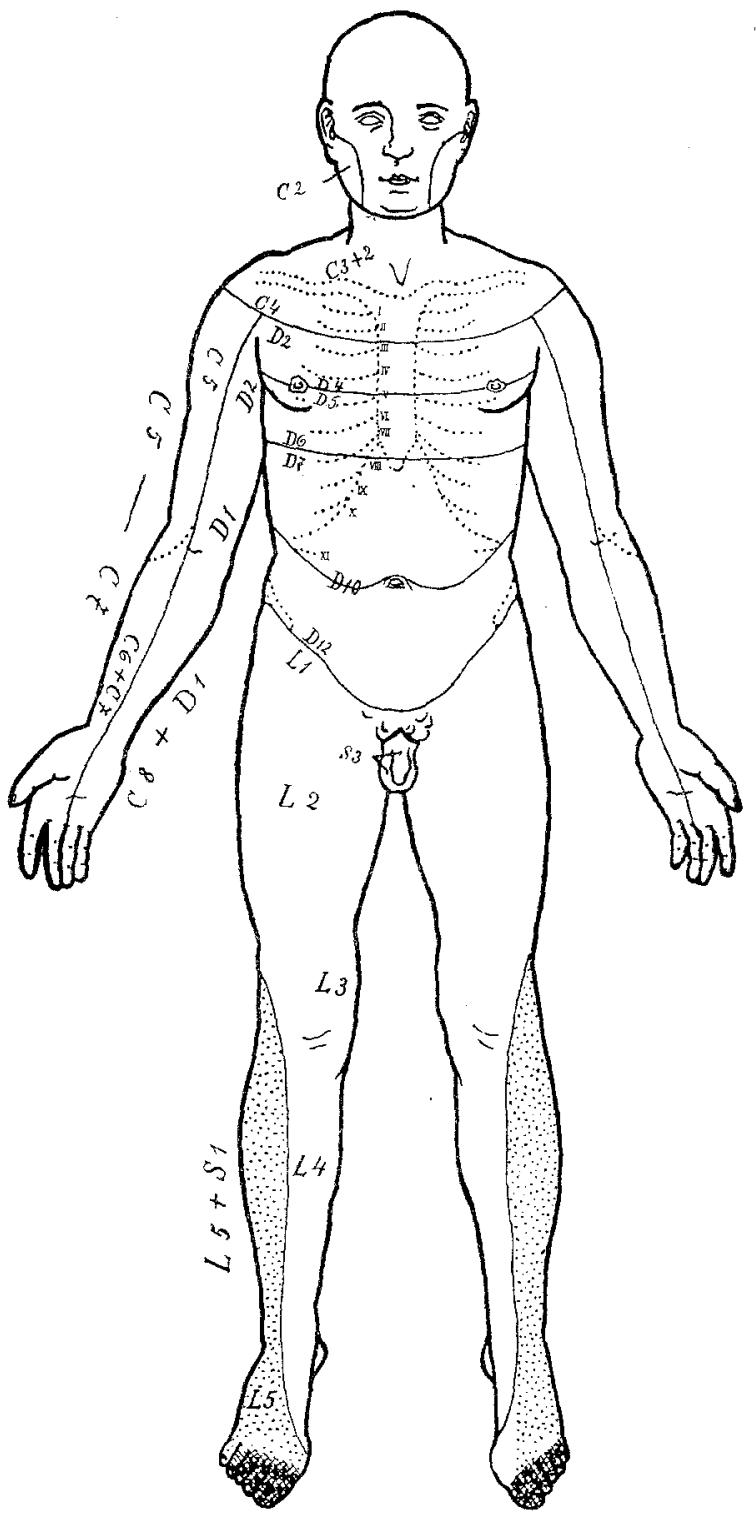

$\because: \because:=$ Berührung. $\quad / / / / /=$ Unterscheidungsvermögen zwischen 
25. 8. 1914.

Fall 2: Wilhelm W.

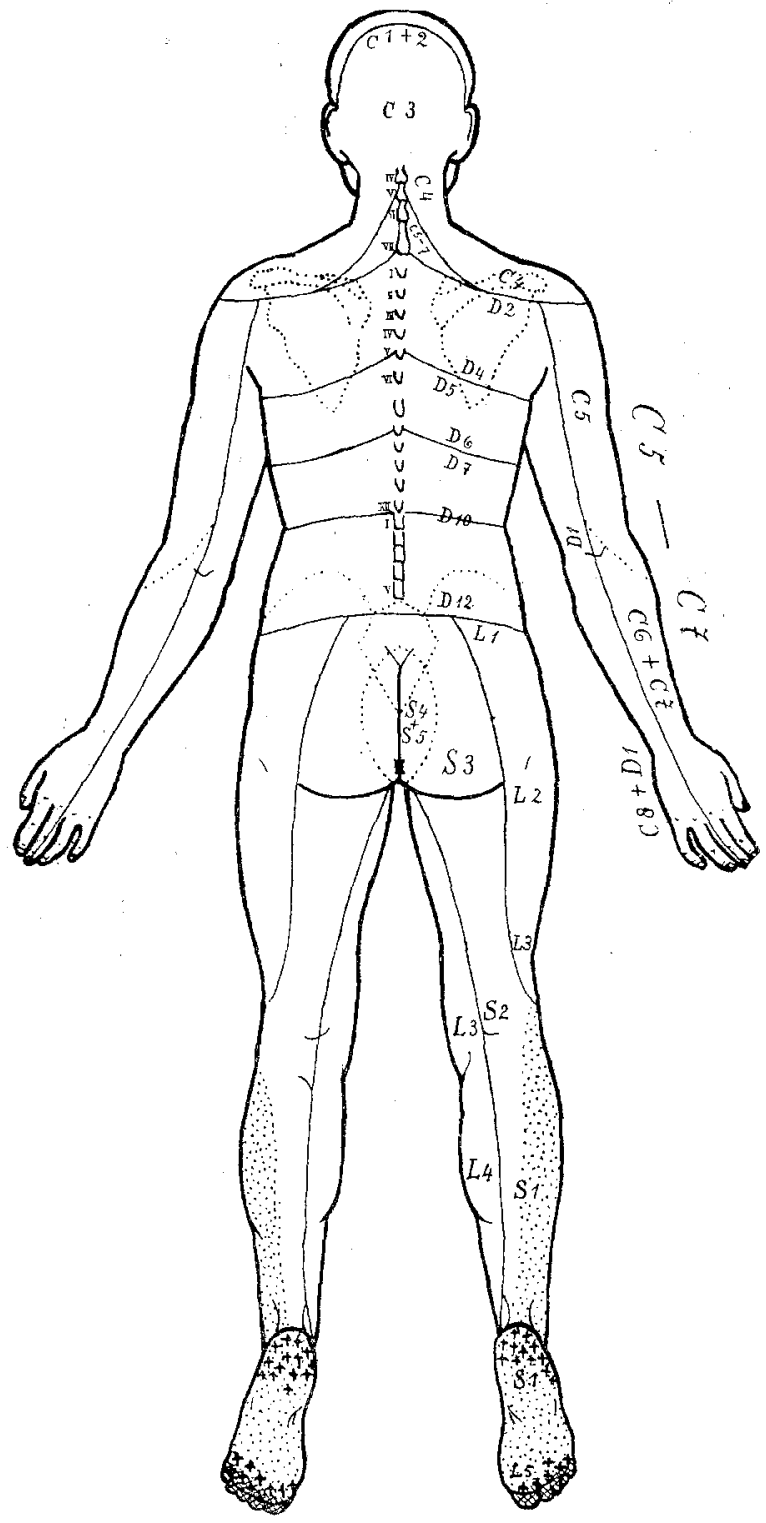

spitz und stumpf. $=$ Schmerz. $\quad+++=$ Temperatur. 
Wir glauben diese Frage bejahen zu müssen, da einerseits die Angaben des Pat, besonders auch über die Ueberempfindlichkeit der Füsse ganz präzise lauten, andererseits die narbigen Veränderungen doch darauf hindeuten, dass wir es hier nicht mit einem gewöhnlichen Wundsein der Füsse zu tun haben können, zumal der Pat. diese auch gar nicht übermässigen Strapazierungen ausgesetzt hat. Auch die Sensibilitätsstörungen waren so ausgesprochen, dass man eine Vortäuschung zum $Z$ wecke der Erlangung eines Attestes nicht glauben kann. Wir müssen tatsächlich nach Allem annehmen, dass auch bei Wilhelm W. das familiäre Leiden im allerersten Anfangsstadium vorliegt.

Fall 6. Christian W., 22 Jahre alt, Sohn des obigen Wilh. W., Bruder des Vorigen, Schneider in B., zurzeit eingezogen im Seebataillon.

Anamnese: Als Kind englische Krankheit. Mit 17 Jahren Diphtherie. Sonst gesund gewesen. Auf der Schule leicht gelernt. Mit 15 Jahren konfirmiert, dann in die Schneiderlehre. Dort bis jetzt. Nie an Bettnässen gelitten.

Seit dem 8.-10. Lebensjahr zuweilen reissende Schmerzen in allen Zehen. Ursache unbekannt. Kamen am Tage, aber auch Nachts im Bett. Abhängigkeit von körperlichen Anstrengungen nicht bemerkt. Früher zuweilen in der Gegend der Gross- und Kleinzehenballen Blasen gelaufen, bereits nach eineinhalbstündigem Gehen. Nie eingeschlafenes Gefühl oder KribbeIn in den Zehen, keine vasomotorischen Störungen, keine Schweissfüsse. Am 1. 10. 1914 beim Militär eingetreten. Habe den Dienst anfangs gut vertragen. Seit dem 20. 10. jeden Tag Märsche, gewöhnlich von morgens $1 / 28$ bis mittags 12 Uhr. Schon nach einstündigem Marschieren Schmerzen in beiden Füssen, an den Fussrücken und an der Anssenseite. Dabei schwellen die Füsse an, sehen rot aus, auch das Reissen in den Zehen kommt dabei wieder. Sei trotzdem immer mitgelaufen, aber die Schmerzen seien immer stärker geworden. Morgens nach dem Schlafen sei es wieder gut gewesen, nur die Schwellung sei noch nicht ganz zurückgegangen. Die längsten Märsche hätten etwa 6 Stunden gedauert. Bisher nicht krank gemeldet. Habe jetzt gerade ein paar Tage Ruhe, jetzt keine Fussbeschwerden.

Befund am 29. 11. 1914: Kleine Statur (1,58 m), leidliche Ernährung, gute Muskulatur. Gesicht asymmetrisch, Ohren abstehend, wenig differenziert. Nase etwas wulstig. Oberkörper lang, Beine kurz. Hirnnerven frei. Zunge zittert, Sprache unbeholfen. Reflexe der oberen Extremitäten vorhanden. Grobe Kraft, Motilität der oberen und unteren Extremitäten beiderseits gleich und gut. Abdominal-Cremasterreflexe vorbanden. Kniephänomene sehr lebhaft, Achillesreflexe vorhanden. Beiderseits mässiges Genu valgum und Pes planovalgus. Zehen werden beim Bestreichen der Fusssohlen dorsal flektiert, besonders rechts, die grosse Zehe besonders stark (Babinski ??). Linkes Schienbein etwas säbelförmig. Neigung zu stärkerer Schleimbeutelentwicklung (infolge Schneiderberuf). Keine Hyperhidrosis pedum. Umfang der Oberschenkel $15 \mathrm{~cm}$ oberhalb der Patella rechts $44^{1} / 2$, links $43 \mathrm{~cm}$, Umfang der Unterschenkel $13 \mathrm{~cm}$ unterbalb der Patella rechts 30 , links $291 / 2 \mathrm{~cm}$. Sensibilität: 
Pinselberührungen überall lokalisiert, jedoch ziemlich ungenau. Spitz und stumpf überall unterschieden, Schmerzempfindung ohne Besonderheiten. Warm und lialt an den Zehen, besonders dorsal rerwechselt, aber Angaben ziemlich unbestimmt. Gang sicher. Innere Organe ohne Besonderheiten. Im Urin kein Eiweiss oder Zucker. Wassermann'sche Reaktion im Blut negativ.

Röntgenbefund (Taf. III, R.-B. 7 u. 8).

Völlig normale Konturen und Struktur, nur an der Basis der Phalanx I des Hallux des linken Fusses findet sich medial eine stecknadelkopfgrosse rundliche, von Knochen mit verwaschener Zeichnung umgebene Aufhellung.

Bei dem 22jährigen, ebenfalls mit Degenerationszeicben und Resten von Rachitis behafteten jungen Mann bestehen in der Hauptsache subjektive Beschwerden, nämlich seit dem 8.--15. Lebensjahr, unabhängig von körperlichen Anstrengungen, reissende Schmerzen in den Zehen. Anch er zeigt, wie sein Bruder, insofern eine grosse Empfindlichkeit der Füsse, als nach kurzem Gehen bereits Blasen entstehen sollen. Es ist möglich und sogar wahrscheinlich, dass die starken Beschwerden während des Militärdienstes, die Fussrückenschmerzen, mit der ausgesprochenen Plattfussbildung im Zusammenhang stehen, jedoch wären dadurch die von Kind auf vorhandenen reissenden Schmerzen in den Zehen nicht ausreichend erklärt. Der objektive Befund ist ausser den erwähnten Zeichen von Rachitis und Pes plano-valgus und den Degenerationszeichen negativ, jedoch scheinen auch hier bei vorsichtiger Untersuchung unter Berücksichtigung der normalen Sensibilitätsverhältnisse, wenn auch nicht mit völliger Bestimmtheit festzulegende, leichte Störungen der Temperaturempfindung an den Zehen zu bestehen; ferner ergab das Röntgenbild an der Basis der Phalanx I des linken Grosszehens eine stecknadelkopfgrosse von Knochen mit verwaschener Zeichnung umgebene Aufhellung. Die bei den anderen Familienmitgliedern meist zu so verderblicher Entwick]ung gelangte Familienkrankheit lässt sich also hier nicht mit Bestimmtheit nachweisen und scheint sich vielleicht erst in subjektiven Beschwerden za äussern. Erwähnenswert ist aber hier die starke Plattfussbildung. Beim Militär wird Patient auf unser Attest hin möglichst geschont und auf der Handwerkerstube beschäftigt.

Fall 7. August W., 21 Jahre alt, Kellner, Sohn des obigen Wilh. W., Bruder der Vorigen.

Anamnese: Nach Angabe des Vaters Geburt des Patienten leicht. Lernte mit 2 Jahren laufen und sprechen. Früher stets gesund. Nie Bettnässen. Vom 15. Lebensjahre ab Schmerzen auf der Dorsalseite der Zehen, an der Fusssohle und der Innenseite des Fusses. Sohmerzen lamen nach langem Laufen. Zehen sahen dann dorsal rot, plantar weiss aus, hatte taubes Gefühl 
darin. Füsse sollen öfter wund gewesen sein, Blasen oder Geschwüre traten aber nicht auf. Schmerzen zeitweilig sehr stark, musste deshalb öfter 3-4 mal täglich die Strümpfe wechseln. Von Geburt an geschielt (habe das vom Grossvater mütterlicherseits geerbt).

Befund Mai 1914: Dürftige Ernährung, Hinterhaupt vorspringend, Gesicht asymmetrisch, Ohren abstehend. Leichter Strabismus convergens concomitans. Hirnnerven frei. Sprache ohne Besonderheiten. Reflexe der oberen Extremitäten, Kniephänomene, Achillesreflexe vorhanden, beiderseits gleich. Grobe Kraft und Motilität der oberen und unteren Extremitäten beiderseits gleich und gut. Fingernasenversuch und Kniehackenversuch sicher. Zehen beim Bestreichen der Fusssohlen dorsal flektiert. Kein Babinski. Genu valgum und Pes planus beiderseits angedeutet. Umfang der Oberschenkel $15 \mathrm{~cm}$ aberhalb der Kniescheibe beiderseits $42 \mathrm{~cm}$, Umfang der Unterschenkel $14 \mathrm{~cm}$ unterhalb der Kniescheibe beiderseits $31 \mathrm{~cm}$. Füsse feucht, kühl. Starke Hyperhidrosis. Bei Bewegungen Krepitieren im Interphalangealgelenk des rechten Hallux, links weniger. Naevus pigmentosus am Rücken. Deutliche Einsenkung des Thorax infolge Rachitis. Wassermann'sche Reaktion im Blut zweifelhaft.

Sensibilität: Pinselberührungen an der Aussenseite des linken Unterschenkels schlecht lokalisiert, ebenso an der Plantarseite der grossen Zehen. Spitz und stumpf wird unterschieden, nur an der Plantarseite der Zehen öfter stumpf statt spitz angegeben. Schmerzempfindung lebhaft. Warm nnd kalt wird an der Plantarseite sämtlicher Zehen verwechselt, einmal auch am linken Fussrücken. Bei einer weiteren Untersuchung wurde warm und kalt auch an den Fusssoblen ungenau angegeben. Sonstiger neuroergischer Befund normal:

Röntgenuntersuchung (T'af, III, R.-B. 9).

Abgesehen von dem sehr zarten Knochenbau und der sehr zart gezeichneten Knochenstruktur handelt es sich um normale Bilder.

Am 18. 3. 1915 ersehien der Patient wieder und bat um ein Attest, da er zum Landsturm eingezogen werden sollte. Er habe seit der letzten Untersuchung nur Reissen in der grossen Zehe, sobald er sich nach Gehen setzte, gemerkt. Es trat immer plötzlich und jeden Tag auf. Seit etwa 4 Wochen habe sich der Nagel an der linken grossen Zehe losgelöst (ohne vorherige Verletzung). Während des Loslösens des Nagels Schmerzen beim Laufen. Besondere Anstrengungen habe er vorher nicht überstanden. Die Untersuchung ergibt, dass der Nagel an der linken Grosszehe nur noch an der Aussenseite und am Nagelfalz haftet. Darunter bereits neugebildeter Nagel bis zur Hälfte des alten. Fuss und Zehe kühl, keine wesentliche Verfärbung der Haut (vielleicht etwas blauroter wie sonst?). Pinselberührungen heute an der ganzen linken Grosszehe bis auf den inneren Teil der Plantarseite ungenau lokalisiert. An denselben Stellen statt spitz stumpf angegeben. In derselben Gegend auch warm und kalt verwechselt, meist warm statt kalt angegeben, ausserdem noch an der Aussenseite bis zum Metatarso-phalangealgelenk.

Bei dem 21jührigen, gleichfalls mit Degenerationszeichen und Resten von Rachitis behafteten Patienten bestehen seit dem 15. Lebensjabre 
Schmerzen auf der Dorsalseite der Zehen, an den Fusssoblen und der Innenseite des Fusses sowie taubes Gefühl in den Zehen. Im Gegensatz zu den übrigen Fällen ist ein Wundsein der Füsse bisher nicht aufgetreten, jedoch waren die subjektiven Beschwerden, die zum Teil, aber sicher nicht alle, mit dem leichten Plattfuss in Verbindung stehen können, zeitweilig so stark, dass der Patient nur durch sehr bäufiges Wechseln der Strümpfe sich helfen konnte. Ausser den erwähntei Zeichen ron Rachitis bestanden auch bier nur Sensibilitätsstörungen und zwar in geringem Umfange, ebenfalls wieder im Bereich des 5. Lumbal- und 1. Sakralsegmentes. Wenn die Sensibilitätsprüfung auch an den Zehen und teilweise an der Fusssohle normalerweise schwankende Ergebnisse zeitigen kann, so waren die Störungen doch hier so auffallend, dass sie wohl als pathologisch angesehen werden können, um so mehr, als sich an derselben Zehe, an der sie sich hauptsächlich befanden, der Nagel ohne Grund abstiess, wie auch in unseren ersten beiden Fällen beobachtet wurde. Dieser Vorgang dürfte als trophische Störung aufzufassen sein und wahrscheinlich auf eine bereits einsetzende Entwicklung des familiären Leidens hindeuten.

Ueber die hereditären Verhältnisse der Familie W. gibt umstehender, nach den Angaben der Patienten verfertigter Stammbaum Aufschluss:

In Einzelnen ist Folgendes zu erwähnen: Es handelt sich um eine in Schleswig-Holstein alteingessene Familie, deren Mitglieder mit einigen Ausnahmen meist auf dem Lande und in kleinen Städten als Landleute, Arbeiter und Handwerker leben. Von besonderen Schädigungen, denen diese Familie ausgesetzt wäre, ist nichts bekannt geworden, Alkoholund Nikotinmissbrauch sowie luetische Infektionen scheinen nicht vorgekommen zu sein, nur ein Mitglied scheint stärker getrunken zu haben. Auffallend ist ein gewisser Wandertrieb bei einzelnen Mitgliedern: Eins ist nach Amerika, eins wach der Schweiz ausgewandert, auch ist das Auftreten von Degenerationszeichen, besonders körperlichen, weniger psychischen bei der jüugsten Generation erwähnenswert.

Dèr Grossvater unserer 3 Brüder W. und ihres Vetters Johann W. Johann W. war einziger Sobn und ist 88 Jahre alt geworden. Auch seine Frau soll in hohem Alter gestorben sein. Von schwereren Krankheiten, die diese überstanden hätten, von Trunksucht bei diesen ist nichts bekannt, insbesondere haben sie nicht an der bei ihren Nachkommen aufgetretenen Familienkrankheit gelitten. Der älteste Sohn dieses Ehepaares Klaus $W$. und dessen Nachkommenschaft sind ebenfalls von der Krankheit verschont geblieben, dafür sind aber in dieser Linie andere Eigentümlichkeiten hervorgetreten: Der älteste Sohn des Klaus W. Hinrich W. zeigte ein auffallendes Talent für Halerei und ist ein ziemlich 


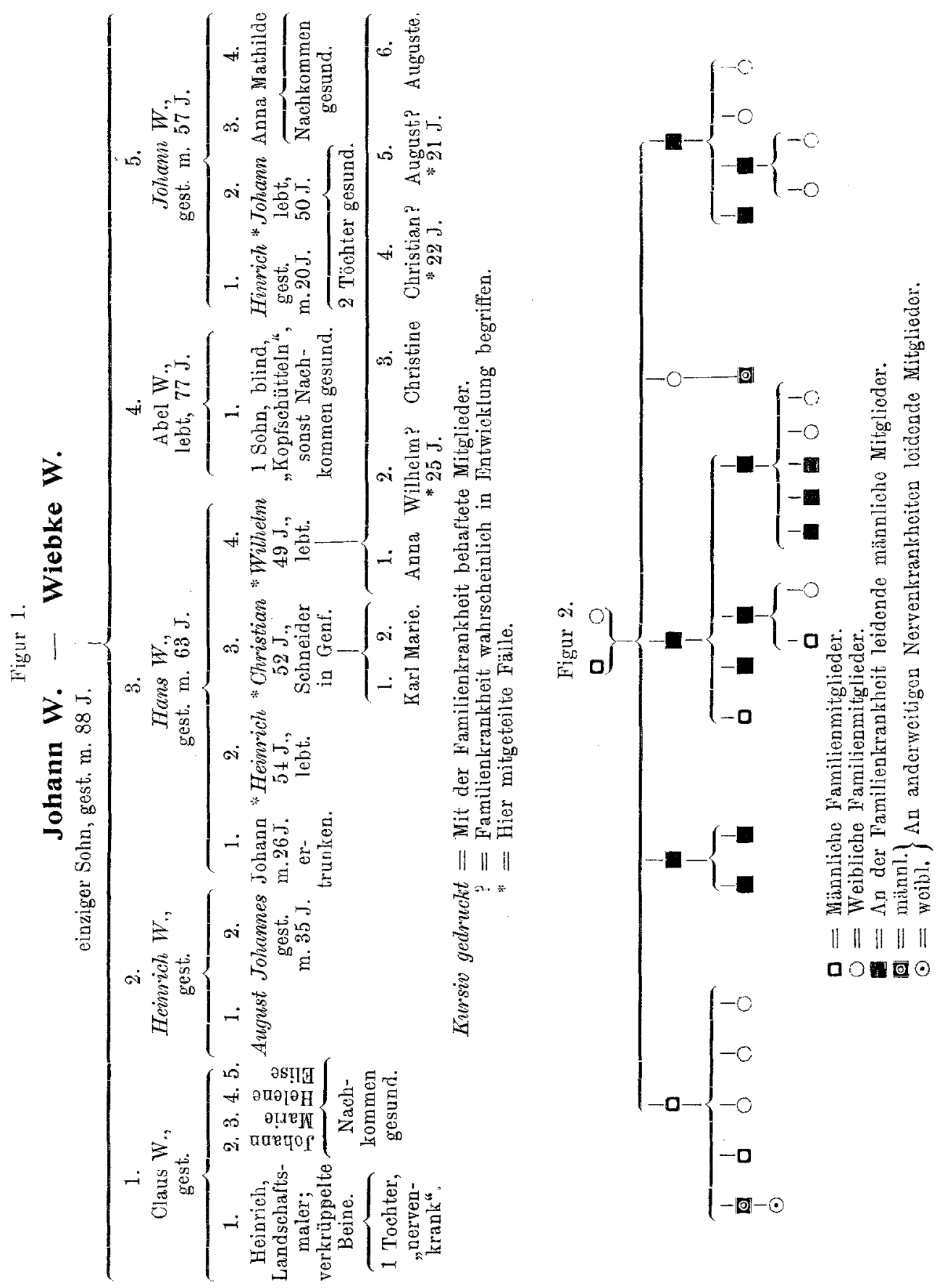


bekannter holsteinischer Landschaftsmaler gewesen, der zeitweise in Rom und München gelebt hat, und von dem noch ein grösseres Gemälde („Dünenlandschaft auf Sylt", gem. 1873) in der Kunsthalle in Kiel hängt. Es ist ja eine bekannte Tatsache, dass zuweilen einzelne auffallende Talente in degenerierten Familien auftreten können. Dieser Mann soll nach einer Krankheit in der Kindheit "verkrüppelte Beine" bekommen haben. Näheres liess sich leider nicht darüber feststellen. Aber die Annahme liegt nahe, dass die Verkrüppelung der Beine auf eine Rückenmarkerkrankung (spinale Kinderlähmung? Spina bifida??) zurückzuführen ist. Eine Tochter dieses Nalers soll an einer unbekannten Nervenkrankheit gelitten haben, ein Bruder und 3 Schwestern sowie deren Nachkommen sollen gesund gewesen sein.

Der zweitälteste Sohn des alten Johann W. Heinrich W. und dessen beide Söhne August und Johannes W. haben nach Angabe unserer Patienten an der gleichen Fusskrankheit gelitten wie sie. Der Vater Heinrich W. wanderte im Alter von ca. 60 Jahren nach Amerika aus. An welcher Krankheit er gestorben ist, ist unbekannt. Ueber seinen ältesten Sohn August ist nur zu erfahren, dass er ebenfalls an der Familienkrankheit gelitten hat, nicht aber, ob er noch lebt. Der 2. Sohn Johannes soll etwas getrunken haben and starb in einem (unbekannten) Hamburger Krankenhaus mit ea. 35 Jahren, als ihrn wegen der trophischen Störungen beide Füsse amputiert werden mussten.

Der 3. Sohn des alten Jobann W. Hans W. ist der Vater unserer 3 Patienten Heinrich, Christian und Wilhelm. Auch bei ihm soll die Krankheit an beiden Füssen aufgetreten sein, sie begann im Alter von ca. 30 Jahren und griff soweit um sich, dass die Füsse „bis zur Hälfte abfielen" und Hans W. schliesslich im Alter von 63 Jahren daran starb. Der älteste Sohn des Hans W. Johann ertrank im Alter von 26 Jahren. Die drei weiteren Söhne sind unsere Patienten. Ein Sohn und eine Tochter des 3 . Bruders Christian sind gesund geblieben. Bei den 3 Söbnen des 4. Bruders (Fälle 5, 6,7) ist die Krankheit vielleicht in Entwicklung begriffen, drei Töchter sind gesund.

Das 4. Kind des alten Johann W. ist eine Tochter Abel W., diese lebt noch im Alter von 77 Jahren und soll nicht an der Familienkrankheit gelitten haben. Offenbar sind aber in ibrer Nachkommensehaft andere Nervenkrankheiten (hereditäre?) aufgetreten: Ein Sohn vou ihr soll im jugendlichen Alter erblindet sein und an Zuckungen des Kopfes leiden. Sorgfältige Nachforschungen nach ibm blieben Jeider erfolglos. Die übrigen Nachkommen der Abel W. sollen gesund sein.

Das jüngste Kind des alten W. war Johann W. Bei ihm begann die Familienkrankheit mit Blasenbildung an den Füssen. „Beide Füsse 
faulten ihm bis an die Hacken ab". Er starb an der Krankheit im Alter von 57 Jahren. Der älteste Sohn dieses Johann W. Heinrich W. soll bereits im Alter von 21 Jahren, angeblich 8 Tage nach dem Vater, an der gleichen Krankheit gestorben sein. Ein zweiter Sohn Joh annes W. lebt im Dorfe B. in Holstein und ist unser Patient Nr. 4. Zwei Töchter desselbeu sind gesund, desgleichen seine 2 Schwestern Anna und Mathilde.

Die Familienkrankheit ist also im Ganzen bei 10 Personen diesel Familie aufgetreten, bei 3 ist sie offenbar in langsamer Entwicklung begriffen. Stets und ausschliesslich wurden in allen Fällen die unteren Extremitäten befallen. Ueber die Art der Vererbung ist Folgendes hervorzuheben: Die Krankheit wurde nur durch männliche Mitglieder vererbt und nur männliche Mitglieder erkrankten an ihr. Die einzige Tochter des alten Johann W., die Schwester von drei kranken Brüdern, ihre Nachkommen und auch die Töchter sonstiger erkrankter Familienmitglieder blieben von der Krankheit verschont, bis auf eine Tochter des Malers Hinrich W. aus der Linie des ältesten Sohnes des alten Johann W., die aber, ebenso wie ein Sohn der erwähnten Tochter des alten Johann W, an einer andersartigen Nervenkrankheit litt. Die Verhältnisse liegen also hier anders wie bei vielen familiären progressiven Organopathien des Nervensystems, bei denen die Uebertragung durch Frauen viel häufiger als durch Männer ist (Higier, Sänger, Brown, Eichhorst), oder der Hämophilie, bei der die Uebertragung ausschliesslich durch Frauen erfolgt. Sie stimmt aber mit anderen heredofamiliären Leiden, wie der neurotischen Amyotrophie, genuinen Optikusatropbie, Pseudohypertrophie, spastischen Spinalparalyse darin überein, dass sie stark das männliche Geschlecht bevorzugt, oder vielmehr, soweit nach unseren Fällen zu sagen ist, ausschliesslich das männliche Geschlecht befällt, sie wird aber eben nicht durch gesund bleibende weibliche Mitglieder, sondern nur durch Männer übertragen, was bei den erwähnten Krankheiten nur ganz ausnahmsweise der Fall ist. Es wäre aber uun möglich, dass das ausschliessliche Auftreten der Krankheit bei Männern darauf zurückzuführen ist, dass die Füsse dieser in den in Frage kommenden Schichten der Bevölkerung vielleicht in stärkerer Weise in Anspruch genommen werden als bei Fraueu. Dass das Auftreten der Krankheit tatsächlich bis zu einem gewissen Grade von der Intensität der Inanspruchnahme der Füsse abhängig ist, zeigt der Umstand, dass die Krankheit in allen Fällen (nach einzelnen Vorläufersymptomen in früherer Zeit) erst im jugendlichen Mannesalter, intensiver besonders in einigen Fällen während des Militärdienstes aufgetreten ist, und in Fall 3 in dieser Zeit sogar eine solche Intensität entwickelte, wie sie im späteren Leben nicht mehr erreicht worden ist. Letzteres mag vielleicht damit zusammen- 
hängen, dass der Patient als Schneider seine Füsse weit weniger grossen Anstrengungen auszusetzen braucht als seine Brüder und andere Verwandten, die Landleute und Arbeiter sind. Wegen der Analogie mit anderen hereditären Krankheiten ist jedoch eher anzunehmen, dass das ausschliessliche Befallenwerden des männlichen Geschlechts in unserer Familie auf einen besonderen Vererbungsmodus zurückzuführen ist und nicht auf die zuletzt erwähnte Ursache, zumal sich im letzteren Falle doch auch irgendwann einmal irgendwelche Krankheitserscheinungen bei weiblichen Mitgliedern gezeigt haben würden.

Die anteponierte oder progressive Form der Heredität, d. h. die Tendenz der Krankheit, sich von Generation zu Generation immer früher einzustellen (wie bei der Chorea Huntington, Myoklonie, spast. Spinalparalyse, Hercdoataxie Marie) liegt, soweit bisher festzustellen ist, in unseren Fällen nicht vor.

In 2 Linien der Familie W, nämlich der des ältesten Sohnes Klaus des alten Johann W., sowie der noch lebenden einzigen Tochter Abel W. sind andersartige Nervenkrankheiten und zwar hier auch bei weiblichen Mitgliedern aufgetreten: Der Maler Hinrich W. aus der 1. Linie soll "verkrïppelte Beine" gehabt, seine Tochter an einer unbekannten Nervenkrankheit, ein Sohn der Abel W. an einer Krankheit, die mit Kopfschütteln und Amaurose einherging, gelitten haben.

Ein solches Auftreten verschiedener hereditärer Krankheiten nebeneinander in einer Familie ist häufiger beobachtet worden (Higier, Kollarits, Jendrassik). Kollarits nnd Jendrassik schliessen daraus, dass eine Reihe von hereditären Krankheiten, wie Muskeldystrophie, bereditäre spast. Spinalparalyse, Friedreich'sche Ataxie, Marie'sche Kleinhirnataxie usw. keine selbständigen Krankheiten sind, vielmehr ohne Grenzen ineinander übergehende Formen der Heredogeneration. 'Ob dieses auch für die in unserer Familie aufgetretenen Krankbeiten gilt, lässt sich nicht entscheiden, da die Art der in der Linie des ältesten Sohnes und der Tochter des alten Johann W. aufgetretenen Krankheiten leider unbekannt geblieben ist.

Die Anwendung der Mendel'schen Regeln stösst, wie oft beim Menschen, bei unserer Familie auf grosse, zum Teil unüberwindliche Schwierigkeiten, und zwar deshalb, weil nur wenige Generationen der Familie und dann noch unvollkommen zu übersehen sind, weil mehrere Nitglieder bereits in früherem Alter gestorben sind, von denen ev. noch eine Fortpflanzung hätte erwartet werden können, weil wenig über die Frauen bekannt geworden ist usw. Versuchen wir eine Anwendung der Mendel'sehen Lehre von der Dominanz und Rezessivität der Merkmale, so lässt sich sagen, dass es sich um eine dominante Vererbung 
der Krankheit in unserer Familie nicht handeln kann, da beide Eltern gesund waren. Gegen die Anwendung einer rezessiven Vererbung sprechen hinwiederum die Zahlenverhältnisse, da nach Mendel nur ein Viertel und nicht wie hier $2 / 5$ der Kinder der gesunden Eltern erkrankt sein dürften. Es wäre allerdings noch möglich, dass andere Kinder der beiden alten W.'s, die von der Krankheit verschont geblieben wären, in jugendlichem Alter gestorben sind, obne dass Näheres von ihnen bekannt geworden wäre. In diesem Falle könnte es sich doch um eine rezessive Vererbung gehandelt haben.

Zusammenfassend lässt sich über das von uns beobachtete Leiden folgendes sagen: Seit 3 Generationen tritt bei männlichen Mitgliedern der Familie W. eine nur von Männern vererbte eigentümliche Erkrankung der unteren Extremitäten, zunächst an den Füssen und Zehen auf, die in der Regel mit Vorläufersymptomen in Form von schmerzhaften Sensationen in den Zehen, zeitweilig mit Abfallen der Nägel, mit schlechtheilenden wunden Stellen teils bereits im 8.-10. Lebensjahr, teils etwas später beginut. Stärkere Erscheinungen treten erst später, in der Regel zur Zeit der stärksten Inanspruchnahme der Füsse während der Militärzeit (Fall 3, 4), zuweilen auch noch später auf; sie bestehen in Blasenbildungen, aus denen sich dann allmählich schlecht oder garnicht heilende Geschwüre, am häufigsten in der Nähe der Grosszehenballen, aber auch an den Zehen selber entwickeln. Diesen Erscheinungen gehen gewöhnlich Sensibilitätsstörungen in Form von Herabsetzung der Intensität aller Empfindungsqualitäten, nicht aber in Form von dissoziierter Empfindungslähmung voraus, deren Grenzen zwar etwas verschwommen waren, die sich aber in allen Fällen auf das Bereich des 5. Lumbalund 1. Sakralsegmentes beschränkten, nur in einem Fall auch auf das 4. Lumbal- und 2. Sakralsegment übergriffen, innerhalb dieser Grenzen aber ganz regellos verteilt, am häufigsten jedoch an den Fussoblen und Zeben nachzuweisen waren. Auffallend war, dass die Kranken trotz der schweren Veränderungen an Haut und Knochen im ganzen wenig über Schmerzen klagten, wenn nicht gerade phlegmonöse Entzündungen vorlagen, dass sie auch trotz dieser Veränderungen noch herumliefen, der eine Patient sogar so lange, bis die Fusswurzelknochen zum Teil zerstört und das freiliegende Tibiaende ganz abgeschliffen war. Ein anderer steckte sich mit Oel getränkte Watte in ein tiefes, an der Fussohle befindliches Geschwür, lief trotz der starken Difformität der Füsse herum und fuhr Rad, ohne über Schmerzen zu klagen. Alles dieses deutet offenbar auf eine starke Beteiligung der Tiefen-Sensibilität bei den pathologischen Vorgängen hin. Einmal wurde Atrophie des einen Beines, gelegentlıch Fehlen der Achillessehnenreflexe und Beeinträchtigung 
der Funktion der kleinen Fussmuskeln beobachtet. Die Geschwüre vergrösserten sich im Laufe von Jahren, heilten auch vorübergehend $a b$, kamen aber immer wieder zum Ausbruch; ab und zu stiessen sich Knochen aus ihnen ab. An den Gelenkenden der Knochen kam es, wie die Röntgenbilder zeigen, zu chronisch arthritischen Prozessen, zu atrophischen und hypertrophischen Veränderungen.

$O b$ diese Knochen- und Gelenkveränderungen oder die Hautveränderungen das Primäre waren, lässt sich schwer entscheiden. Da aber Sensibilitätsstörungen an der Haut und trophische Störungen an den Gebilden der Haut, wie den Zebennägeln vorausgingen, da lange Zeit vor dem Erscheinen eigentlicber Knochen- und Gelenksymptome über Wundsein, Blasen- sowie Geschwürbildung an der Haut geklagt wurde, ist es wahrscheinlicher, dass die Hautveränderungen zum Teil wenigstens den Knochenveränderungen vorausgingen. Es kommen offenbar leichte Anfälle ohne Gelenkbeteiligung und andererseits auch schwerere Anfälle mit Beteiligung von Knochen und Gelenken vor, wobei dann die Hautveränderungen ganz in den Hintergrund treten können. Nach Abstossung von nekrotisch gewordenen Knochen tritt bald Heilung ein. Werden die Füsse nicht geschont, und tritt keine geeignete Behandlung ein, so wird aus dem einfachen Geschwür ein Malum perforans pedis (mal perforant du pied), welches einmal mit dém Knochen- und Gelenkprozess zusammenhängt, ein andermal nicht. Später $\mathrm{kam}$ es in den Fällen, in denen die genannten Prozesse noch weiter gingen, zu einer starken Verdickung und Schwellung der Haut der Füsse, zu einer hochgradigen Verkrümmung und Verkürzung der Zehen wie auch der Füsse, die gleichzeitig breiter wurden, sodass sie in besonders ausgesprochenen Fällen das Aussehen von Elefantenfüssen hatten. Häufige von den Geschwüren ausgehende Infektionen mit Drüsenschwellung und Fieber, in einem Fall mit sehr starker Eiweissausscheidung brachten mehrere der Patienten in Lebensgefahr. Im Verlauf solcher infektiöser Prozesse wurde gelegentlich die Amputation einzelner Zeben, des Fusses und des Unterschenkels notwendig. - Soweit uns bekannt, sind 5 Mlitglieder der Familie an der Krankheit zugrunde gegangen, wohl weil eine Infektion eingetreten war, und die in einzelnen Fällen noch vorgenommene Amputation zu spät kam; ein Beweis dafür, wie ausserordentlich deletär die Krankheit werden kann, wenn nicht rechtzeitig chirurgisch eingegriffen wird. Erfolgte die Amputation hoch genug, so batte nach den bisherigen Erfahrungen der Prozess sein Ende erreicht. Die Krankheit kann, wie in einigen unserer Fälle, in der Praxis dann von Wichtigkeit werden, wenn es sich um die Einstellung von Leuten zum Militärdienst handelt, bei denen sich die Krankheit noch im allerersten Entwicklungsstadium befindet. - 
Das heredo-familiäre Leiden scheint ausserordentlich selten zu sein. Bei genauer Durchsicht der Literatur fanden wir nur ganz vereinzelte Fälle von familiär auftretenden trophischen Störungen an den unteren Extremitäten, die vielleicht mit den in unseren Fällen beobachteten identisch sind.

1903 berichtete Bruns über die Familie eines jüdischen Schlächters aus der Provinz Hessen, bei der ähnliche Erkrankungen wie in unseren Fällen vorgekommen sind. Der Inhalt der Krankengeschichten ist kurz folgender:

Von 5 Kindern, deren Eltern gesund waren und über 70 Jabre alt geworden sind, sind 4, darunter eine Schwester, auf dieselbe Weise erkrankt und zwar alle in ungefähr in demselben Alter von 17 Jahren. Bei dem drittältesten Sohn begann die Erkrankung beiderseitssymmetrisch mit Geschwüren unter den Grosszehenballen, die in die betreffenden Zehengelenke durchbrachen und schliesslich zu einer Abstossung der Endphalange der grossen Zehe rechts und zu einer Ankyloso der 2., links zur Abstossung der ersten beiden Zehen führten. Bald darauf, im Anschluss an eine umschriebene Entzündung am Fussrücken, Erkrankung des rechten Sprunggelenkes, die schliesslich zur Vereiterung und mehrfachen Fistelbildung führte. Der Kranke ging trotzdem noch viel auf dem Fusse, so dass der rechte Unterschenkel und Fuss allmäblich stark deformiert wurden, der Fuss schliesslich kürzer war als der linke. Der Unterschenkel war auf dem Fuss stark nach vorn geschoben. „Der ganze rechte Fuss ähnelte einem Pferdefuss". Sprunggelenk schlotternd, abnorm beweglich. Bewegungen trotz Eiterungen nicht schmerzhaft. In der verdickten Gelenkkapsel Knocheneinlageruugen.

Beide Beine besonders die Unterschenkel in ihrer Muskulatur deutlich atrophisch und geschwächt, Funktion der kleinen Fussmuskeln erheblich gestört, wobei die Knochenveränderungen und Entzündungen am Fusse in Betracht zu ziehen sind. In den atrophierten Muskeln fibrilläre Zuckungen. Elektrische Erregbarkeit für beide Ströme in der beiderseitigen Unterschenkelmuskulatur stark herabgesetzt, weniger in der Oberschenkelmuskulatur. Fussmuskeln unerregbar. Tastgefühl und Schmerzempfindung sowie Temperaturempfindung an beiden Unterschenkeln und Füssen bis zum Knie sehr stark herabgesetzt, warm mit kalt dort häufig verwechselt. Auf dem linken äusseren Knöchel Verbrennungsnarbe durch zu heisse Umschläge. Im rechten Sprunggelenk fehlt Bewegungsempfindung. Geringe Schmerzen im rechten Fuss. Patellarreflexe fehlen beiderseits. Keine Blasen- und Mastdarmstörungen. Wirbelsäule intakt, sonst keine neurologischen Veränderungen. April 1903 A.mputation an der oberen Grenze des unteren Drittels des rechten Unterschenkels. Röntgenbefund des amputierten Beines: Griffelartige Zuspitzung der unteren Enden beider Unterschenkelknochen. Malleolen, Sprungbein fehlen. Calcaneus länger und breiter als normal, Os naviculare und cuboideum zusammengedrüikt. Haut am Fuss enorm verdickt. 
Rasche Heilung der Amputationswunde. Eine neue Untersuchung im Mai 1903 ergab im übrigen keine besonderen Abweichungen von dem Status im Jahre 1891.

Bei dem 5 Jahre älteren Bruder begann das Leiden ebenfalls mit perforierenden Geschwüren. Am linken Fuss fehlt die grosse Zehe, am rechten Fuss Fusswurzelknochen; die Metaphalangen sind operativ entfernt, so dass die noch vorhandenen Zehen an einer Fleischbrücke des Fusses hängen. Dadurch starke Verkürzung des Fusses. An der Sohle desselben ein 5 markstückgrosses, flaches Geschwür. Sensibilitätsverhältnisse fast genau so wie im ersten Fall. Muskelschwund weniger stark, keine elektrischen Störungen und fibrilläre Zuckungen. Patellarreflexe fehlen. Keine Blasen- und Mastdarmstörungen. Bei der letzten Untersuchung war der Kranke 39 Jahre alt. Er ist längere Zeit auf einer Kniestütze des rechten Beines gegangen, dabei heilte das Geschwür unter dem rechten Fusse, jedoch bildete sich ein Dekubitus am Knie, der wieder heilte, nachderm Pat. wieder auf der rechten Fusssohle ging.

Ein jüngerer Bruder erkrankte mit 17 Jahren an Ulcera beiderseits symmetrisch unter den Ballen der grossen Zehen, die in die Gelenke und in das Gebiet der Metaphalangen durchdrangen. Aus den Fisteln entleerten sich Knochenstücke. Auch hier die gleiche Sensibilitätsstörung aber nur an den Füssen, Patellarreflexe fehlten. Unterschenkel wenig atrophisch. 10 Jahre nach Beginn der Krankheit akute Gangrän des ganzen linken Vorderfusses. Beide Unterschenkel jetzt sehr atrophisch, rechter Fuss in Varoequinusstellung: (Schwäche der Mm. peronei). Fehlen der Sehnen- und Hautreflexe an beiden Beinen. Schmerzgefühl für Nadelstiche an beiden Eüssen erloschen, an den Unterschenkeln sehr herabgesetzt. Stinkende Fistelbildungen an beiden Füssen, septisches Fieber, am nächsten Tage Gangrän bis an den Unterschenkel. Tod. Keine Sektion.

Eine Schwester, die in gleicher Weise erkrankte, starb im frühen Stadium der Krankbeit an den Folgen der Amputation.

Die Hauptunterschiede der Bruns'schen Fälle gegenüber den unseren bestehen in Folgendem: Die Krankheit blieb nicht auf die männlichen Mitglieder beschränkt, sondern befiel auch ein weibliches Mitglied. Das schliesst aber nicht aus, dass es sich um dieselbe Frkrankung handelt wie in unseren Fällen. In den Bruns'schen Fällen waren ferner bäufiger als in unseren Muskelatrophien an den unteren Extremitäten, teilweise sogar mit fibrillären Zuckungen, sowie Fehlen der Achillesreflexe nachzuweisen; auch die Patellarreflexe fehlten bei ihnen meist, waren bei unseren erhalten. Die Schmerzempfindung schien teilweise an der Haut stärker herabgesetzt als in unseren Fallen, jedoch sei ausdrücklich darauf hingewiesen, dass auch bei den Brunsschen Fällen stets die Tastempfindung mit betroffen war, es sich also bei ihnen um keine reine dissoziierte Empfindungslähmung handelte. 
Die Gefühlsstörungen waren, wie offenbar der ganze Prozess, ausgedehnter wie in unseren Fällen. Bei diesen ist es auch niemals; soweit bekannt geworden, zu einer Gangrän des ganzen Vorderfusses gekommen wie in einem der Bru us'schen Fälle. Dass eine solche Gangrän aber gelegentlich auch einmal in unseren Fällen eintreten kann, halten wir bei den weitgehenden Ernährungsstörungen, den gelegentlichen starken Wundinfektionen und Entzündungsprozessen durchaus für möglich.

Gemeinsam mit den unseren haben die Bruns'schen Fälle das gehäufte familiäre Auftreten der Krankheit, den Beginn im jugendlichen Alter, die symmetrische Lokalisation trophischer Störungen ausschliesslich an Haut und Knochen der unteren Extremitäten, der Füsse und Zehen, die primäre Lokalisation der geschwürigen Veränderungen mit Vorliebean den grossen Zehenballen, die Herabsetzung sämtlicher Empfindungsqualitäten an der Hant mit Beteiligung der Tiefensensibilität, das Fehlen vasomotorischer Störungen, den langsamen Verlauf der Krankheit, die zunehmende Verstümmelung und Deformierung der Füsse infolge Geschwürsbildung und Abstossung von Knochenteilen, das Fehlen irgendwelcher Blasen- und Mastdarmstörungen.

Von Vorläufererscheinungen, wie Schmerzen in den Zehen, Abfallen der Nägel, berichtet Bruns nichts, was jedoch das Vorkommen in seinen Fällen nicht ganz ausschliessen dürfte. Die Ulcera der Haut drangen, wie Bruns annimmt, von aussen in die Tiefe, wodurch teilweise Abstossung der Phalangen erfolgte, eine Auffassung, mit der wir jedoch die arthropathischen Prozesse in unseren Fällen nicht ausschliesslich erklären können. Wir nehmen vielmehr, wie erwähnt, an, dass Haut-, Gelenk- und Knochenprozesse vielleicht zunächst zum Teil selbstündig nebeneinander hergingen. Die Deformierung, der Füsse war eine ganz ähnliche wie in unseren Fällen. Die fibrillären Zuckungen in einem Falle von Bruns. denten vielleicht auf Prozesse im Rückenmark hin, die wir auch, wie wir seben werden, in unseren Fällen anzunehmen genötigt sind. Bruns. meint, dass es sich in seinem ersten Fall um eine langsam fortschreitende Syringomyelie handeln könne, trotz mancherlei Abweichungen. Wir halten eine solche Erkrankung aus später zu erörternden Gründen, sowohl in seinen wie in unseren Fällen, wahrscheinlich nicht für vorliegend. Jedenfalls ist, trotz mancherlei Abweichungen, die Aehulicbkeit der Bruns'schen Fälle mit den unsrigen eine sehr weitgehende.

1909 teilte weiter Oehlecker die Krankengeschichten von 2 Brüdern mit, die ebenfalls an trophoneurotischen Erscheinungen an den unteren Extremitäten litten. Der Inhalt der Krankengeschichten ist kurz folgender:

Keine erbliche Belastung; Missbildungen, Nervenkrankheiten, Lues usw. sind in der Familie nicht rorgekommen. 
Der erste, jetzt 25 jährige Pat. war bis zum 15. Lebensjahre gesund. Dann plötzlich über Nacht starke Anschwellung des linken Fusses obne vorkergegangenes Trauma, jedoch ist Pat. am Tage vorher viel herumgelaufen. Nach 8 Tagen Verschwinden dieser Erscheinungen, ohne dass bedeutendere Schmerzen aufgetreten wären. Einige Zeit darauf an der Soble des linken Fusses in der Kleinzehengegend Ausbildung eines kleinen Hautgeschwürs, das nur langsam heilte und immer wieder aufbrach. Deshalb Aufnahme ins Eppendorfer Krankenhaus, Hamburg. Eine Röntgenuntersuchung ergab damals starke Verdickungen der distalen Enden der 2.-4. Metatarsalknochen, ebendort. alte Frakturen mit starker Knochenwucherung. Die anatomische Untersuchung der teilweise abgetragenen Metatarsalknochen ergab keine Tumorbildung. Uebriger Befund, besonders des Nervensystems normal. - 1901 wegen Wiederaufbrechens des kleinen Geschwürs Aufnahme ins Eppendorfer Krankenhaus. Abtragung eines T'eils der geschwulstartig verdickten Mittelfussknochen. Anatomische Untersuchung des Knochengewebes ergab keine Besonderheiten. Nervensystem ohne Besonderheiten. Trotzdem wurde die Möglichkeit einer Syringomyelie in Betracht gezogen. 1902 Zunahme der Verbildung und Verunstaltung des linken Fusses. Röntgenuntersuchung ergab schwere Zerstörung auch der Fusswurzelknochen. Das kleine Geschwür am Aussenrande des linken Fusses hatte zu Phlegmone und Eiterung Anlass gegeben. Amputation des linken Fusses nach Pirogoff. Die gründliche, auch mikroskopische Untersuchung des Fusses ergab keine tuberkulöse, syphilitische Veränderungen, kein Tumorgewebe. Pat. war dann ein Jahr völlig gesund. Dann allmählich Erkrankung des rechten Fusses: Ohne erhebliche Beschwerden Auftreten von Schwellungen und Gelenksergüssen sowie eines Hautgeschwürs an der Fusssoble, das gegenüber den Knochenveränderungen mehr zurücktrat als links. Trotz Stützstiefel Zunahme der Deformität. 1908 Aufnahme in Eppendorf. Allgemeinbefund normal. Keine Lues, keine Spina bifida occulta, wie aus Röntgenaufnabmen geschlossen werden konnte. Liquorbefund normal, W. R. im Blut negativ. Nervensystem olne Besonderheiten, keine Atrophien, Sensibilitätsstörungen, keine Blasen- oder Mastdarmstörungen. Am Stumpf des linken Beines nichts Besonderes. Rechter Fuss in Gegend des Fussgelenkes und Mittelfusses geschwollen, in leichter SpitzfussstelIung, gegen die Achse des Unterschenkels nach innen verschoben, mässige Kontrakturen der Wadenmuskulatur. Am Aussenrande des rechten Fusses kleines Hautgeschwür. Keine Schmerzen. Röntgenuntersuchung: Schwere Zerstörung der Fusswurzel- und Mittelfussknochen. Knochen verschoben, subluxiert, in ihrer Form verändert. Os naviculare nach dem Fussrücken zu herausgepresst, Köpfchen der 1. und 2. Mittelfussknochen abgebrochen, Diaphyse der 4. und 5. Mittelfussknochen aufgetrieben. Aehnliche Veränderungen an den Phalangen. -- Geschwür am rechten Fuss, brach beim Gehen immer wieder auf. 10. 2. 1902. Amputation des rechten Fusses nach Pirogoff. Nach verschiedenen Zwischenfällen Heilung. Anatomische Untersuchung des Fusses: Keine Veränderungen an Gefässen und Nerven. Geschwür ging nicht in die Tiefe. Prozesse an den Fusswurzelknochen, die Knochen und Knorpel sowohl angebaut wie abgebaut batten. 
Bei dem 18jährigen Bruder im Alter von 15 Jahren ohne Verletzung Anschwellang des linken Fusses. Er arbeitete, da keine Beschwerden bestanden, weiter. Da Anschwellung nicht schwand, Aufnahme in Eppendorf (1906): Röntgenuntersucbung ergab Schrägbruch des 1. und 2. Mittelfussknochens mit einer Periostitis ossificans. Mai 1908 Wiederaufnahme, Entfernung der 2. Zehe, die eine Hammerzehe ist und auf dem Rüeken ein Geschw ür trägt, das trotz bester Pflege nicht heilen wollte. März 1908 Wiederaufnahme. An der 2. Zehe links seitlich kleines Geschwür, das trotz Behandlung keine Neigung zum Heilen zeigte. Nervenbefund normal, keine Lues. Keine Muskelatrophien. W. R. im Blut negativ. Andeutung von Hohl- und Spitzfuss. Röntgenbild: 1. und 2. Mittelfussknochen leicht verdickt, Köpfchen des Grundgliedes der grossen Zehe abgebrochen, infolgedessen leichte Valgusstellung des Endgliedes. Gesobwür an der 2. Zehe lag gegenüber dieser Abknickung, so dass das Geschwür durch mechanische Einwirkung entstanden erklärt werden konnte. „Eine Trophoneurose scheint hier nicht die Ursache zu sein". Pat. will sich nur 1908 seinen Fuss gestossen haben. Damals vier T'age lang Anschwellung der grossen Zehe ohne Beschwerden. Im Interphalangealgelenk der linken grossen Zehe leichtes Knarren. Entfernung der 2. linken Zehe. Keine Zirkulations- oder Ernährungsstörungen an der Haut der Füsse.

Gewisse Abweichungen von unseren Fällen finden sich wie in denen von Bruns auch in denen von Oehlecker. Bei den Fällen Oehlecker's scheint es, als ob die Knochen- und Gelenkveränderungen das Primäre waren, die Geschwürsbildung an der Haut erst sekundär in Erscheinung trat, während in unseren Fällen die Hautaffektionen scheinbar das Erste waren, und die Gelenk- und Knochenerkrankungen sich erst später ausbildeten, oder doch höchstens vielleicht der Beginn beider Affektionen in die gleiche Zeit fällt. Oehlecker meint sogar, dass es sich bei den Geschwüren in seinen Fällen zum Teil garnicht um trophoneurotische Störungen gehandelt hat, sondern ihnen mechanische Ursachen zu Grunde liegen. Sicher erscheint es jedoch, dass wenigstens die bartnäckigen und immer wieder aufbrechenden Geschwüre an den beiden Füssen in seinem ersten Fall nicht allein auf mechanische, sondern auch auf tropboneurotische Ursachen zurïckzuführen waren. Im ganzen kann man aber sagen, dass die Hautveränderung in den Fällen Oehlecker's gegenüber den Knochenveränderungen mehr zurücktraten als in unseren Făllen. Es sollen ferner Sensibilitätsstörungen in der von ihm beobachteten Erkrankung gefeblt haben. Jedoch weist der Umstand, dass die Patienten im Anschluss an die Spontaubrüche fast gar keine Schmerzen und Beschwerden hatten, doch zum mindesten darauf hin, dass die Tiefensensibilität, die Schmerzempfindung schwer affiziert waren.

Im Uebrigen ist die Aehulichkeit der Erkrankung in den Fällen Oehlecker's mit der in unseren Fällen eine recht grosse. Jene haben 
mit den unseren gemeinsam: Das familiäre Auftreten der Krankheit, das ausschliessliche Erkranken des männlichen Geschlechts, die ausschliessliche und symmetrische Lokalisation trophischer Störungen an den unteren Extremitäten, die auffallende Herabsetzung oder Aufhebung der Tiefensensibilität, besonders der Schmerzempfindlichkeit, das ausserordentliche Zurücktreten oder Fehlen sonstiger pathologischer Veränderungen des Nervensystems. Wir glauben aus allem schliessen zu können, dass es sich in den Fällen Oehlecker's um eine der unseren analoge Krankheit handelt, besonders auch mit Rücksicht darauf, dass gerade bei heredo-familiären Krankheiten auch sonst ausserordentliche Variationen in den einzelnen Fällen festzustellen sind.

Die Tatsache, dass bei Hinrich W. das gelöste Capitulum eine Bruchfläche, bei Wilhelm W. das Röntgenbild am rechten Metatarsus $\tilde{0}$ eine Fissur aufwies, ist deshalb von besonderer Wichtigkeit, weil von den beiden Fällen Oehlecker's, bei dem einen Bruder neben anderen Knochenverschiebungen und Subluxationen auch ein Querbruch der Köpfehen der 1. und 2. Mittelfussknochen vorhanden war, bei dem anderen Bruder das Köpfchen des Grundgliedes der grossen Zehe abgebrochen war, ohne dass die Patienten es ahnten. -

Levi and Ludloff's Fall 21 zeigt neurologisch grössere Abweichung, röntgenologisch besteht mit dem Befund bei Hinrich eine frappante Lebereinstimmung. Der Fall ist folgender:

32 jähriger Kutscher. Bekam im Alter von 28 Jahren unter beiden grossen Zeben "offene Stellen", die sich erst nach 3 monatiger Behandlung im Krankenhaus schlossen. Pat. konnte jedoch seitdem nicht wieder arbeiten, sooft er es versuchte, bildeten sich die Geschwüre an den Zehen wieder, so dass er deshalb 4 mal in Krankenhausbehandiung war. Seitdem sind die Geschwüre nicht wieder geheilt. Wenn Pat. eine Zeit lang gegangen ist, bilden sich in der rechten Leistengegend schmerzhafte Knoten.

Befund: Rechter Unterschenkel bedeutend dicker als der linke durch ein nach unten stärker werdendes Oedem. Zehen unförmig dick, drängen sich zum Teil übereinander. An der Innenfläche des rechten Unterschenkels dreifingerbreit unter dem Kniegelenk markstückgrosse, eingezogene, mit dem Knochen verwachene Narbe. Auf der Fusssohle entsprechend dem Metatarsophalangealgelenk zwei kleine lineare Narben. An der Beugeseite der grossen Zehe ein flaches bohnengrosses Geschwür mit glattem Grund und Rand. Am linken Fuss und unteren Drittel des linken Unterschenkels mässiges Oedem. An der Beugeseite der grossen Zehe ein $3 \mathrm{~cm}$ langes, ca. $1 \mathrm{~cm}$ breites Geschwür, welches ganz symmetrisch mit dem Geschwür am anderen Fuss liegt. Die neurologisohe Untersuchung ergibt eine etwas unsichere Temperaturempfindung an beiden Füssen, sowie eine auffallend lebhafte Reaktion auf sensible Reize an den Füssen. Röntgenbild: Am linken Fuss geringe Deformierung 
einzelner Interdigitalgelenke. Am rechten Fuss groteske Subluxationsstellung aller Zehen. Zerstörung einiger Metatarsalepiphysen; Periostwucherungen, keine Spur ron Atrophie.

Die Aehnlichkeit mit der Erkrankung in unseren Fällen besteht hauptsächlich im Auftreten von symmetrischen, schlecht heilenden Geschwüren an den grossen Zehen, sowie von Knochen-Gelenkaffektionen im jugendlichen Alter. Die Geschwürsbildung scheint auch hier in grosser Abhängigkeit von der Intensität der Inanspruchnahme der Füsse zu stehen. Die Sensibilitätsstörungen waren aber weit weniger ausgesprochen als in unseren Fällen und bestanden nur in einer Unsicherheit der Temperaturempfindung. Letztere, sowie das Fehlen des Nachweises von der Familiarität der Krankheit, könnte uns, trotz der im übrigen grossen Aehnlichkeit mit unseren Fällen, besonders was die Knochenveränderungen betrifft, trotz des Hinweises von neurologischer Seite. (welche den Fall ebenfalls sah), dass sichere Anbaltspunkte für ein spinales Leiden fehlten, den Gedanken nahelegen, dass es sich vielleicht hier um eine beginnende Syringomyelie handelte, bei der auch Fälle beobachtet sind, in denen trophische Störungen den übrigen Symptomen der Syringomyelie jahrelang vorausgingen. - Die weiteren in der Literatur aufgefundenen Fälle von familiären trophischen Störungen an den unteren Extremitaten folgen erst später, da sie unserer Ansicht nach nicht mit unseren Fälen identisch sind.

Es fragt sich nun, um welche der uns bekanuten Krankheiten es sich in unseren und den anderen bisher mitgeteilten Fällen handelt. Differentialdiagnostisch kommen Lepra, Lues, trophische Störungen infolge Neuritis oder Arteriosklerose, Raynaud'sche Krankheit, Spina bifida occulta, oder sonstige Missbildungen des unteren Rückenmarkabschnittes, sowie Syringomyelie in Betracht.

Von vornherein auszuschliessen jst Lepra. Für diese Frkrankung fehlen trotz des gebäuften Auftretens alle sicheren Anhaltspunkte. Die Fälle stammen aus keiner Lepragegend, Beziehungen zu einer solchen Gegend, ähnliche Fälle sind ausserhalb der Familie W. in deren Heimat nicht bekannt geworden. Die für Lepra typischen Hautaffektionen, die Verdickung an den peripherischen Nerenstämmen usw. fehlten. Vergebens wurden an dem amputierten Bein des Falles 2 Leprabazillen gesucht. Es wäre fermer auffallend, wenn sich die Lepra gerade immer und ausschliesslich an den unteren Extremitäten lokalisiert hätte, und die Krankheit bei ihrem Jahrzehnte langen Bestehen nicht allmählich auch auf andere Körpergegenden übergegriffen hätte. Auch Oehlecker und Bruns schliessen die Lepra, zum T'eil aus denselben Gründen wie wir, in ihren Fällen aus. Auch in dem Fall von Levy und Ludloff ist 
nichts von den genannten Symptomen, die für Lepra sprechen würden, erwähnt worden.

Deyke-Pascha hat uns in einer höchst interessanten Arbeit mit den Knochenveränderungen bei Lepra nervorum bekannt gemacht. Die Aehnlichkeit mehrerer unserer Röntgenbilder mit denen Deyke's von Lepra ist so gross, dass einem zunächst Zweifel kommen, ob nicht ansere Fälle auch solche von Lepra nervorum sind.

Zum Beispiel Fall 1. R.-B. 2. Beugekontraktur und Subluxationsstellung in den Interphalangealgelenken, normale Gelenklinien verwischt, Gelenflächen plantarwärts verschoben.

Fall 2. Linker Fuss Am Metarsus 1 fehlt der Gelenkkopf vollständig. An der Basis der ersten Phalanx fehlt auch der Gelenkteil. Scheibenartige Beschaffenheit der proximalen Phalangenepiphyse bei sehr schlankem Schaft. Die Grundphalangen sehen im Röntgenbild wie eine umgekehrte Krücke oder wie ein Hemdenknopf aus.

Fall 3, R.-B.9. Am Ringfinger und Mittelfinger sind die Endglieder bis auf Reste verschwunden. Diese Reste bilden eine aus dichter Knochensubstanz bestehende Haube.

Fall 9, R.-B. 18. Beide Füsse entbehren der Zehen. Haubenform der Basis des Grundgliedes des Hallux mit starker Hyperostose derselben.

Für seine Fälle charakteristisch ist nach Deyke-Pascha das so gut wie vollständige Fehlen jeder produktiven Bildung, jeder reaktiven Entzündung oder Sklerose des Knochengewebes. Es handelt sich um rein destruktive oder resorptive Vorgänge. Ein und dasselbe auf Kalkresorption der Knochen hinzielende Prinzip scheint an den verschiedensten Stellen der Finger- und Fussknochen anzugreifen.

Der Kalkverlust bedingt Aufhellung der Röntgenschatten und vakuoläre Auflockerung der Knochenstruktur. Die bezeichneten Röntgenbilder Deyke's haben in der Tat grosse Aehnlichkeit mit den Röntgenbildern von Hinrich und Wilhelm W. Auch in unseren Fällen sehen wir Haubenform und die Krückenform, sowie Kragenknopform der Grundphalangen. Was aber unsere Fälle von denen Deyke's unterscheidet, das ist:

1. dass die Kalkresorption in unseren Fällen nur relativ gering: und umschrieben ist,

2. dass sich deutliche periostitische Wucherungen und Hyperostose (Sklerose) an den zurïckgebliebenen befallenen Knochen zeigen, und endlich ist der Unterschied in den Krankheitsbildern sehr gross.

Die Patienten Deyke's, welche obigen Röntgenbefund aufwiesen, litten an schwerster. Lepra nervorum und Sensibilitätsstörungen an allen Extremitäten, während in unseren Fällen sich pathologisch-anatomisch 
von Lepra nichts nachweisen liess, und die Patienten an den oben geschilderten sehr chronisch verlaufenden, nur die Füsse betreffenden Veränderungen litten. Den Grund dafür, dass die Röntgenbefunde zum Teil so ähnlich sind, müssen wir wohl darin finden, dass es sich in beiden Fällen, bei der Lepra und bei unseren Patienten, um Störungen der Tiefensensibilität hande!t. Ein Lepröser wird ebenso rücksich tslos seine Füsse belasten wie unsere Patienten es, ohne es zu wissen und zu wollen, tun. So wird es auch bei den Leprösen zu Frakturen und Fissuren kommen, und sich dann die gelösten Phalangen wie in unseren Fällen durch die offenen Fisteln abstossen.

Für Lues, speziell für hereditäre Lues, liegen ebensowenig Anhaltspunkte wie für Lepra vor. Abgeseben davon, dass es auffallend wäre, wenn sich die Lues gerade immer auf die unteren Extemitäten lokalisiert hätte, und dass auch entferntere Verwandte, wie Vetiern, erkrankt waren, ist auch in den meisten Fällen die Wassermann'scbe Reaktion, sowie die Liquoruntersuchung, die nur in 2 Fällen gemacht wurde, negativ ausgefallen. Negativ war die Wassermann'sche Reaktion im Blut in Fall 1, 4, und 6, in Fall 1 bei zweimaliger Untersuchung. In Fall 2 war sie zweimal zweifelhaft, zweimal negativ. Aus dem zweifelhaften Ausfall kann nicht auf Lues geschlossen werden, da gerade diese Reaktionen von ungeübten Kräften angestellt waren. Ebensowenig kann aus dem zweifelhaften Ausfall der Wassermann'schen Reaktion in Fall 7 auf Lues geschlossen werden, zumal sonstige Anhaltspunkte für Lues fehlten. Die Reaktion konnte leider nicht ein zweites Mal angestellt werden.

Auch in den Fälen von Bruns, Oehlecker, Levy und Ludloff liegen keine Anhaltspunkte für Lues vor.

Auch die Neuritis alcoholica muss differential-diagnostisch in Erwägung gezogen werden, hat doch Max Hofmann (Meran) nicht weniger als 19 Fälle von Malum perforans pedis bei ausgesprochenen Weinsäufern der arbeitenden Klasse beobachten können. Und unsere Fälle 1,2 und 4 boten ja zeitweise durchaus das charakteristische Bild eines Mal perforant du pied. Es bestehen auch in den Röntgenbildern verschiedentlich grosse Aehnlichkeiten: z. B. Fall 6, Hofmann's Arbeit: „Beiträge zur Entstehung und Behandlung des Mal perforant du pied." Taf. 8 Fig. 7 Endphalange der grossen Zehe an Grösse stark reduziert ist vollständig knöchern mit der Grundphalanx verbunden. - Die Grundphalanx zeigt die charakteristische Habenform und beide Phalangen vermehrte Knochendichte.

In der Arbeit: das "Malum perforans pedis" finden wir im Röntgenbild Abb. 4 starke Gabelung der Basis der Grundphalanx der 2. Zehe, 
Zerstörung des Cap. metatarsi 5.; der distalen Hälfte der 2. Phalanx der 2. Zehe, starke Knochendichte und in Abb. 7 eine geheilte Spontanfraktur der Diaphyse des Metatarsus 5.

Hofmann fand bei seinen Fällen als einziges nervöses Symptom: Sensibilitätsstörungen entsprechend der unmittelbaren Nachbarschaft des Geschwürs, selten in etwas grösserer Ausdehnung. Hofmann sieht als Ursache der Sensibilitätsstörung eine Neuritis alcoholica an. Als ätiologisches lloment konnte nur chronischer Alkoholismus (Wein), verbunden mit schwerer meist stehend verrichteter Arbeit bei älteren Leuten männlichen Geschlechts festgestellt werden.

Potus kommt aber, wie oben schon hervorgehoben ist, in unseren Fällen als Ursache kaum in Frage, sämtliche Familienglieder, welche uns zu Gesicht gekommen sind, machten den Eindruck durchaus nüchterner Leute. Zeichen von chronischem Alkoholismus fanden sich bei den häufigen Untersuchungen nicht. Aus der Aehnlichkeit unserer Röntgenbilder mit denen Max Hofmann's beim Malum perforans pedis ersehen, wir, dass die unsere Fälle charakterisierenden Knochen- und Gelenkveränderungen sich offenbar immer dann finden, wenn die Sensibilität insbesondere auch die Tiefensensibilität herabgesetzt ist, ohne dass die Knochen in ihrer Festigkeit, in ihrer Heilungsfähigkeit und in ihrer Fähigkeit auf entzündliche Reize zu reagieren, gelitten haben.

Deshalb ist es auch nicht erlaubt aus der Gleichheit der Röntgenbilder die Gleichheit der neurologischen Krankheitsbilder zu konstruieren. Und es erscheint uns auch nicht angängig nur wegen der grossen Uebereinstimmung unserer Röntgenbilder mit dem des Falles 21 von Levy und Ludloff, ihn für mit den unsrigen identisch anzusehen, sondern wir führen ihn nur als einen vielleicht analogen Fall an.

Differentialdiagnostisch käme weiter die Raynaud'sche Krankheit in Frage. Das familiäre Auftreten dieser Krankheit ist einige Male von Makins, Arning, Curschmann (s. Cassirer) beschrieben worden. Ferner haben Stewart, Bramann, Nekam Fälle von familiären trophisehen Störungen, die in der Hauptsache an den unteren Extremitäten auftraten, mitgeteilt, die durch einzelne Symptome an die Raynaud'sche Krankheit erinnern, andererseits aber auch in manchen Beziehungen eine gewisse Aehnlichkeit mit unseren Fällen aufweisen und deshalb von Cassirer zu den von Bruns und Oehlecker mitgeteilten Fällen gerechnet werden. Es sei deshalb genauer auf diese eingegangen:

Bei den Fällen von Stewart handelt es sich um eine familiäre Krankheit, welche drei Brïder im Alter von 3,4 und 5 Jahren befiel. 
Die Beschreibung lautet:

nBei allen drei traten in einem Winter umschriebene Nekrosen an den Füssen auf. Bei dem Aeltesten entstand erst eine Nekrose der Haut an beiden Hacken, später zeigten sich äbnliche Stellen auf dem rechten Fussrücken und an der 4. linken Zehe. Beim 2. Kinde fand sich Zyanose und eine geringe Nekrose an beiden Fussrücken, bei dem Jüngsten eine tiefe Nekrose an der 1., 4. und 5. Zehe des rechten Fusses und ein kleiner nekrotischer Bezirk an der linken grossen Zehe."

Bei den Stewart'schen Fällen findet sich noch die grösste Aehnlichkeit mit den unsrigen: Das familiäre Auftreten nur bei Individuen männlichen Geschlechts, die Beschränkung der trophischen Prozesse auf die unteren Extremitäten sind die Punkte, welche mit den Erscheinungen in unseren Fällen übereinstimmen. Erhebliche Abweichungen finden sich aber insofern, als die Krankheit in den Stewart'schen Fällen in viel jugendlicherem Alter und zwar bereits in den ersten fünf Lebensjahren auftrat. Ferner blieb die Krankbeit, soweit sich aus den Angaben Stewart's ersehen lässt, auf die Haut beschränkt und ging nicht auf die Kuochen über. Drittens ist die Zyanose auf den Fussrücken in einem Fall hervorzuheben und dentet auf vasomotorische Vorgänge hin, die in unseren Fällen wenigstens dann, wenn die Prozesse noch so wenig umfangreich waren, fehlten. In diesem Sinne ist ausserdem das gleichzeitige Auftreten der Krankbeit bei allen 3 Fällen im Winter, also in der kalten Jahreszeit hervorzuheben, da gerade die Kälte bei den vasomotorischen Vorgängen der Raynaud'schen Krankheit von einem gewissen Einfluss ist. Ein solcher Einfluss lässt sich aber in unseren Fällen nicht feststellen. Diese Abweichungen haben uns bewogen, die von $\mathrm{S}$ tew art beschriebene Krankheit ganz von der in unseren Fällen zu trennen, wenn sich auch eine sichere Entscheidung darüber bei der unvollkommenen Darstellung Stewart's, dem Fehlen jeder Angabe über Verhalten der Sensibilität, über den Röntgenbefund, sowie über den Befund an der Wirbelsäule nicht treffen lässt.

1889 stellte Bramann 3 Brüder mit trophischen Störungen der Extremitäten vor.

Sie befanden sich im Alter von 7,10 und 13 Jahren. Yon Geburt an wiesen sie grosse kolbige Fingerspitzen sowie eine grosse Ungeschicklichleit im Fassen und Halten ron Gegenständen auf. Im 4. Lebensjahr erkrankten alle drei Brüder an Geschwüren an den Fingerspitzen und an den Spitzen mehrerer Zeben, die schliesslich zur Zerstörung der Finger- und Zehenkuppen inkl. der peripherischen Nagelhälfte, bzw. zum vollständigen Verlust der Nägel, ja aller Eudphalangen bei dem zweitältesten Patienten, geführt hatten. Die Affektion trat stets in Form der lokalen Asphyxie mit konsekutiver Gangrän in einzelnen 
mebr oder weniger schnell aufeinanderfolgenden Attacken auf, die mit lebbaften Schmerzen sowie Fieber und Störungen des Allgemeinbefindens einhergingen, bis die brandigen Stellen sich abgestossen hatten. Dann heilten die Geschwüre schmerzlos. Alle drei Patienten hatten so allmählich Defekte an Fingern und Zeben bekommen. Ausserdem zeigten zwei Patienten symmetrisch gelegene, fast gar nicht pigmentierte Narben auf dem Rücken beider Füsse sowie auf der Streck- und Aussenseite der beiden Kniee, die von Ulzerationen aus dem 6. bzw. 8. Lebensjahre herrührten. Die Sensibilität soll insofern gestört gewesen sein, als sich Herabsetzung der Empfindlichkeit augenscheinlich für alle Qualitäten bis zur Anästhesie an den Fingern und Zehen, Händen und Füssen, sowie an den Unter- und Oberschenkeln, den Vorder- und Oberarmen fanden. Eine Gefässerkrankung sowie Lepra konnten ausgeschlossen werden.

Bramann hält eine Syringomyelie in seinen Fällen für wahrscheinlich, Cassirer die Diagnose einer unkomplizierten Raynaud'schèn Krankheit für nicht sicher. Er glaubt, dass vielleicht eine Kombination von Raynaud'scher Krankheit und Gliosis vorliege. Handelt es sich tatsächlich hier un eine zentrale Erkrankung, die, wie wir sehen werden, auch in unseren Fällen angenommen werden muss, so ist es doch nicht möglich, die Krankheit in den Bramann'schen Fällen mit der in den hier mitgeteilten Fällen zu identifizieren und zwar aus folgenden Gründen: Die Affektion trat, genau wie in den Stew art'schen Fällen, mit denen sie überhaupt gewisse Aehnlichkeiten aufweist, in viel früherem Lebensalter auf als in unseren Fällen, es wurden die unteren und oberen Extremitäten gleichmässig befallen, die ersten Erscheinungen bestanden in lokaler Asphyxie, die wir niemals beobachteten, es bildeten sich Geschwïre an den Finger- uud Zehenspitzen, in unseren Fällen an den Zeheuballen und einzelnen Zehengliedern, nie an den Spitzen. Allerdings fanden sich bei den Bramann'schen Fällen ähnlich wie in denen von Stewart auch Narben früherer Geschwüre auf den Fussrücken, wie sie auch gelegentlich in unseren Fällen beobachtet werden konnten. Diese Analogie ebenso wie das familiüre Auftreten der Krankheit, das ausschliessliche Befallenwerden von Personen männlichen Geschlechtes, dürften nicht genügen, dieselbe Krankheit wie in unseren Fällen anzunehmen, wenn sich auch gewisse Anklänge finden. Ein wesentlicher Unterschied der pathologischen Vorgänge in den Bramann'schen Fällen von den in unseren Fällen liegt darin, dass es sich bei ihnen um trophische Prozesse auf Grund ausgesprochener vasomotorischer Vorgänge, ähnlich wie bei der Raynaud'schen Krankheit (die Cassirer hier nicht für erwiesen hält) handelt, während in unseren Fällen deutliche vasomotorische Erscheinungen fehlten.

Eine ähnliche Erkrankung wie in den Fällen Bramann's, die gewisse Analogien mit den hier mitgeteilten anfweist, aber weder dieser 
noch nach Cassirer's Ansicht der Ray ua ud 'schen Krankheit zuzuzählen ist. liegt bei den 8 Geschwistern, über die Nekam 1903 berichtete, vor:

Die Eltern dieser Gesehwister heirateten sich als Witwer, aus der 1. Ehe des Vaters stammte ein gesunder Sohn, aus der 1. Ehe der Frau ein Sohn, der erkrankte. Beide Eltern litten an Parästhesien und Kältegefühl an den Füssen und Zehen.

Sohn der Frau aus 1. Ehe (Fall 3 Nekam's): Mit 17 Jahren nach Synkopeanfällen Gangrän des linken Vorderfusses und Amputation desselben. Später Asphyxie des Stumpfes mit Schmerzen, Amputation des Unterschenkels. Gleichzeitig asphyktische Anfälle am rechten Vorderfuss, einige oberflächliche Nekrosen am inneren Knöchel, die bald abfallen.

Fall 4 Nekam's: (Aeltester Sohn der erwähnten Eltern.) Mit etwa 17 Jahren ständige Zyanose der Hände und Füsse. Parästhesien in den Extremitäten. Linke 3. Zehe intensiv rot mit minimaler thermischer Sensibilität.

Fall 5: Soln, gesund.

Fall 6: Sohn, geb. 1888: Verhornungen der Handflächen und Sohlen. Zeitweise Schmerzen der Sohlen und Fersen.

Fall 7: Tochter, geb. 1890. Häufige asphyktische Anfälle der Hände und Füsse mit Schmerzen. Zuweilen Schmerzen und Zyanose der Knie.

Fall 8: Tochter. Mit 6 Jahren häufige lokale Asphyxie der Fiusse mit Zyanosen und Schmerzen. Plötzlicbe dunkle Verfärbung der Vorderfüsse und Abfall der Zehen. Fünf Monate später erneute schmerzhafte Asphyxien mit Abstossung der Metatarsal- und Tarsalknochen. Seitdem epileptiforme Anfälle.

Fall 9: Sohn. Mit 5 Jahren Asphyxie der linken grossen Zehe, Gangrän und Abstossung beider Füsse distal vom Tarsalknochen. Nach mehreren Monaten weiteres Fortschreiten der Asphyxien, Gangrän und Abstossung kileiner Knochensplitter. Hämoglobin $65 \mathrm{pCt}$. Amputation des linken Unterschenkels.

Fall 10: Sohn. Mit 3 Jahren Zyanose an den Händen, Gangrän und Abfall eines Fingergliedes. Später Dystrophien der Fingernägel, schmerzhafte Zyanose und Gangrän der Fersen, mit 4 Jabren Zyanose und Gangrän der linken grossen Zehe. Hyperalgesio an den Rändern der Geschwüre. Hämoglobin $60 \mathrm{pCt}$. Weiterhin geringe Schmerzen, häufige Zyanose des linken Vorderfusses, Gangrän.

Obwohl sich die Erkrankung in den Fällen Nekam's mehr wie in denen Bramann's und bis auf Fall 10 ausschliesslich auf die unteren Extremitäten wie in unseren Fällen beschränkt, so sind doch im übrigen dieselben Gründe wie in den Bramann'schen Fällen dafür anzuführen, dass es sich nicht um eine mit dem Leiden in unseren Fällen identische Krankheit handeln kann: Sie begann bei einigen der Fälle schon im 3.-6. Lebensjahr, sie befiel in einem Fall auch die Hände, sie begann immer mit lokaler Asphyxie, sie trat nicht in Form von Geschwüren an den Zehenballen und Zehen, sondern nach vorausgegangener Asphyxie in Form von Gangrän der Zehen, Finger, des Vorderfusses oder der Fersen auf. Arthropathische Vorgänge sind nicht erwähnt. Es handelt 
sich also auch hier um trophische Prozesse auf Grund vasomotorischer Vorgänge, die in unseren Fällen fast ganz fehlten oder sich höchstens bei dem frühzeitigen Abfallen der Zehemnägel in Form von Rötung zeigten. Der Ansicht Cassirer's, dass die Fälle Nekam's, bei denen seiner Ansicht nach die Diagnose: Raynaud'sche Krankheit sebr zweifelhaft ist, den ron Bruns, Oehlecker mitgeteilten Fällen zuzuzählen sei, können wir uns aus denselben Gründen, mit denen wir eine Analogie der Nekam'schen Krankheit mit der in unseren Fällen ablehnten, nicht anschliessen. Nekam selber lässt die Diagnose in seinen Fällen zweifelhaft und spricht nur von einer unter Raynaud'schen Symptomen erkrankten Familie.

Nicht nur die familiäre Krankheit in den hier aufgezählten Fällen, die in mancher Beziebung an Raynaud'sche Krankheit sowie an die in unseren Fällen erinnern, bei denen sich aber eine sichere Diagnose nicht stellen lässt, sondern auch die sehr selten familiär beobachtete echte Raynaud'sche Krankheit können wir in unseren sowie in den Fällen von Bruns, Oehlecker, Levy und Ludloff ausschliessen, und zwar aus folgenden Grüuden: Es fehlten in unseren Fällen den eigentlichen trophischen Störungen vorausgehende ausgesprochene, anfallsweise mit Schmerzen auftretende vasomotorische Erscheinungen, insbesondere Synkope. Trotz ganz besonders genauer Nachforschong in dieser Richtung liessen sich derartige paroxysmale Erscheinungen nicht feststellen. Wobl ergaben anamnestische Erbebungen, dass einige Male subjektive Empfindungen bestanden haben sollen, die gerade auch bei vasomotorischen Störungen vorkommen. So soll in Fall 1 zuweilen nach Anstrengungen während der Militärzeit ein Sengeln und Kribbeln in den Unterschenkeln bis zu den Knien hinauf bemerkt worden sein. Die eigentlichen trophischen Störungen, die Gescbwürsbildungen, setzten aber gerade in diesem Fail erst 20 Jahre später ein. Es kann sich also nicht um vasomotorische Störungen im Sinne der Raynaud'schen Krankheit gehandelt haben. Im selben Falle sollen unter vorhergehender Rötung, unter geringen Schmerzen in der Jugend zuweilen die Zehennägel abgefallen sein. Auch diese Erscheinungen machen nicht den Eindruck vasomotorischer und trophischer Störungen im Sinne der Raynaud'schen Krankheit. Es ist bier auch möglich, dass die Rötung mit entzündlichen Vorgängen im Zusammenhang stand. In den beiden ersten Fällen sollen sich in der Jugend mehrfach die Grosszehennägel nach Schwarzwerden abgestossen baben und zwar ohne Schmerzen. Auch diese Vorgänge machen nicht den Eindruck von Erscheinungen, wie sie bei der Raynaud'schen Krankheit auftreten, da die Synkope hier von Schmerzen begleitet zu werden pflegt. Finmal soll auch die Geschwürsbildung 
selber unter Rötung der ganzen Zehe zustande gekommen sein. Auch hier hat es sich wahrscheinlich um eine entaündliche Erscheinung gehandelt, zumal die Geschwürsbildung sonst nicht von Rötung begleitet war. In Fall 2 soll der rechte Fuss häufig kalt gewesen sein, aber erst nachdem stärkere Geschwüre schon vorher im 34. Lebensjahr aufgetreten waren. In Fall 3 trat ohne wesentliche vasomotorische Erscheinung ein Geschwür an der kleinen Zehe auf, erst bei Wiederbolung des Geschwürs schwoll die Zehe stark an, was also ebenfalls wohl als Symptom einer Entzündung zu deuten ist. Wohl traten bäufig, lange Jahre vor der Geschwürsbildung, gewöhnlich in der Kindheit und Jugend, Schmerzen in den Unterschenkeln (Fall 1), den Zehen (Fall 2, 6, 7) auf. Auch war die Geschwürsbildung selber mehrfach von Schmerzen begleitet, jedoch fehlte diesen Schmerzen der paroxysmale Charakter, sie gingen nicht Hand in Hand mit vasomotorischen Störungen. Auch in den sämtlichen übrigen Fällen wie auch in denen von Bruns, Oehlecker, Levy und Ludloff fehlten paroxysmale vasomotorische Störungen.

In dem einen Fall von Bruns kam es einmal akut zu einer Gangrän des ganzen linken Vorderfusses, aber erst, nachdem schon lange vorher Ulcera an beiden Grosszehenballen bestanden hatten, sich ferner Knochensplitter aus den Geschwüren entleert hatten. Synkopeähnliche Erscheinungen sind aber dieser Gangrän nicht vorausgegangen, sie dürfte vielmehr auf die schon lange bestehenden trophischen und schweren entzündlichen Prozesse zurückzufübren sein. Eine Analogie mit der Raynaud'schen Krankheit ist daraus nicht zu konstruieren.

Fs ist ferner hervorzuheben, dass die Krankheit in unseren und in anderen Fällen mit Geschwüren an den Zehenballen, selten an den Zehen einhergingen, nie aber mit trophischen Störungen an den Zehenspitzen, nie mit anfallsweise symmetrisch auftretenden Zeichen einer gestörten Vasomotoreninnervation, die an die Akra des Körpers gebunden war, wie meist bei der Raynaud'schen Krankheit. Allerdings können gelegentlich wohl einmal auch bei dieser schwere trophische Störungen ohne vasomotorische Erscheinungen auftreten, in seltenen Fällen auch wohl einmal andere Stellen wie die "Akra" des Körpers befallen werden, jedoch handelt es sich hierbei meist um Fälle, bei denen die Diagnose "Raynaud'sche Krankheit" nach Cassirer nicht ganz sicher war. Schliesslich spricht auch die langsame, sich über Jahre hinziehende Entwicklung der trophischen Störungen, die grosse Ausdehnung derselben, ihre ausschliessliche Lokalisation an den unteren Extremitäten in unseren Fällen gegen eine Raynaud'sche Krankheit, trotzdem bei dieser selbst Fälle mit Muskelatrophien, die ja auch in unseren und den Bruns'schen Fällen vorkamen, beschrieben sind (Weiss, 
Defrance, Englisch, Cassirer u. A.). Die angeführten Abweichungen dürften genügen, die Raynaud'sche Krankheit in unseren sowie in den Fällen von Oehlecker, Bruns, Lev y und Lud loff mit Sicherheit auszuschliessen.

Erwähnt sei anhangsweise noch, dass eine andere, mit vasomotorischtrophischen Störungen einhergehende Krankheit öfter als die Raynaudsche Krankheit familiär auftritt, nämlich das akute umschriebene Oedem (Fälle von Cassirer, Dinkelacker, Falcone, Diehl usw.) und dass Boks neuerdings ein solches familiäres Oedem mit geringeren trophischen Störungen der Haut in Form von Ulcera, Rissen, Papeln usw. an den unteren Extremitäten beschrieben hat. Auch diese Fälle haben mit den unseren absolut keine Aehnlichkeit.

Es könten weiter neuritische Erkrankungen der peripherischen Nerven, ferner Arteriosklerose, besonders der Unterschenkelund Fussarterien, als Ursache für die trophischen Störungen in Betracht kommen. Weder für Erstere noch für Letztere fanden sich irgendwelche Anhaltspunkte. Die Fusspulse waren gut erhalten, nur in Fall 2 bestand eine leichte Arteriosklerose. Da aber auch hier die Fusspulse vorhanden waren, ferner in sämtlichen übrigen untersuchten Fällen die genannten trophischen Störungen auch ohne Arteriosklerose aufgetreten waren, ist eine solche, gegen die schon das jugendliche Alter bei Beginn der Krankheit spricht, als Ursache für diese nicht anzunehmen.

Von zentralen Erkrankungen käme zunächst die von Virchow entdeckte Spina bifida occulta in Betracht, und zwar deshalb, weil bei dieser, die am häufigsten am Lumbosacralteil der Wirbelsäule vorkommt (Joachimsthal, Muscatello), neben Atrophien, Paraplegien, Reflexstörungen an den unteren Extremitäten, neben Hohl- und Plattfussbildungen, Sensibilitätsstörungen an den unteren Extremitäten zum Teil in Form ron dissoziierter Empfindungslähmung, auch vasomotorische und trophische Störungen an den Zehen, mal perforant-ähnliche Geschwüre beobachtet sind. Spezielle Fälle mit ausgesprochenen Geschwürsbildungen an den Zehen und Fusssohlen, Abstossen der Phalangen, Verkrüppelung der Zehen sind von Katzenstein, von v. Recklinghausen, Brunner, Greenberg, Elsberg mitgeteilt. Besonders der Katzenstein'sche Fall, bei dem die Haut des linken Unterschenkels ödematös geschwollen, die Haut des linken Fusses stark verdickt war, ein Geschwür an der Fusssohle, Verkrüppelung der Zehen vorlagen, gleicht unseren Fällen auf das Genaneste. Auch bei der Enuresis, bei der neuerdings öfter eine Spina bifida occulta festgestellt worden ist, finden sich zuweilen Sensibilitätsstörungen, Reflexstörungen u. a. an den unteren Extremitäten (Fälle von Fuchs, Saenger, Pernitzky, Peritz). Auch fällt der Beginn der Erkrankung der unteren Extremitäten, wie in 
unseren Fällen bei der Spina bifida occulta, häufig in die Zeit des grössten Körperwachstums, die Pubertät (Katzenstein, Bibergeil). Ueber familiäres Auftreten der Spina bifida occulta ist allerdings bisher wenig bekannt geworden, jedoch ist Ernst der Ansicht, dass für erbliche Einflüsse bei Entstehung der Spina bifida occulta das Vorkommen von Hypertrichosis lumbaris bei Grossvater, Vater und Sohn spreche, die bei der Spina bifida occulta sehr häufig nachzuweisen ist (Joachimsthal). Ferner ist auch das familiäre Auftreten der Enuresis, bei der in 68 pCt. der Fälle nach Peritz eine Spina bifida occulta festzustellen ist, von Stern, Honro beobachtet worden. Speziell unter den Fällen von Enuresis bei Erwachsenen von Scharnke, bei denen zum Teil eine Spina bifida occulta festgestellt ist; finden sich ebenfalls einige, bei denen die Enuresis familiär vorkam. Neuerdings hat Jancke dann Mitteilungen über eine Familie gemacht, bei der rom Urgrossvater bis zu den Enkeln Bettnässen aufgetreten war und in 3 Fällen röntgenologisch eine Spina bifida occulta nachgewiesen war. Denkbar wäre es also schliesslich, dass auch die Spina bifida occulta ohne die Erscheinung der Enuresis gelegentlich familiär auftritt ${ }^{1}$ ).

Trotz der also vorhandenen ziemlich grossen Anzahl ron Analogien $z$ wischen unseren Fällen und solchen mit Spina bifida occulta feblen einige typische Symptome in unseren Fällen, die bei letzterer sehr häufig sind, nämlich die Hypertrichosis und die fistelartige Einziehung der Sakrococcygealgegend. Gelegentlich kann aber die Spina bifida occulta auch ohne diese vorkommen, wie besonders bei der Enuresis festgestellt ist. So konnte der eine von uıs (R.) in einem Fall durch röntgenologische Untersuchung bei Enuresis eine Spina bifida occulta feststellen, trotzdem äusserlich keine Anzeichen für diese vorhanden waren. Wegen der Analogie vieler Symptome in unseren Fällen mit denen bei Spina bifida occulta baben wir nun in Fall 1 und 2 eine Durchleuchtung der Lendenwirbelsäule und des Kreuzbeins vorgenommen. Diese ergab jedoch einen vollkommen normalen Befund. Danach können wir eine Spina bifida occulta mit Wahrscheinlichkeit auch in den anderen Fällell, ebenso wie Oehlecker auf Grund des röntgenologischen Befundes in seinen Fällen ausschliessen. Gegen eine Spina bifida occulta spricht ja auch das Fehlen der bei dieser so häufig nachweisbaren Enuresis. In den Fällen von Bruns, Levy und Ludloff ist eine spezielle Untersuchung anf Spina bifida occulta nicht vorgenommen worden. Wir können eine solche in diesen Fällen deshalb nicht mit Sicherheit aus-

1) Anmerkung: In einer während der Drucklegung erschienenen drbeit teilt Jancke weitere derartige Fälle mit. Deutsche Zeitschr. f. Nervenheilk. Bd. 55. 1916. H. 4-6. 
schliessen, balten das Vorhandensein einer solchen aber bei ihnen wegen der Analogie mit unseren und Oehlecker's Fällen nicht für wahrscheinlich. Die Aehnlichkeit der Symptome in unseren Fällen gerade mit denen in manchen Fällen von Spina bifida occulta, ist aber eine so grosse, dass unsere Vermutung, es könne sich auch in unseren Fällen um zentrale Vorgänge handeln, verstärkt wird.

Es käme weiter in unseren Fällen die Syringomyelie in Frage, mit der die Krankheit zweifellos eine grosse Aehnlichkeit hat.

Ueber das familiäre Auftreten der Syringomyelie ist, trotzdem ron einer grossen Reihe von Forschern die Entstehung der Syringomyelie auf entwicklungsgeschichtliche Anomalien (in der Ausbildung des Zèntralkanals, akzessorische Zentralkanäle, Bildung einer zentralen Gliose auf Grund von Entwicklungsstörungen, embryonal einsetzende Erkrankung der Ependym- oder Gliazellen [Schieferdecker und Leschke]) zurückgeführt wird, bisher wenig bekannt. Ernst hebt im Hinblick auf diese Punkte ausdrücklich hervor, dass der mangelnde Einfluss der Vererbung und das Fehlen des familiären Autretens der Syringomyelie auffallend sei. Bisher sind nur wenige Fälle ron angeblich familiärer Syringomyelie von Verhogen und Vandervelde, Ferranini, v. KraffEbing, Nalbandoff, Preobajenski, Goldbladt, Krukowski, Clarke und Groves beschrieben worden. Ausser dem Fall von Verhogen und Vandervelde ist aber kein Fall von angeblich familiärer Syringomyelie anatomisch untersucht worden, und gerade bei diesem hält Schlesinger den Befund für höchst zweifelhaft: der beschriebene Hohlraum soll aucb in normalen Rückenmarken vorkommen und nicht selten wie hier erweitert sein. Auch unter den 12 ganz neuerdings von Frey mitgeteilten und ausfübrlich bearbeiteten Fällen von Syringomyelie findet sich kein einziger, bei dem die Syringomyelie familiär aufgetreten wäre. Schlesinger schliesst aus den oben erwähnten Fälleu von angeblich familiärer Syringomyelie, dass die Syringomyelie in recht seltenen Fällen familiär resp. hereditär auftreten dürfte, hebt aber ausdrïcklich hervor, dass der strikte anatomische Beweis fehle. Dieser Auffassung können wir uns auch heute noch anschliessen.

Von den erwähnten Fällen von familiärer Syringomylie haben nur diejenigen von $\mathrm{Clarke}$ und $\mathrm{Groves}$, bei denen aber anch die Diagnose Syringomyelie nicht ganz sicher ist, mit unseren Fällen einiges gemeinsam Sie seien deshalb genauer mitgeteilt. Die Beschrcibung im Referat lautet:

"Der erste der Patienten von Clarke und Groves hat ron Jugend auf an Geschwüren und Entzündungen an den Füssen gelittẹn und lionnte nie ohne Stöcke gehen. Jetzt mit 23Jahren bildet er folgendes Bild: lilcxionstiontraktur der Knie mit entsprechender Beugung der Hüftgelenke und Lordose, Paiellar. 
und Fussklonus beiderseits, Babinski positiv. Füsse elefantenartig, links fehlen: Zehe, ebenso sind Köpfchen der Metatarsen nicht zu fühlen, der Stumpf ist von Narbengewebe, herrührend von früheren Ulzerationen, bedeckt. Am rechten Fuss ist eine verkrümmte 1. und 2. Zehe und Stammel der 3. und 4. zu erkennen. Das Röntgenbild bestätigt das Fehlen der Phalangealknochen und dio verschwommene Struktur der benachbarten Metatarsen. Als Ursache der Kontraktur ergibt sich beiderseits eine Verdoppelung der Patella, von der sich nioht feststellen lässt, ob sie den Rest früherer Frakturen oder eine angeborene Missbildung darstellt. An beiden Füssen strumpfartig zirkulär begrenzte Anästhesie für warm, kalt und Stich. Nadelstich häufig als heiss angegeben, Berührungs- und Druckempfindung normal. Ueber das Verbalten der Muskulatur ist nichts angegeben. Endphalangen beider Daumen auffallend kurz und breit. Durch zwei orthopädische Operationen wurde die Beugekontraktur der Knie beseitigt und der Gang des Pat. gebessert.

Die 15jährige Schwester dieses Kranken leidet seit 4 Jahren ebenfalls an Ulzerationen an den Füssen, die durch heisse Umschläge wit nachfolgenden Hautverbrennungen verschlimmert wurden und zum Verlust der drei letzten Zehen des rechten Fusses und Verstümmelung der Zehen des linken führten. Durch die Schmerzlosigkeit der Prozesse war Pat. nie am Gange verhindert gewesen. Beide Knie- und Achillesreflexe erhöbt, aber kein Fussklonus. Rechts. konstant, links häufg Babinski positiv. Motilitätund Muskulatur intakt. Thermanästhesie, zackenartig scharf begrenzt und Hypalgesie, unscharf etwas höher begrenzt, erhaltene Berührungsempfindung. Die Ulcera an den Füssen heilten rasch bei Ruhigstellung."

Der Referent dieser Arbeit im Jahresbericht für Psychiatrie und Neurologie hält trotz der gegenteiligen Annahme der Verfasser hier eineSyringomyelie nicht für vorliegend, weil jedes Anzeichen für ein Fortschreiten eines destruierenden Prozesses auf höhere Segmente besonders. im ersten Fall, der seit 23 Jahren stationär ist, fehlten. Er möchte eher an eine Bildungsanomalie, einen Hydromyelus oder eine Spina bifida occulta denken. Ob allein das lange Stationärbleiben des Leidens bier zur Ablehnung einer Syringomyelie genïgt, sei dahingestellt, es sind auch sonst seltene Fälle von Syringomyelie beobachtet, bei denen. die Erkrankung sehr lange Zeit keine Fortschritte machte. Wir möchten noch auf die ausschliessliche Lokalisation des Leidens an den unteren Extremitäten in beiden Fällen hinweisen, die bei der echten Syringomyelie jedenfalls auffallend wäre. Eine gewisse Aehnlichkeit mit dem Leiden in unseren Fällen besteht wegen des familiären Auftretens, der ausschliesslichen Lokalisation an den unteren Extremitäten, der ähnlichen Deformation der Füsse. Auch sind wir in unseren Fällen zu einer ähnlichen Diagnose genötigt, wie der Referent der Arbeit von Clarke und Groves. Immerhin sind die Abweichungen (dissoziierte Empfindungslähmung, Steigerung der Reflexe, Babinski'scher Reflex, Kon- 
traktur der Knie in jenen, teilweise Aufhebung der. Sehnenreflexe, kein Babinski, Herabsetzung sämtlicher Empfindungsqualitäten in unseren Fällen) so grosse, dass wir uns nicht entschliessen können, hier dieselbe Krankheit wie in unseren Fällen anzunehmen. Hier sowohl wie in unseren Fällen ist an den Satz des erfahrenen Kenners der Syringomyelie Schlesinger zu erinnern, der lautet: "Man kann nicht energisch genug davor warnen in Erkrankungsfällen nervöser Natur, welche mehrere Familienmitglieder in gleicher Weise betroffen, die Diagnose auf Syringomyelie zu stellen, wenn nicht die Erkrankungen so entwickelt sind, dass ein $Z$ weifel an der Diagnose ausgeschlossen erscheint".

An die Lösung der Frage, ob auch in unseren Fällen eine familiäre Form der Syringomyelie vorliegt, muss also mit grosser Vorsicht herangetreten werden. Zweifellos finden sich in unseren Fällen wie in dem von Levy und Ludloff, besonders aber in denen von Bruns, der auch eine Syringomyelie in seinen Fällen annimmt, gewisse Aehnlichkeiten mit der Syringomyelie. Es könnte nur der Sakrolumbaltypus der Syringomyelie in Betracht kommen: Häufig sind bei diesem Atrophien der Untersehenkel und Fussmuskulatur, diese fehlen zwar in den Fällen von Oehlecker und Levy und Ludloff ganz, in unserem Fall 1 fand sich aber eine Atrophie des ganzen rechten Beines, in den Fällen von Bruns traten sie am deutlichsten hervor und zwar fand sich im ersten und dritten Fall eine Atrophie der Beine, besonders der Unterschenkel. Trophische Störungen an den unteren Extremitäten, die in unseren und den sonst mitgeteilten Fällen so ausgesprochen waren, finden sich auch gerade bei dem Sakrolumbaltypus der Syringomyelie besonders oft. Auch bei diesem kann es zur Verbildung und bedeutender Verkürzung der Füsse kommen. Geschwüre an den Zehen, Nekrose der Zehenknochen, Destruktion des ganzen Fussskeletts sind öfter beobachtet. Fisteln können wie in unseren Fällen bei der Syringomyelie entstehen (Sterling). Mertens (s. Sterling) sah bei der Syringomyelie Verkürzung des Fusses, Vereiterung einzelner Zehenabschnitte und Schwund der Zehenglieder, also ähnliche Vorgänge, wie in unseren Fällen. Auch Spontanfrakturen wie in den Fällen Oeblecker's werden häufig genug beobachtet. Besonders häufig fehlen beim Sakrolumbaltypus der Syringomyelie die Achillessehnenreflexe, wie in einem unserer Fälle, seltener die Patellarreflexe wie nach Angabe von Bruns in nicht wenig als drei seiner Fälle.

In der Tat bestehen also weitgehende Aehnlichkeiten mit dem Sakrolumbaltypus der Syringomyelie in unseren Fällen und zwar käme wohl am ehesten der sogenannte Morvan'sche Typus der Syrin- 
gomyelie mit seinem starken Hervortreten trophischer und dem starken Zurücktreten rein nervöser Störungen differentialdignostisch in Betracht.

Wir glauben aber trotzdem eine Syringomyelie in unseren und den Fällen Oehlecker's, mit einer gewissen Wahrscheinlichkeit auch in den Fällen von Bruns, Levy und Ludloff ausschliessen zu können und zwar aus folgenden Gründen: Das familiäre Auftreten der Syringomyelie ist höchst ungewöhnlich und mit völliger Sicherheit noch nicht nachgewiesen. Das ausschliessliche Befallensein der unteren Extremitäten in sämtlichen mitgeteilten Fällen, das absolute Verschontbleiben der oberen Extremitäten, trotzdem die Krankheit besonders in unseren Fällen teilweise bereits jahrzehntelang besteht, spricht eigentlich gegen eine Syringomyelie. Nach Schlesinger finden sich die Gelenkerkrankungen bei Syringomyelie in $80 \mathrm{pCt}$. aller Fälle an den oberen Extremitäten, unter den 17 neuerdings von $\mathrm{Mich}$ J mitgeteilten Fällen von Gelenkerkrankungen bei Syringomyelie war das Leiden nur in 3 Fällen an den unteren Extremitäten lokalisiert. Das ausschliessliche Befallensein der unteren Extremitäten in allen unseren Fällen, d. h. die ausschliessliche Lokalisation des Leidens in allen Fällen im unteren Rückenmarksabschnitt wäre also bei der echten Syringomyelie zum mindesten sehr auffallend. - Die Sensibilitätsstörungen in unseren und den übrigen mitgeteilten Fällen entsprechen nicht denen, die wir bei der Syringomyelie zu seben gewohnt sind. "Störungen der Temperaturempfindung und des Schmerzes sind" -, so sagt Frey, auf Grund eigener und fremder Beobachtungen - „immer rorhanden; entweder liegt Thermoanästhesie oder Dissoziation vor, der Tastsinn ist viel weniger gestört". In unseren Fällen fand sich dagegen eine Herabsetzung der Intensität sämtlicher GefühIsqualitäten, keine dissoziierte Empfindungslähmung, keine Thermoanästhesie. Nur im 2. Fall schien einmal, als die trophischen Störungen an dem einen Fuss sehr grossen Umfang angenommen hatten, stellenweise, besonders an den Zeben, aber immer gleichzeitig mit einer völligen Anästhesie und Analgesie eine Thermoanästesie zu bestehen, die bei einigen Untersuchungen vorher nicht vorhanden war. In den Fällen Oehlecker's fehlte angeblich jede. Sensibilitätsstörung an der Haut, insbesondere jede Temperaturstörung oder dissoziierte Empfindungslähmung, dafür bestand aber offenbar, wie nebenbei auch in unseren Fällen, eine Störung der Tiefensensibilität: es traten Spontanfrakturen ein, ohne dass die Patienten wesentliche Beschwerden davon hatten, in unseren Fällen liefen die Patienten noch mit dem stark destruierten Knochengerüst des Fusses und tiefgehenden Geschwüren herum, ohne schwerere subjektive Beschwerden, die sich erst dann: stärker bemerkbar macliten, wenn Entzündungserscheinungen binzukamen. 
Mag auch dieses auf eine stärkere Störung der Schmerzempfindung besonders am Periost hindeuten, so kann doch von einer echten dissoziierten Empfindungsiähmung oder von einer Thermoanästhesie an der Haut nicht die Rede seiu. Niemals ist es auch bekannt geworden, dass sich unsere Patienten oder die Oehlecker's etwa eine Verbrennung zugezogen hätten, obne etwas davon zu bemerken, wie man das so oft bei der Syringomyelie sieht. In den Bruns'schen Fällen und in dem Fall von Levy und Ludloff sind die Sensibilitätsstörungen nicht ganz so einwandsfrei von denen bei Syringomyelie zu unterscheiden, wie in unseren und denen Oelilecker's. In den beiden ersten Fällen von Bruns sind zwar sämtliche Empfindungsqualitäten an den Füssen und Unterschenkeln herabgesetzt, im ersten Fall fanden sich aber Verbrennungsnarben durch $\mathrm{zu}$ heisse Umschläge, was vielleicht auf eine besonders starke Herabsetzung der Temperaturempfindung hindeutet. Im lezten Fall ist nur erwähnt, dass die Schmerzempfindung erloschen bzw. herabgesetzt war, aber nichts von den übrigen Empfindungsqualitäten gesagt. Es lässt sich also im ganzen nicht sicher sagen, ob die von Bruns erwähnten Störungen als dissoziierte Empfindungslähmung zu deuten sind oder nicht, es ist aber auch hier eine vollkommene Thermoanästhesie kaum anzunehmen und eine Beteiligung der Tastempfindung zum Teil sicher. In dem Fall von Levy und Ludloff bestanden überhaupt keine ganz sicheren Sensibilitätsstörungen, nur schien die Temperaturempfindung gegenüber einer etwas lebhaften Tastempfindlichkeit leicht unsicher, was vielleicht anf eine in Entwicklung begriffene dissoziierte Empfindungslähmunghindeutet. Sicheres lässt sich aber darüber nicht sagen.

In den meisten Fällen des Sakro-Lumbaltypus der Syringomyelie sind ferner Blasenstörungen beobachtet worden, die in unsern und sämtlichen andern Fällen fehlten, trotzdem die Krankheit teilweise schon jahrzehutelang bestand. Nur in einem unserer Fälle soll vorübergehend das Wasserlassen etwas erschwert gewesen sein. Da aber seitdem, d. h. 2 Jahre danach, solche Störungen nicht mehr aufgetreten sind, dürfte es fraglich sein, ob diese nur subjektiv empfundene Störung auf eine mangelhafte Funktion des Sphineter bzw. Detrusor ves. zurückzuführeu ist. Dieses Feblen jeder zentralen Störung der Blase oder des Mastdarms scheint in den mitgeteilten Fällen ganz besonders charakteristisch. Das wäre, wenn es sich um Syringomyelie bandelte, durchaus auffallend, da bei dieser nur ganz gelegentlich einmal Fälle ohne Blasenstörungen beobachtet sind (Gnesda, llertens).

Schliesslich ist die ausserordentlich langsame, mit starken Remissionen einhergehende Entwicklung des Leidens in unsern Fällen, das jahrzehntelange Bestehen der Krankheit, ohne dass deutlichere Er- 
scheinungen der Syringomyelie aufgetreten wären, für eine Syringomyelie doch etwas ungewöbnlich. In unsern 4 ersten Fällen liegt der Beginn der Krankheit nunmehr fast 30 Jahre zurück, vielfach ist der Zustand jahrzehntelang stationär geblieben, in Fall 3 hat der Prozess seit langen Jahren überbaupt keine Fortschritte gemacht, nur ganz vorübergehend traten noch Gescbwüre auf, die ausgeheilt sind. Gewiss sind auch bei der Syringomyelie Fälle von 30-40jähriger Dauer bekannt (Schlesinger), meist sind dann aber die typischeren Symptome der Syringomyelie früher hervorgetreten. In dem sehr langsam verlaufenden Fall von $\mathrm{Fischer}$ gingen dem Manifestwerden der eigentlichen typischen Syringomyeliesymptome 16 Jahre lang ähnlich wie in unsern Fälleu trophische, bullöse und ulzeröse Störungen an der Haut der Hand voraus. Selbst in diesem Fall war die Zeit von Beginn der ersten Störungen bis zum Manifestwerden typischer Syringomyeliesymptome, aus denen die Diagnose gestellt werden konnte, also erheblich kürzer, als die bisher seit Beginn der Erkrankung verstrichene Zeit in unsern Fällen, in denen es wie auch in den Fällen von Oehlecker zu typischeren Syringomyeliesymptomen bisher nicht gekommen ist. Etwas schneller als in unsern und den Fällen von Oehlecker schien der Verlauf der Krankheit in den Fällen von Bruns, aber auch hier ergab eine erneute Untersuchung im ersten Fall nach 12 Jahren kein Fortschreiten der Krankheit, im 2. Fall bestand die Krankheit 22 Jahre, ohne dass sie auf andere Körperregionen übergegriffen hätte, der 4 . Fall starb in noch früherem Stadium der Krankheit. Wie wir gesehen haben, besteht überhaupt bei den Bruns'schen Fällen eine grössere Aehnlichkeit mit der Syringomyelie als in unseren und Oehlecker's, eine ganz scharfe Abgrenzung gegenüber dieser wird bei ihnen überhaupt nicht möglich sein, aber neben den übrigen Abweichungen scheint uns auch das lange Stationärbleiben der Krankheit in seinen beiden ersten Fällen erwähnens. wert. In dem Fall von Levy und Ludloff bestand die Krankheit zur Zeit der Untersucbung überhaupt erst 6 Jahre.

Die Gesamtheit der hier angeführten Gründe dürfte uns berechtigen, jedenfalls eine typische Syringomyelie in unsern und Oehlecker's Fällen mit ziemlicher Sicherheit, in denen von Bruns und Levy und Ludloff jedoch höchstens mit einer gewissen Wabrscheinlichkeit auszuschliessen. Es bestehen weiter in unseren und einigen der aus der Literatur mitgeteilten Fällen wichtige Unterschiede in den Knochenveränderungen gegenüber der Syringomyelie, die uns die Abtrennung unserer Fälle von der Syringomyelie noch mehr ermöglichen.

Oben wurde schon darauf hingewiesen, dass das Röntgogramm des Falles 21 von Lery und Lad off mit dem letzten Röntgenbild unseres 
Falles 1 Hinrich W. ausserordentlich viel Aehnlichkeit hat, so dass man versucht ist zu sagen: Dieser pathologische Zustand kann nur durch die gleiche Ursache hervorgerufen sein. Jedenfalls haben Levy und Ludloff recht, wem sie zu ihrer Skizzierung des Röntgenbefundes hinzusetzen: Keine Spur von Atrophie.

Wichtig erscheint uns ferner, dass in unseren Fällen zwar kleine Knochenherde in dem Hallux und Vakuolen in den Endphalangen der Grosszeben zu finden waren, sonst aber nur Sudeck'sche Inaktivitätsatrophie. Auch stand nicht, wie bei der Syringomyelie, der Atrophie Hypertrophie gegenüber, sondern den wenigen Knochenlücken stand Hyperostose gegenüber. Immer fand sich dann, wenn Knochenteile abgestossen waren, eine vermehrte Knochendichte der zurückbleibenden Knochenreste und benachbarter Knochen und als Ausdruck einel abgelaufenen Entzündung: periostitische Auflagernngen.

Im Gegensatz zur tabischen Arthropathie kommt es in unseren Fällen wicht zur Ausstossung ron Knochenscherben - die Tabiker mahlen sich ihre barten Knochenenden zu lluss - sondern zur Ausstossung von halben oder ganzen Phalangen und zur Ausstossung von 1/3 Metatarsen ev. auch ganzen Fusswarzelknochen nach vorausgehendem Aufflackern einer längere Zeit latent bleibenden, mit Eiterung einhergehenden Entzündung. Es ist deshalb auch nicht erlaubt, anzunehmen, dass die kleinen, von dichterer Knochensubstanz umgebenen Knochenherde die ersten Anfänge eines zum völligen Schwund führenden chronischen fortschreitenden Prozesses sind. Wahrscheinlich sind diese Knochenherde kleine ostitische Herde im Knochen, zuerst entstanden durch eine Knochenkontusion und sekundäre Infektion. Durch ein stärkeres Trauma kommt es dann zum Aufflackern des Prozesses und, eventuell begünstigt durch eine Fissur oder Fraktur, zur fast geradflächigen Lösung eines Knochenteils.

Nit Syringomyelie und Tabes kann man demnach auch, was die Knochenveränderungen betrifft, unsere Fälle nicht verwechseln. - Für Tabes finden sich auch sonst keine genügenden Anbaltspunkte. In den beiden ersten vorgeschrittenen Fällen hatte die Liquoruntersuchung: bis auf eine nur spurweis vorhandene Eiweissvermehrung ein vollkommen negatives Resultat.

Nach Ausschluss sämtlicher erwähnter Krankheiten wenden wir uns der Erörterung der Frage zu, um was es sich in unsern Fällen handelt. Die Beantwortung wird naturgemäss erschwert und keine ganz sichere sein können, weil bisher kein Selktionsergebnis vorliegt.

Es wäre zunächst der Sitz des Leidens näher zu bestimmen, und zwar käme entweder eine peripherische Lokalisation in Frage oder 
aber die Ursache der peripherischen Veränderungen wäre in einer Erkrankung des Zentralnervensystems zu suchen. Bei Entscheidung der Frage nach der Lokalisation der Krankheit ist nochmals hervorzuheben, dass die sichtbaren pathologischen Veränderungen sich ausschliesslich auf die unteren Extremitäten, in der Hauptsache auf die Füsse beschränkten, und zwar ohne Ausnahme in allen Fällen, dass bei der Entwicklung des Leidens eine auffällige Abhängigkeit von der Intensität der Inanspruchnahme der Füsse nachzuweisen ist und die Krankheit dementsprechend in einer Reihe von Fällen in ausgesprochener Weise zum erstenmal während der Militärzeit zum Ausbruch kam, nachdem zum Teil schon unbedeutende Prodromalsymptome vorausgegangen waren, dass in Fall 3 die während der Militärzeit zutage getretenen schwereren Symptome bei Beendigung desselben unter sachgemässer Behandlung für eine Zeit von über 10 Jahren vollkommen verschwanden und dass bei der sitzenden Lebensweise des Patienten später niemals wieder so schwere Symptome wie gerade während der Militärzeit zutage getreten sind. Möglicherweise nimmt die Disposition zum Erkranken mit zunehmendem Alter noch zu, da 4 unserer Patienten mit ibren sehr schweren Eischeinungen im Alter von Ende der 40er bis Anfang der 50er Jahre standen. Im Ganzen hat man deu Eindruck, dass die unteren Extremitäten und speziell die Füsse bei unseren Patienten einen Locus minoris resistentiae darstellen und bei stärkerer Einwirkung äusserer Schädlichkeiten erkranken. Diese herabgesetzte Widerstandsfähigkeit der Füsse, die sich sowohl auf die Haut wie auf Knochen und Knorpel erstrecken kann, ist erblich, besteht offenbar von Kind anf und nimmt vielleicht im Laufe der Jahre noch zu.

Es ist schwer zu erklären, um was es sich handeln könnte, wenn wir rein peripherische Prozesse annelimen wollten und worauf sich dann die herabgesetzte Widerstandsfähigkeit gründet. Wie wir sahen, sind Raynaud'sche Krankheit, neuritische arteriosklerotische Veränderungen, Allgemeinerkrankungen bzw. Intoxikationen (chronischer Alkoholismus), wie Lepra, Lues, Diabetes, Blutkrankheiten mit Sicherheit auszuschliessen. Die uns bekannten peripherischen Prozesse liegen also nicht vor. Mit diesen wäre auch die ausschliessliche und dauernde Lokalisation der Veränderungen an den unteren Extremitäten nicht zu erklären. Es ist vielmehr anzunehmen, dass die herabgesetzte Widerstandsfähigkeit an den Füssen, zumal wenn wir die Aehnlichkeit der pathologischen Veränderungen mit denen bei gewissen zentralen Fr. krankungen berücksichtigen, ihre Ursache in irgend einer zentralen Erkrankung hat - und hierin stimmen wir mit der Auffassung von Oehlecker, Bruns, Levy und Ludloff über ihre Fälle überein. 
Vielleicht deutet die von uns in 2 Fällen festgestellte spurweise Eiweissvermehrung im Liquor auch auf zentrale Vorgänge hin. Die Ursache für die trophischen Störungen an den unteren Extremitäten dürfte unserer Ansicht nach in einer kougenitalen Missbildung oder sich später entwickelnden familiären Erkrankung des unteren Rückenmarksabschnittes, wo sich ganz besonders häufig Missbildungen finden, oder der Cauda equina zu suchen sein. Von angeborenen, später fortschreitenden Veränderungen in der Caudagegend kämen wohl nur Geschwülste und Spina bifida in Betracht. Letztere liegt, wie bereits ausgeführt, auch in okkulter Form nicht vor. Gegen Tumoren spricht das Fehlen starker Schmerzen in der Kreuzbeingegend (L. R. M üller), der Klopfempfindlicbkeit der Kreuzbeingegend (L. R. lü̈ller, Oppenheim); die trophischen Störungen, die gerade in unseren Fällen das hervorstechendste Symptom bilden, sind bei Caudaaffektionen viel seltener als bei Rückenmarksaffektionen (Thorburn, L. R. Müller). Auch das ausserordentlich langsame Fortschreiten der Prozesse und ihr jahrzehntelanges Stationärbleiben wäre für Caudatumoren ausserordentlich ungewöhnlich. Wir halten danach eine Caudaaffektion in unseren Fällen für durchaus unwahrscheinlich. Für die aus der Literatur mitgeteilten Fälle gilt dasselbe.

Es wären also nur noch irgend welche angeborenen familiären Missbildungen oder pathologischen Veränderungen im Rückenmark selber in Erwägung zu zieben. Was die Lokalisation der pathologisehen Veränderungen dort betrifft, so spricht gegen einen Sitz in dem als Conus bezeichneten Teil des Rückenmarks, also der Gegend vom 3.--5. Sakralsegment, in unseren Fällen und den sämtlichen übrigen das Feblen von Blasen- und Mastdarmstörungen, die in keinem der mitgeteilten Fälle jemals aufgetreten sind; nur in Fall 1 wurde, wie erwähnt, angegeben, dass vor Jahren eine vorübergehende Erschwerung des Wasserlassens aufgetreten war und in der letzten Zeit sollte die Potenz etwas nachgelassen haben, was wohl mit dem Alter des Patienten zusammenhängt. Wir baben bereits ausgeführt, dass wir eine Innervationsstörung des Sphincter oder Detrusor vesicae hier nicht für wahrscheinlich halten, wenn solche auch nicht mit völliger Sicherheit ausgeschlossen werden kann. Blasen-, Mastdarm-, Ejakulations- und Erektionszentrum werden nun ron Bruns, Flatau, Edinger in die Höhe von $S_{3}, S_{4}$ und $S_{5}$, vou Head in $S_{2}-S_{4}$, von $R$ aymond in $S_{3}$ verlegt. L. R. Müller und sich ihm anschliessend Rosenfeld, Wimmer, Balint und Benedict nehmen dagegen nur ein Zentrum für die Schliessmuskeln der in Frage kommenden Organe im Rückenmark an und schreiben die Regulation aller dieser Funktionen dem sympathischen System zu, eine Annahme, 
gegen die sich Berger, Oppenheim, Frankl-Hochwart, Roussy und Rossy, Zimmer u. a. wenden. Sowohl bei der einen wie bei der andern Auffassung wären aber auf jeden Fall bei Läsionen des unteren Sakralmarks Blasen- oder Mastdarmstörungen dauernder oder vorübergehender Art zu erwarten. Die Annahme irgend einer hereditären Veränderung im Conus würde also zu den bisherigen Beobachtungen nicht passen. Wenn wir weiter feststellen, dass die in den mitgeteilten Fällen beobachteten Sensibilitätsstörungen sich auf das Gebiet des 5. Lumbalund 1. Sakralsegmentes beschränkten und nur in Fall 1 auf das 4. Lumbal- und 2. Sakralsegment übergriffen, so würde auch dieses nicht mit der Annahme einer Affektion im eigentlichen Conus übereinstimmen, vielmehr spräche dieses sowie das Fehlen von Blasen- und Mastdarmstörungen für einen Sitz der in Frage kommenden pathologischen Veränderung im sog. Epiconus und dessen Umgebung (5. Lumbal-, 1. und 2. Sakralsegment) (Minor). Sollte es sich in Fall 1 doch trotz unserer gegenteiligen Annahme um eine wirkliche Innervationsstörung der Blase gehandelt haben, so würde auch dieses nicht gegen unsere Annahme sprechen, da gerade in diesem Fall, wie erwähnt, auch die Sensibilitätsstörung über den Bereich des 5. Lumbal- und 1. Sakralsegments auf das 2. Sakralsegment, in das ja bereits das Blasenzentrum verlegt wird, übergriffen. In die Gegend von $\mathrm{L}_{5}, \mathrm{~S}_{1}$ und $\mathrm{S}_{2}$ wird auch der Reflexbogen des Achillesreflexes verlegt ( 0 p penheim, $\mathrm{Ziehen}$ ), der in Fall 1 zuerst rechts, später beiderseits fehlte, ferner auch der des Plantarreflexes (E. Flatau, Bruns), der in Fall 4 beiderseits fehlte. In den Bruns'schen Fällen, die wir aber, wie ausgeführt, nicht mit Sicherheit zu unsern Fällen rechnen können, bei denen mehr Anklänge an die Syringomyelie zu finden sind, seheinen die Prozesse im Rückenmark einen grössern Umfang gebabt zu haben als in den Fällen von uns, Levy und Ludloff sowie Oehlecker, da hier die Sensibilitätsstörungen ausgedehnter waren, soweit sich aus dem Bericht ersehen lässt, auch auf $L_{4}$, vielleicht auf $L_{3}$ übergriffen, ferner auch die Patellarreflexe fehlten.

Auffallend ist zunächst bis zu einem gewissen Grade bei einem solchen Rückenmarkprozess das starke Zurücktreten motorischer Erscheinungen und das starke Hervortreten sensibler und trophischer Störungen, es lässt sich dafür aber, wie wir sehen werden, eine allerdings theoretische Erklärung beibringen. Nur in dem ersten unserer Fälle war das gesamte rechte Bein etwas atrophisch, was aber von Jugend auf bestanden haben soll und augenscheinlich keine weiteren Fortschritte gemacht hat. In den Fällen von Oehlecker, Levy und Ludloff liessen sich keine muskulären Erscheinungen nachweisen, nur in einem Fall Oehlecker's bestand eine gewisse Kontraktur der Waden- 
muskulatur, ob primär oder sekundär ist wohl fraglich. Die stärksten muskulären Störungen wiesen wieder die von unsern und den andern abweichenden Fälle von Bruns auf: In Fall 1 waren beide Beine, besonders die Unterschenkel, "atrophisch", "geschwächt", die Funktion der kleinen Fussmuskeln war erheblich gestört, in Fall 2 und 3 waren die Atrophien weniger stark, im Fall $3 \mathrm{kam}$ es jedoch später zu einer stärkeren Atrophie der Unterschenkel, besonders der Peroneusgegend. Vielfach wurden fibrilläre Zuckungen beobachtet, die elektrische Erregbarkeit war in den atrophischen Partien herabgesetzt, die Fussuuskeln waren im ersten Fall unerregbar. Die Abweichungen, die die Fälle von Bruns unsern und den andern gegenüber zeigen, sind also ziemlich auffallend und weitgehend und bestehen insgesamt in einer grösseren Ausdehnung der Sensibilitätsstörungen, der Reflexstörungen und in einer starken Beteiligung der Muskulatur. Trotz der grösseren Aebnlichkeit dieser Fälle mit der Syringomyelie und ibren Abweichungen von unseren Fällen kömnen wir uns aus den oben angeführten Gründen nicht entschliessen, sie der Syringomyelie zuzuzählen, sondern glauben, dass das gleiche Leiden wie in unsern Fällen vorliegt, zumal ja überhaupt eine genaue Uebereinstimmung der einzelnen Fälle bei den familiären Erkrankungen des Nervensystems fehlt (Raymond, s. Bing). Wir können zunächst bei der sonst weitgehenden Uebereinstimnung der Bruns'schen Fälle mit den unsern annehmen, dass der Rückenmarksprozess eine grössere Ausdehnung hatte als in unsern Fällen und sowohl, was Höhe und Tiefe wie Breite betrifft, umfangreicher war wie in den anderen Fällen. Wenn auch hier die starke Beteiligung der Fussmuskeln und der Peroneusgegend ebenfalls besonders auf eine Epiconusaffektion hinweist.

Ueber die Art der Affektion lässt sich bei dem gänzlichen Fehlen jeglichen Sektionsbefundes nichts Bestimmtes sagen. In Betracht käme jedenfalls eine Hydromyelie, die gerade im Lumbo Sakralmark häufiger als anderen Stellen vorkommt (Schlesinger) und deren familiäres Auftreten von Higier erwähnt wird. Auch Oeh] ecker hält in seinen Fällen das Vorhandensein einer Hydromyelie für möglich. Die Annahme einer solchen würde auch mit der Tatsache des überwiegenden Auftretens sensibler und trophischer Störungen und des $\mathrm{Zu}$ rücktretens motorischer Störungen ganz gut übereinstimmen, da die Hydromyelie mit Vorliebe die ventralen Abschnitte der Hinterstränge, die graue Kommissur okkupiert (Schlesinger), Gegenden, die für die Leitung der Berührungs-, Temperatur- und Schmerzempfindung sowie des Muskelsinnes von besonderer Bedeutung sind. Gelegentlich, und zwar in Fällen, in welchen allem Anschein nach bereits in früherm Fötalleben Störungen vorhanden waren, kann der erweiterte Zentral- 
kanal sogar die lintere Peripherie des Rückenmarks erreichen und mit dem Subpialraum frei kommunizieren. Das soll speziell im Lumbalund Sakralmark häufiger als an anderen Stellen vorkommen. Alles dieses gäbe also eine Erklärung dafür, dass in den mitgeteilten Fällen ganz überwiegend sensible und trophische Störungen zutage traten. Dass etwas derartiges bei Rückenmarkskrankheiten überhaupt vorkommen kann, zejgen von Gnesda, Mertens, Stertz beschriebene Fälle von Syringomyelie, bei denen trophische und sensible Störungen jahrelang ohne Erscheinungen von seiten der Muskulatur bestanden haben.

Wir können uns vorstellen, dass in den mitgeteilten Fällen eine Hydromyelie von Hans aus vorhanden war oder sich allmähich entwickelte, dass die unteren Extremitäten infolge dieser in der Gegend des Epiconus sitzenden und besonders die sensiblen Bahnen schädigenden Hydromyelie loci minoris resistentiae wurden, und dass es dort bei grosser Inanspruchnahme zu trophischen Schädigungen besonders während der Vilitärzeit kommen musste. Dass offenbar schon Jahre vor dem Militärdienstalter irgend ein pathologischer Prozess in jener Gegend des Rückenmarks vorhanden sein musste, zeigen ja die Sensibilitäłsstörungen, die in unseren drei letzten Fällen schon vor dem Auftreten irgendwie stärkerer trophischer Prozesse nachzuweisen waren, zeigen ferner auch die Ueberempfindlichkeit der Füsse, das Abfallen der Nägel, die schmerzhaften Sensationen im jugendlichen Alter. Dass eine Hydromyelie überhaupt zunächst symptomlos bleiben kann, bewies Utchida, der unter 78 kindlichen Rückenmarken 8 mal Hydromyelie fand, ohne dass in vivo irgend welche Erscheinungen darauf hingedeutet hätten, zeigte ferner Bittorf, der bei der Sektion eines 12 jährigen an Diabetes leidenden Knaben eine Hydromyelie fand, die symptomlos geblieben war.

Um einen erweiterten Zentralkanal kanu es zu einer melr oder weniger starken Gliawucherung kommen (Kaufmann). Denkbar wäre es also auch, dass in unseren Fällen gleichzeitig ein gewisser Grad ron Gliose vorliegt. In ausführlicher Weise haben ferner Leyden, Kaiser and Küchenmeister (s. Ernst), Starker und Wosnesensky, Schüller, nenerdings auch wieder Schiefferdecker und Leschke dargetan, dass entwicklungsgeschichtliche Anomalien in der Ausbildung des Zentralkanals resp. akzessorische Zentralkanäle weiter auch eine zentrale Gliose, die auf Entwicklungsstörnngen zurückzuführen wäre, zur Entstehung einer Syringomyelie Anlass geben könnten. Es bestehen sogar anatomisch fliessende Uebergänge zwischen der Hydromyelie und Syringomyelie und es ist nach Ernst unmöglich, eine scharfe Grenze zwischen beiden zu ziehen. Berücksichtigen wir diese Tatsachen, so fänden vielleicht gewisse Anklänge an die Syringomyelie in unseren und Oeh- 
lecker's Fällen, und die grössere Aehnlichkeit der Krankheit in den Bruns'schen Fällen und in dem Fall von Levy und Ludloff mit der Syringomyelie ihre Erklärung, ohne dass wir damit gezwungen wären, ohne weiteres eine typische Syringomyelie in unseren Fällen anzunehmen.

Ausser einer Hydromyelie wäre in unseren und den anderen mitgeteilten Fällen auch das Vorhandensein einer Zweiteilung des Zentralkanals, einer Zweiteilung des unteren Rückenmarksendes (Diastematomyelie) (Fälle von Ernst, Recklinghausen, Pick, Westphal) in Betracht zu ziehen, Missbildungen, die nicht im ganzen Verlauf des Rïckenmarks aufzutreten brauchen, die vielmehr auf bestimmte Teile desselben beschränkt sein können, die auch kombiniert mit der Hydromyelie und Syringomyelie vorkommen (Fall von Minor). Speziell hat Erust einen Fall von ZweiteiJung des Rückenmarks im Lumbalmark mit Klumpfuss und chronisch-fungösem Geschwür beschrieben. Immerhin lat die Annahme einer solchen Missbildung nicht so viel für sich wie die einer Hydromyelie, da über ihr familiäres Auftreten usw. nichts beknant ist.

Die endgültige Entscheidung darüber, was für ein Prozess in den mitgeteilten Fällen wirklich vorliegt, kann und wird erst die Autopsie erbringen. Nur soviel können wir bisher schon sagen, dass es sich aller Wabrscheinlichkeit nach um einen Prozess im Rï̈ckenmark handelt.

Es sei nun noch auf eine Behauptung Oehlecker's näher eingegangen. Dieser ist der Ansicht, dass seine Fälle vielleicht als Stütze dafür dienen könnten, dass im Rückenmark besondere trophische Zentren für Knochen und Gelenke bestehen. Cassirer hat aber ausgeführt, dass, wenn auch die trophischen Störungen oft im Vordergrund stehen, keine isolierte trophische Nerven und Zentren anzunehmen seien, weil namentlich vasomotorische und sensible Reizzustände fast stets als Begleiterscheinungen gefunden werden. Wir müssen entgegen der Auffassung Oehlecker's dieser Ansicht beipflichten und glauben nicht, dass unsere und die anderen mitgeteilten Fälle einschliesslich der Oehlecker's der Auffassung Cassirer's widersprechen: denn in allen diesen Fällen waren ausgesprochene Sensibilitätsstörungen neben den trophischen Störungen nachzuweisen, und auch die trophischen Störungen in den Fällen Oehlecker's scheinen durchaus nicht isoliert aufgetreten zu sein, da nach dem ganzen Verlauf, dem unbemerkten Auftreten von Spontanbrüchen sicherlich ganz erhebliche Störungen der Tiefensensibilität vorgelegen haben. Dieses kombinierte Auftreten trophischer und sensibler Störungen in sämtlichen mitgeteilten Fällen spricht für die Auffassung Cassirer's, dass der trophische Einfiuss des Nerven- 
systems die vorhandenen Bahnen benutzt, und dagegen, dass es etwa isolierte trophische Zentren und Bahnen im Nervensystem gibt.

Die Prognose der familiären Trophoneurose der unteren Extremitäten, wie wir die Erkrankung vorläufig bis zur genaueren anatomischen Wesenbestimmung bezeichnen müssen, ist eine sebr ernste, wie die zahlreichen Todesfälle in der von uns beobachteten Familie zeigen. Nur dann, wenn eine frühzeitige Propbylaxe bei den Mitgliedern solcher Familien, sowie eine möglichst frühzeitige Behandlung einsetzt, kann die Prognose günstiger gestaltet werden.

Hinsichtlich der Prophylaxe wäre folgendes zu überlegen:

Es ist selrr wahrscheinlich, dass bei unseren Fällen, wie z. B. auch in den Fällen von Oeblecker das mechanische Moment bei der Ausbildung ernsterer Symptome eine grosse Rolle spielt durch die Einwirkung relativ geringer Gewalten, bei stärkerem Umherlaufen (0 ehlecker I und II), beim Holzhauen (unser Fall II), während der Dienstzeit (unser Fall III), beim Radfahren (unser Fall IV).

In unsereo Fällen kam es durch mässige Inanspruchnahme zu Blasenbildung, Hautnekrose und zum Abfall der Nägel, also trophoneurotischen Störungen, bei stärkerer Inanspruchnahme kommt es zur Abstossung von Knochen unter Eiterung, und es scheint gerade hierfür das mechanische Moment eine sehr wichtige Rolle zu spielen. Es kann eine Fissur oder Fraktur diese Abstossung von Knochen einleiten.

Diese Fraktur möchten wir, wie E. W. Baum bei den Tabischen Frakturen, nicht als Spontanfraktur bezeichnen. Der Mittelfussknochen des Hinrich W. (Fall I) war recht fest. Es bestand an ihm keine Osteoporose oder Atrophie.

Liegt eine Osteopsathyrosis oder Fragilitas ossium vor, so führt schon normale Beanspruchung zur Fraktur. Ist die Knochenfestigkeit normal, und wird die Beanspruchung, weil die Tiefensensibilität herabgesetzt ist, und infolgedessen die reflektorischen Hemmungen fehlen, abnorm, so führt sie zum Bruch.

Da die Knochenfestigkeit in unseren Fällen nichts $z u$ wünschen übrig lässt, so kann es nur die Herabsetzung der Tiefensensibilität sein, welche bewirkt, dass unsere Patienten ihre Füsse noch weniger schonen wie ein gesunder Mensch und dadurch so leicht die Fissuren eintreten.

Für Johann W. (Fall 4) war es sicher nicht günstig, dass er Damenrad gefahren ist. Es hatten sich bei ihm auch schon viele Knochen losgestossen: am rechten Fuss, abgesehen von den Zehenpbalangen, die Capitula metatarsorum 1, II, IIl, IV, am linken Fuss abgesehen von Zehenphalangen vom I. Metatarsus, die Hälfte vom II., $1 / 3$ von den IIl,, 
IV., V. des Capitulum und wenig mehr. Es wird sich also, wie wir es bei Hinrich W. erlebt haben, bei Johann W. 9 mal ein Metatarsalcapitulum abgestossen haben.

Gerade beim Abspringen vom Rade können sehr leicht Frakturen der Mittelfussknochen auftreten.

Wie schon an anderer Stelle betont wurde, liess Johann W.'s Fähigkeit, mit seinen Füssen noch rüstig zu arbeiten, Rad zu fahren und dergleichen mehr, gerade erkennen, wie sehr die Tiefensensibilität in unseren Fällen herabgesetzt ist. Jedenfalis wird man gut tun, der ganzen Familie W, auch das Radfahren zu verbieten.

Ueberhaupt ist im Hinblick auf das Zustandekommen der Prozesse im Anschluss an mechanische Einwirkungen gerade die Prophylaxe von ganz besonderer Wichtigkeit. Es muss darauf gesehen werden, dass die Patienten in der Auswahl ibres Berufes richtig angeleitet werden, damit sie möglichst wenig traumatischen Einflüssen ausgesetzt sind. Befreiung rom Militärdienst ist im Hinblick auf den Ausbruch der Krankheit während desselben in einer Reihe von Fällen von ganz besonderer Wichtigkeit.

Therapie: Weitgehendste Schonung ist auch im Beginn des Leidens anzuraten. Wenn sich in einem Anfall ein Knochen abstösst, so wird man möglichst konservativ verfahren und Exartikulationen nur dann vornehmen, wenn die Zehen nicht mehr zu erhalten sind. Schreitet der Prozess am Mittelfuss weiter fort, so wäre eine Operation nach Pirogoff in Erwägung zu ziehen. Natürlich scheuen sich die Leute vor einem grösseren Eingriff, namentlich vor einer Amputation. Patient Wilhelm W. liess sich zur Amputatio femoris osteoplastica nach Gritti nur deshalb überreden, weil die Schmerzen im linken Fuss unerträglich geworden waren. Mit Oehlecker glauben wir, dass man in unseren Fällen sicher osteoplastische Operationen, zum Beispiel Operation nach Pirogoff und die nach Gritti ausführen kann. Hier handelt es sich ja um Sensibilitätsstörungen, die nicht sehr ausgedehnt sind und die Knochenheilung hat nicht gelitten.

\section{Literaturverzeichnis.}

Balint und Benedict, Ueber die Erkrankungen des Conus terminalis und der Cauda equina. Deutsche Zeitschr. f. Nervenh. 1906. Bd. 30. S. 35. Baum, E. W., Knochenbrüch $\theta$ bei Tabes und deren ätiologische Stellung. Habil.-Schrift. Zeitschr. f. Chir. Bd. 89. H. 1.

Berger, Zur Frage der spinalen Blasenstörungen. Deutsche Zeitschr. f. Nervenh. 1904. Bd. 27. S. 424. 
Bernhardt, Neuropathologische Betrachtungen. Zur Lehre von den Läsionen des Epikonus des Rückenmarks. Beitr. z. wissenschaftl. Med. u. Chem. Festschr. E. Salkowski. Berlin 1904. Ref. Jahresber. f. Neur. u. Psych. 1905. S. 582.

Bibergeil, Der Klauenhohlfuss. Münchener med. Wochenschr. 1912. S.1805. - Die klinische Bedeutung der Spina bifida oeculta. Berliner klin. Wochenschr. 1913. S. 1481.

Brillaud, Syndrômes du cône terminal et de l'épicône. Paris 1904. Ref. Neurol. Zentralbl. 1905. S. 363.

Bing, Eine kombinierte Form der heredofamiliären Nervenkrankheiten. Deutsches Arch. f. klin. Med. 1905. Bd. 83. S. 199.

Bittorf, Ein Beitrag zur Lehre von der Entstehung von Höhlen im Rückenmark und über symptomlose Hydromyelie. Virchow's Arch. f. pathol. Anat. Bd. 182. S. 520.

Boks, Angeborenes familiäres Oedem der unteren Extremitäten. Ned. Tijdschr. f. Geneesk. 1913. 57. (I) 416. Ref. Zeitschr. f. die ges. Neur. u. Psych. 1913. Referate Bd. 7. S. 184.

Bramann, Ueber symmetrische Gangrän. Chir.-Kongr. 1889. Zentralbl. f. Chir. 1889.

Brunner, Ein Fall ron Spina bifida occulta mit liongenitaler lumbaler Hypertrichose, Pes varus und "Mal perforant du pied". Virchow's Arch. 1887. Bd. 108. S. 494. - Ein weiterer Beitrag zur Kasuistik der Spina bifida occulta. Virchow's Arch. 1892. Bd. 29. S. 246.

Bruns, Referat über Verhoogen. Dentsche med. Wochenschr. 1895. - Die Geschwülste des Nervensystems. 2. Aufl. Berlin 1908. Verlag Karger. Familiäre symmetrische Gangrän und Arthropathie an den Füssen. Neur. Zentralbl. 1903. S. 599.

Cassirer, Die trophischen Störungen. Handb. d. Neur. von Lewandowski. Allgem. Teil. Bd.2. S. 1135. - Die vasomotorisch-trophischen Neurosen. Berlin 1912. Verlag Karger.

Deycke Pascha, Knochenveränderungen bei Lepra nervorum. Fortschr. auf dem Geb. der Röntgenstrablen. Bd. 9. S. 9.

Diebl, Familiäres Auftreten ron vasomotorisch-trophischen Störnngen. Monatsschr. f. Psych. u. Neur. 1901. Bd. 10. S. 401.

Ernst, Missbildungen des Nervensystems. 3. Teil, 2. Abt. der Morphol. der Missbildgn. ron E. Schwalbe. Jena 1909. Verlag Fischer.

Ewald, Ueber Spina bifida occulta. Fortschr. auf dem Geb. der Röntgenstrahlen. Bd.18. H.4. S.276. - Ueber Gelenkerkrankungen bei Syringomyelie. Zeitschr. f. orthop. Chir. 1911. Bd. 29. S. 350.

Elsberg, Spina bifida occulta with trophic disturbances followed by fibrolipoma of cauda equina; operation, recovery. Journ. of nerv. and ment. disease. 1911. Vol, 38. p. 289.

Fischer, Ueber Blasenbildung bei Syringomyelie. Arch. f. Dermat. Bd.113. S. 301 . 
Flatau, Die motorische, sensible und Reflexsegmentierung im Rückenmark. Handb. der Neur. von Lew andowski. Bd. 2. S. 669.

Frankl-Hochwart, Zur Differentialdiagnose der juvenilon Blasenstörungen. Deutsche Ges. f. Urol. in Wien. Ref. Neur. Zentralbl. 1911. S. 1179. Frey, Zur Klinik und pathologischen Anatomie der Syringomyelie. Zeitschr. f. die ges. Neur. u. Psych. 1914. Bd. 21. S. 77.

Fuchs, Ueber Beziehungen der Enuresis nocturna zu Rudimentärformen der Spina bitida occulta ("Myelodysplasie"). Wiener med. Wochenschr. 1910. 60. Jahrg. S. 1569. - Sacrococeygeale Narben und Fisteln. Wiener klin. Wochenschr. 1910. S. 1057.

Goldb]adt, Syringomyelie bei Mutter und Tochter. Deutsche med. Wochenschr. 1910. S. 1523.

Greenberg, Spina bifida. The Journ. of the Amer. med. assoc. 1907. Vol.58. Nr. 13. p. 1093. Ref. Jahresber. f. Neur. u. Psych. 1907. S. 336.

Higier, Pathologie der angeborenen familiären und hereditären Krankheiten, speziell der Nerven- und Geisteskrankheiten. Arch. f. Psych. u. Neur. 1911. Bd. 48. S. 41.

Hofmann, Max. Beiträge zur Entstehung und Behandlung des Mal perforant du pied. Beitr. z. klin. Chir. Bd. 73. S. 127. - Das Malum perforans pedis. Ergebn. d. Chir. a. Orthop. 1914. Bd. 8.

Jancke, Ueber eine Beltnässerfamilie, zugleich ein Beitrag zur Erblichkeit der Spina bifida. Deutsche Zeitschr. f. Nervenh. 1915. Bd.54. H.4. S. 255. Idelsohn, Ein Beitrag zur Pathologie und Histologie des tabischen Fusses.

Dentsche Zeitsohr. f. Nervenb. 1904. Bd. 27. S. 12.

Jendrassik, Beiträge zur Kenntnis der hereditären Krankheiten. Deutsche Zeitschr. f. Nervenh. 1902. Bd. 22. S. 444. - Die hereditären Krankheiten. Handb. d. Neur. von Lewandowski.

Joachimsthal, Ein weiterer Beitrag zur Kasuistik der Spina bifida occulta mit lokaler Hypertrichose. Virchow's Arch. 1893. Bd. 131. S. 488.

Katzenstein, Beitrag zur Pathologie und Therapie der Spina bifida occulta. Arch. f. klin. Chir. 1901. Bd. 64. S. 607.

Kaufmann, Lehrbuch der speziellen pathologischen Anatomie. 4.Aufl. 1907. Kollarits, Beiträge zur Kenntnis der vererbten Nervenkrankbeiten. Deutsche Zeitschr. f. Nervenh. 1906. Bd. 30. S. 293. - Weitere Beiträge zur Kenntnis der Heredodegeneration. Deutsche Zeitsehr. f. Nervenh. 1908. Bd. 34. S. 410 .

Krukowski, Zwei Fälle von familiärer Syringomyelie. Neur.-psychiatr. Sektion der Warschauer med. Ges. 17. 5. 1913. Ref. Zeitschr. f. die ges. Neur, u. Psych. 1913. Referate Bd. 8. S. 529.

Levy und Ludloff, Die neuropathischen Gelenkerkrankungen und ihre Diagnose durch das Röntgenbild. Beitr. zur klin. Chir. 1909. Bd.63. S.399. Leyden, Ueber Hydromyelus und Syringomyelie. Virchow's Arch. 1876. Bd. 68. S. 1. 
Mertens, Ueber einen atypischen Fall von Syringomyelie. Bruns' Beitr. 1901. Bd. 30, S. 121.

Michel, Zur Kasuistik der Gelenkerkrankungen bei Syringomyelie. Beitr. zur klin. Chir. 1902. Bd. 36. S. 387.

Minor, Zur Pathologie des Epiconus medullaris. Deutsche Zeitsehr. für Nervenh. 1906. Bd. 30. S. 395. - Zur Pathologie des Epiconus medullaris. Korsakoft'sches Journ. f. Neur. u. Psych. 1905. Nr.1. Ref. Neur. Zentralkl. 1906. - Traumatische Erlkrankungen des Rückenmarks. Handb. der pathol. Anat. des Nervensystems von Flatau und Jacobsohn. 1904. Bd. 2. S. 1008. - Zur Lehre von der Syringonyelie. Zeitschr. f. klin. Med. 1898. Bd. 34. S. 373.

L. R. Müller, Untersuchungen über die Anatomie und Pathologie des untersten Rückenmarksabschnittes. Deutsche Zeitschr. f. Nervenh. 1899. S. 1. Ueber Exstirpation der unteren Hälite des Rückenmarks und deren Folgeerscheinungen. Deutsche Zeitschr. f. Nervenh. Bd. 30. S. 413.

II uscatello, Ueber die angeborenen Spalten des Schädels und der Wirbelsäule. Arch. f. klin. Chir. 1894. Bd. 47. S. 257.

Nalbandoff, Ein Fall von erblicher Syringomyelie. Gesellsch. der Neurapathologen und Irrenärzte in Moskau. 1899. Ref. Neurol. Zentralbl. 1900. S. 429.

Nekam, Ueber eineunter Raynaud'schen Symptomen erkrankteFamilie. Beilage z. Orvosi Hetilap. Nr. 29. Ref. Jahresber. f. Neur. u. Psych. 1903. S.771. Oehlecker, Zur Kasuistik und Behandlung neuropathischer Gelenkerkrankungen. Beitr, z. klin. Chir. 1909. Bd. 25. S. 63.

Oppenheim, Ueber eine sich auf den Conus terminalis des Rückenmarks beschränkende traumatische Erkrankung. Arch. f. Psych. 1899. Bd. 20. S. 298. - Beiträge zur Diagnostik und Therapie der Geschwülste im Bereich des zentralen Nervensystems. Berlin 1907. Verlag, Karger. -Lehrbuch der Nervenkrankheiten. Bd. I. 6. Aufl. Berlin 1913. Verlag, Karger.

Peritz, Enuresis nocturna und Spina bifida occulta (Myelodysplasie). Deutsche med. Wochenschr. 1911. S. 1256.

Pernitzky, Zur Lehre von der Enuresis nocturna. Militärärztl. Journal. (russ.) 1910. 88, 66. Ref. Zentralbl. für die ges. Neur. u. Psych. 1910. Bd. 1. S. 269.

Piltz, Ein Beitrag zur Kenntnis der Dissoziation der Temperatur- und Schmerzempfindung bei Verletzungen und Erkrankungen des Rückenmarks. Neur. Zentralbl. 1905. S. 242.

Preobajenski, Zur Frage über die erbliche Syringomyelie. Gesellschaft der Neur. u. Irrenärzte zu Moskau. 1899. Ref. Neur. Zentralbl. 1900. S.982. Raymond, Erkrankungen des Conus medullaris. Handb. der path. Anat. des Nervensystems von Flatau-Jacobson, Minor. Bd. II. Berlin 1904. Verlag, Karger.

Recklinghausen, Untersuchungen über die Spina bifida. Virchow's Arch. 1886. Bd. 105. S. 243. 
Rose und Franģais, Amyotrophie des membres supérieurs et du thorax sans troubles de la sensibilité, syringomyélie probable. Rev. neur. 1907. No. 23. p. 123. Ref. Jahresber. f. Neur. u. Psych. 1907. S. 679.

Rosenfeld, ZurLäsion des Conus medullaris undder Cauda equina. Deutsche Zeitschr. f. Nervenh. 1902. Bd. 22. S. 166.

Roussy und Rossi, Troubles de la mietion et de la défécation consécutifs aux lésions expérimentales du cône terminale ou de la queue de cheval. Arch. de méd. expérim. et d'anat. path. 1910. 2. Série. 199. Ref. Zentralbl. für die ges. Psych. und Neur. 1911. S. 537. - Troubles de la miction. Soc. de biol. T. LXIV. Nr. 114. p. 640. 'Ref. Jahresber. für Neur. u. Psych. 1908. S. 162. - Harnblase und Defäkationsbeschwerden usw. Int. med. Kongress in Budapest. 1909. Ref. Neur. Zentralbl. 1909. S. 1114.

Saenger, Ueber Myelodysplasie und Enuresis nocturna. Deutsche Zeitschr. f. Nervenh. 1913. Bd. $47 / 48$.

Schaffer, Zur anatomischen Wesenbestimmung der Heredodegeneration. Zeitschr. f. die ges. Neur. u. Psych. 1914. Bd. 21. S. 49.

Scharnke, Enuresis und Spina bifida occulta. Archiv f. Psych. Bd. 53. S. 43 .

Schiefferdecker und Leschke, Ueber die embryonale Entstehung von Höblen im Rückenmark. Zeitschr. für die ges. Neur. u. Psych, 1913. Bd. 20. S. 1.

Schlesinger, Die Syringomyelie. 2. Aufl. Leipzig u. Wien, 1902. Verlag, Deuticke.

Schüller, Ein Beitrag zur Pathologie der kombinierten organischen Erkrankungen des Nervensystems. Jahrb. f. Psych. u. Neur. 1905. Bd. 26.

Schultze, F., Syringomyelie. Deutsche Klinik. 1906. 6. Bd. 1. Abt. S. 449. Verlag Urban u. Schwarzenberg.

Spiller, The epiconus symptom-complex of cerebro-spinal syphilis. Rev. of neur. a. psych. Vol. VI. No. 2. p. 77.

Stern, Familiäre Enuresis nocturna. Wiener klin. Rundschau. 1905. Nr. 22. S. 381. Ref. Jahresber. f. Neur. u. Psych. 1905. S. 350.

Stewart, Die Diagnose der Nerrenkrankheiten. (Deutsche Uebersetzung von He in.) Leipzig 1910. Verlag, Vogel.

Starker and Wosnesensky, Zur Lehre von der konzentrischen Syringomyelie. Deutsche Zeitschr. f. Nervenh. 1912. Bd. 45. S. 140.

Sterling, Die Knochenveränderungen bei den Erkrankungen des zentralen und peripherischen Nervensystems. II. Teil. Zeitschr. f. die ges. Neur. u. Psych. 1914. Bd. 10. S. 337.

Stertz, Spontanfraktur und Arthropathien bei einer Syringomyelie sakrolumbaler Lokalisation. Berliner klin. Wochenschr. 1908. Nr. 44. S. 1990.

Utchida, Ueber symptomlose Hydromyelie im Kindesalter. Beitr. zur path. Anat. 1902. Bd. 31. S. 559.

Westphal, Ueber eine bisher anscheinend noch nicht beschriebene Missbildung etc. Arch. f. Psych. 1906. Bd. 41. S. 712. 
364 Dr. Rudolf Göbell u. Dr. Werner Runge, Eine familiäre Trophoneurase.

Weber, A case of osteopathy and perforating ulcer of the foot in syringomyelia. Transact of the med. Soc. of London. Vol. XXXIII. Ref. Jahresber. f. Psych. 1. Neur. 1910. Bd. 14. S. 672.

Weisenburg, A clinical report of three cases of injury to the lower spinal cord and cauda equina. Ther. amer. journ. of the med. sciences. May 1914. Ref. Jahresber. f. Neur. u. Psyoh. 1904. S. 597.

Wimmer, Lidelser i Rygmaryens nederste Afsnit. Hospitaltidende. 1910. Nr. 3. Ref. Zentralbl. f. die ges. Neur. u. Psych. Bd. I. S. 468.

Wendel, Osteoplastische Unterschenkelamputation bei Arthropathia tabica. Münchener med. Wochenschr. 1908. S. 1372.

Zimmer, 6 Fälle von traumatischer Erkrankung des untersten Rüokenmarksabschnittes. Deutsche Zeitschr. f. Nervenh. 1907. Bd. 33. S. 100.

\section{Erklärung der Abbildungen (Tafelı I-III).}

\section{T'afel I.}

Abb. 1. Hinrich Wr. Linker Fuss. Aussenansicht. 1913.

Abb. 2. Hinrich Wr. Linker Fuss. Sohlenansicht. 1913.

Abb. 3. Hinrich Wr. Linker Fuss. Rückenansicht. 1916.

Abb. 4. Hinrich Wr. Linker Fuss. Sohlenansicht. 1916.

Abb. 5. Wilh elm Wr. Linker Fuss. Aussenansicht. 15. 5. 1913.

Abb. 6. Wilh elm Wr. Linker Fuss. Sohlenansicht. 15. 5. 1913.

Abb. 7. Wilhelm Wr. Rechter Fuss. Vorderansicht. 28. 4. 1916.

Abb. 8. Wilhelm Wr. Rechter Fuss. Aussenansicht. 28. 4. 1916.

Tafel II.

R.-B. 1. Hinrich Wr. Linker Fuss I. am 15.3.1913.

R.-B. 2. Hinrich Wr. Linker Fuss II. am 11.6.1914.

R.-B. 3. Hinrich Wr. Linker Fuss III. am 13, 7. 1916.

R.-B. 4. Hinrich Wr. Rechter Fuss am 13. 7. 1916.

R.-B. 5. Wilhelm Wr. Linker Fuss am 15. 5. 1913.

R.-B. 6. Wilhelm Wr. Rechter Fuss I. am 15. 5. 1913.

Tafel III.

R.-B. 7. Christian Wr. Linker Fuss.

R.-B. 8. Christian Wr. Rechter Fuss.

R.-B. 9. A ugust Wr. Beide Füsse. 

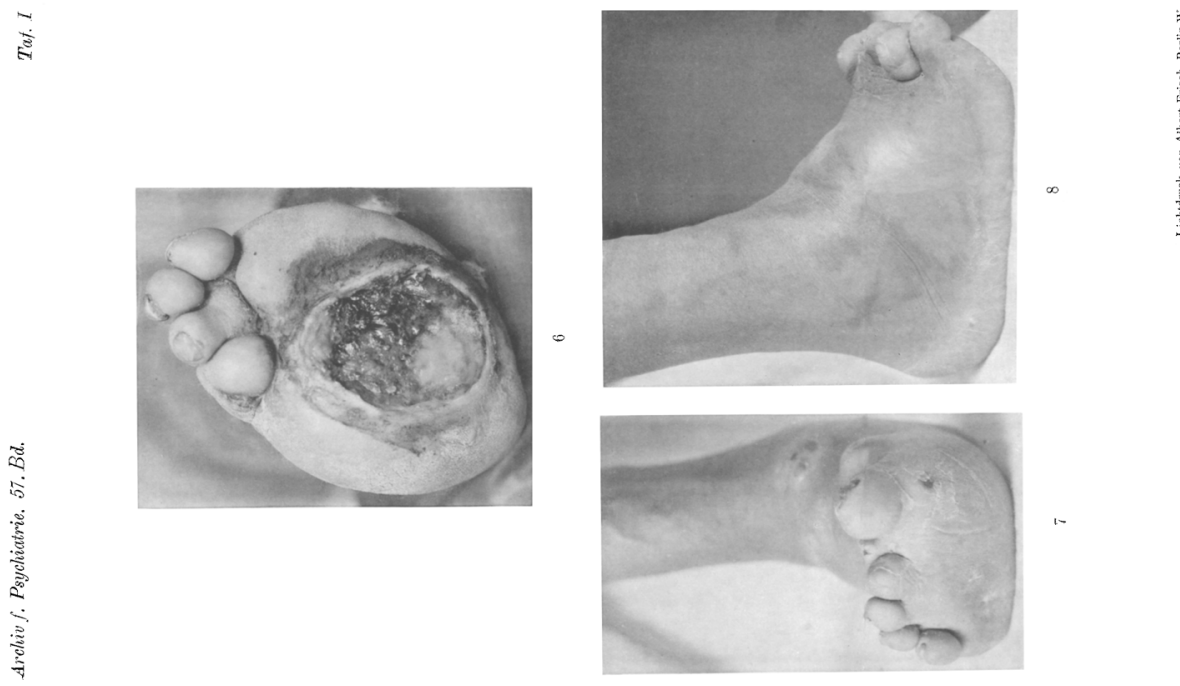

in
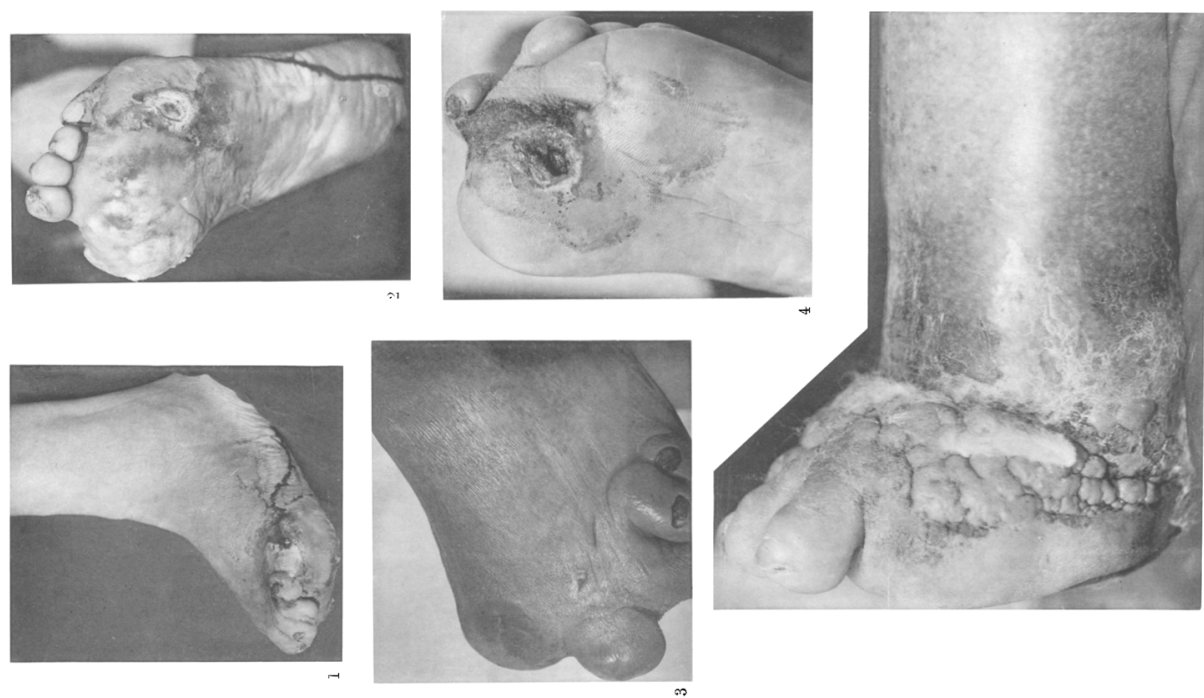

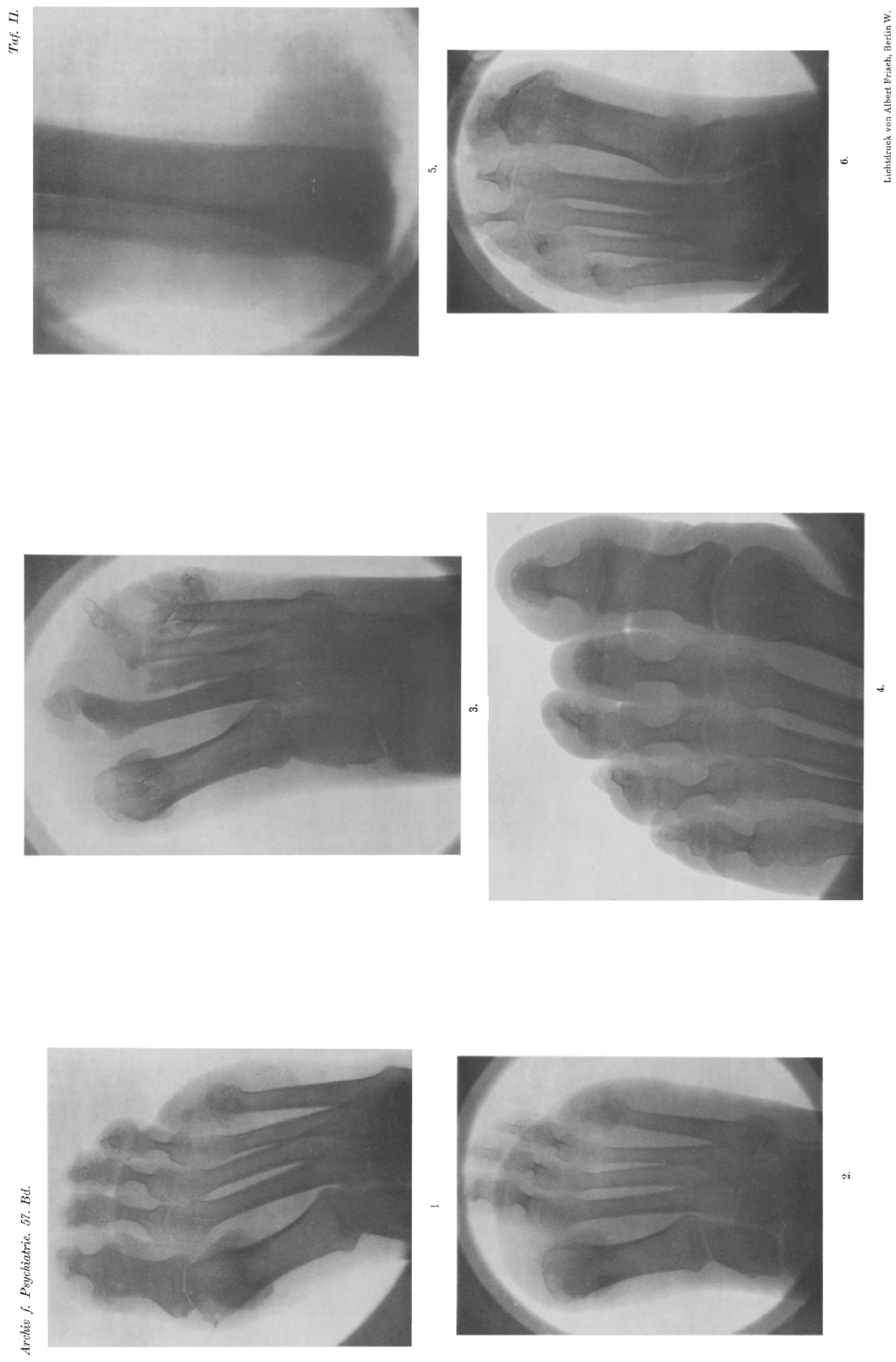
콜

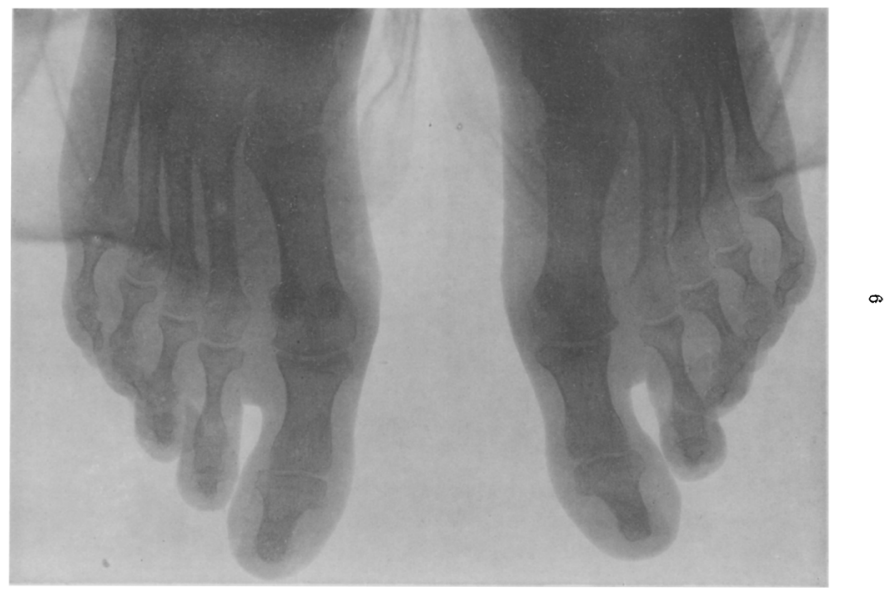

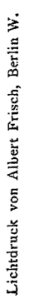
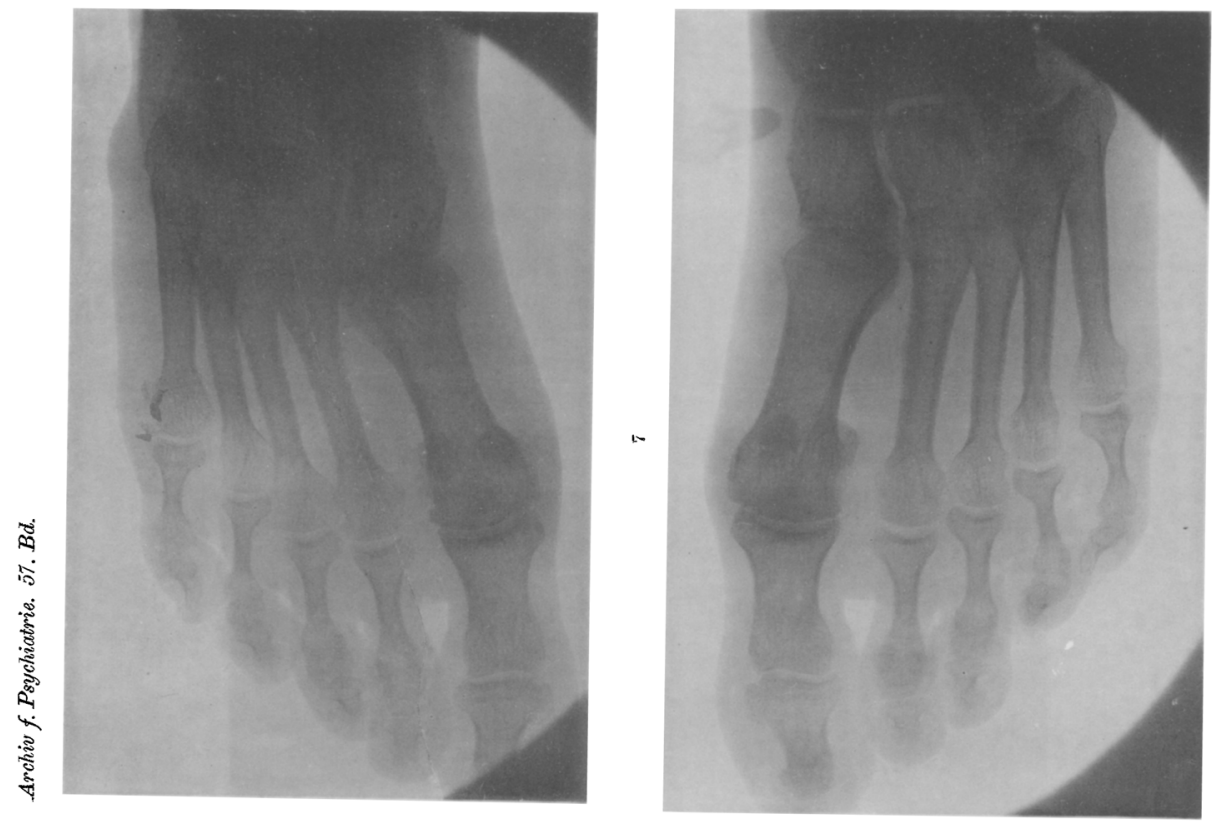